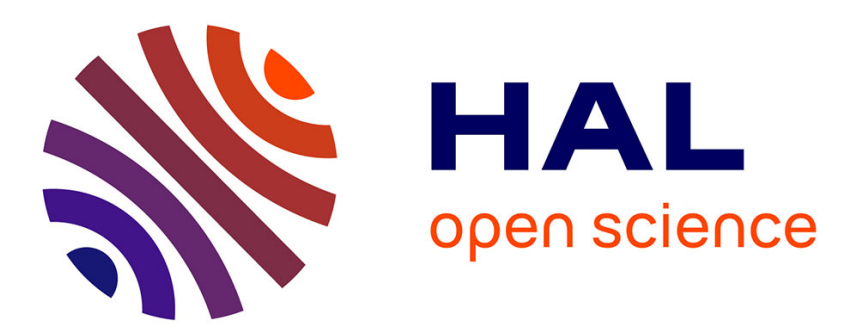

\title{
Phosphorylated aldehydes: Preparations and synthetic
} uses

Bogdan Iorga, Frédéric Eymery, Virginie Mouriès, Philippe Savignac

\section{To cite this version:}

Bogdan Iorga, Frédéric Eymery, Virginie Mouriès, Philippe Savignac. Phosphorylated aldehydes: Preparations and synthetic uses. Tetrahedron, 1998, 54 (49), pp.14637-14677. 10.1016/s00404020(98)00896-5 . hal-03161361

\section{HAL Id: hal-03161361 https://hal.science/hal-03161361}

Submitted on 10 Mar 2021

HAL is a multi-disciplinary open access archive for the deposit and dissemination of scientific research documents, whether they are published or not. The documents may come from teaching and research institutions in France or abroad, or from public or private research centers.
L'archive ouverte pluridisciplinaire HAL, est destinée au dépôt et à la diffusion de documents scientifiques de niveau recherche, publiés ou non, émanant des établissements d'enseignement et de recherche français ou étrangers, des laboratoires publics ou privés. 


\title{
Phosphorylated Aldehydes : Preparations and Synthetic Uses*
}

\author{
Bogdan Iorga, Frédéric Eymery, Virginie Mouriès and Philippe Savignac
}

Laboratoire Hétéroéléments et Coordination, UMR CNRS 7653, DCPH, Ecole Polytechnique

91128 Palaiseau Cedex, France.

\section{Contents}

1. Introduction

2. Synthesis of phosphorylated aldehydes (n represents the carbons between $\mathrm{P}(\mathrm{O})$ and $\mathrm{C}(\mathrm{O})$ groups)

2.1. $\mathrm{n}=0$

2.2. $\mathrm{n}=1$

2.3. $\mathrm{n}=2$

2.4. $\mathrm{n}=3$

2.5. $\mathrm{n}=4$

2.6. $\mathrm{n}=5-9$

2.7. $\mathrm{n}=11-16$

3. Reactions of phosphorylated aldehydes

3.1. Reactions of the carbonyl group

3.2. Preparations and reactions of diethyl chloroformyl- and dichloroformylmethylphosphonates

3.3. Heterocyclic systems with phosphorylated substituents

3.4. Horner-Wadsworth-Emmons (HWE) reaction

3.5. Phosphonoacetaldehyde in nature

3.6. Reductive amination

3.7. Aminocarboxylation (Strecker and related reactions)

4. Conclusion

5. Acknowledgements

6. References

*Dedicated to the memory of Professor Henri Normant (1907-1997), one of the founders of French modern organic chemistry 


\section{INTRODUCTION}

Aldehydes are among the most fundamental chemical functionalities in organic chemistry. In turn, phosphorylated aldehydes are popular reagents which occupy a unique position in organic chemistry and the specific properties of these compounds have given rise to a large number of developmental and synthetic applications. ${ }^{1}$ Since the review on the subject written by Razumov et al. ${ }^{1}$ in 1973 , these compounds have received considerably more attention than during the 21 years following their first preparation by Dawson and Burger $^{2}$ in 1952 . The number and diversity of papers in the literature attest to the wide acceptance and general utility of these reagents. The intervening 25 years have seen decisive progress in the development of the chemistry of these compounds: the blossoming of research on phosphonate carbanions, including their use in intermolecular and intramolecular Horner-Wadsworth-Emmons reactions; the discovery of phosphonoacetaldehyde in nature; and the application of phosphorylated aldehydes to the preparation of aminophosphonic acids. So much knowledge has been accumulated that the time seemed appropriate to gather the results of phosphorylated aldehyde research in a review. In this review, the various methods for the preparation of phosphonates containing a formyl group in the alkyl substituent linked to phosphorus, the types of reaction they undergo, their use as synthetic intermediates and their conversion into biologically active compounds are summarised.

\section{SYNTHESIS OF PHOSPHORYLATED ALDEHYDES}

One of the advantages of phosphorylated aldehydes is their synthetic accessibility. In principle, the formyl group can be introduced at any position relative to the phosphorus, and compounds with formyl group in positions 1 to 16 are known (Fig. 1). The methods for the preparation of phosphorylated aldehydes are generally a combination of phosphorus and carbon chemistry. To this end either a trivalent phosphorus compound reacts with an alkyl halide attached at a masked formyl group, or the formyl group is introduced into the alkyl substituent linked to the phosphoryl group using organometallic coupling methods ( $\mathrm{C}-\mathrm{C}$ bond formation) or functional group transformations. The choice of method, $\mathrm{P}-\mathrm{C}$ versus $\mathrm{C}-\mathrm{C}$ bond formation, depends on the relative position of the formyl group to phosphorus. The selected preparations here described include compounds containing alkoxy groups on the phosphorus atom.

$$
\begin{aligned}
& \mathrm{R}^{1}=\mathrm{Me}, \mathrm{Et} j-\mathrm{Pr} \quad \mathrm{n}=0-16 \\
& \mathrm{R}^{1} \mathrm{O}=\left(\begin{array}{c}
\mathrm{R}^{2} \\
\mathrm{R}
\end{array}\right){ }_{\mathrm{n}} \mathrm{C}_{\mathrm{O}}^{\mathrm{H}}
\end{aligned}
$$

Fig. 1. Dialkyl $\omega$-formylalkylphosphonates. 


\section{1. $\mathbf{n}=\mathbf{0}$.}

Compounds containing the formyl group attached directly to the phosphoryl group are somewhat controversial and information on their synthesis is extremely limited and to some extent doubtful. In 1973 it was written "possibly they cannot exist at all".1,3 In 1974 the preparation of the dimethyl formylphosphonate was briefly reported in a patent providing a method for the production of fosfomycin. ${ }^{4}$ In 1982 the reaction of the sodium derivative of dimethylphosphite with formic acetic anhydride in $\mathrm{Et}_{2} \mathrm{O}$ at $-10^{\circ} \mathrm{C}$ was reproduced on laboratory scale to give what appeared to be a mixture containing the desired dimethyl formylphosphonate and presumably oligomers. $5^{5}$ In 1987 it was shown that diethyl formylphosphonate $\mathbf{1}$ decomposes at $-10^{\circ} \mathrm{C}$ into diethylphoshite and carbon monoxide (Fig. 2). As diethylphosphite accumulates in the reaction mixture the addition reaction of diethylphosphite to the carbonyl group of the formylphosphonate takes place leading to the formation of tetraethyl (hydroxymethylene)diphosphonate 2, which isomerizes into (diethoxyphosphinyl) methyl diethyl phosphate 3 (79\%). ${ }^{6}$ The difficulty in isolating 1 by hydrolysis of an iminium salt has been reported. 187

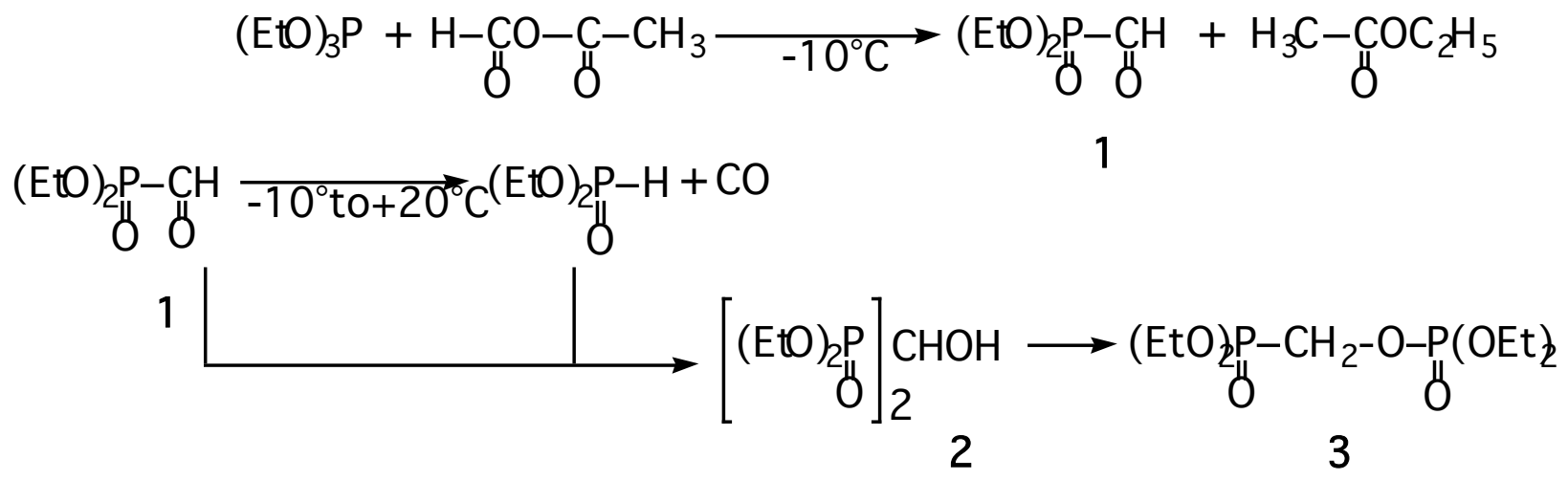

Fig. 2. Formation and decomposition of diethyl formylphosphonate.

On the other hand, acetals, hemithioacetals and thioacetals of formylphosphonates are known and readily available. ${ }^{7}$ In contrast to the parent compound, acetals and thioacetals are chemically stable. They can be obtained in two ways. Condensation of dialkylphosphites with orthoformic esters at $182^{\circ} \mathrm{C}$ for $5 \mathrm{~h}$ provides formylphosphonates with satisfactory yields (60 to 80\%). ${ }^{8}$ The second route, from either chlorophosphites and orthoformic esters, or trialkylphosphites and chloroacetals, is more general. ${ }^{9}$ For example, the synthesis of thioacetals is usually accomplished in high yields by reaction between the appropriate chlorodithioacetals and trivalent phosphorus compounds. ${ }^{7}$ A recent method for the synthesis of thioacetals involves the reaction between a dialkyl 1-lithioalkylthiophosphonate and a disulfide. The mixed thioacetals, obtainable in 70-90\% yields from $\mathrm{PhS}-\mathrm{SPh}$, are accompanied by $5-20 \%$ of symmetrical thioacetals. ${ }^{10}$ The hydrolysis of diethyl formylphosphonates acetals with $\mathrm{HCl} 2 \mathrm{M}$ at $117^{\circ} \mathrm{C}$ for $3 \mathrm{~h}$ does not lead to the corresponding aldehydes but involves the dissociation of the $\mathrm{C}-\mathrm{P}$ bond with formation of the initial diethylphosphite, $\mathrm{EtOH}$ and $\mathrm{HCO}_{2} \mathrm{Et}^{11}$

\section{2. $\mathbf{n}=\mathbf{1}$}

Possibly the most frequently used and most widely known phosphorylated aldehyde is the diethyl 1-formylmethylphosphonate 4. A variety of methods for the preparation of $\mathbf{4}$ have been reported in the literature. The oldest is via the thermal Michaelis-Arbuzov (MA) reaction ${ }^{2}$ between triethylphosphite, $(\mathrm{EtO})_{3} \mathrm{P}$, and the bromoacetaldehyde diethylacetal yielding diethyl 2,2-diethoxyethylphosphonate 5 (Fig. 3). Use of a 
protecting group for the aldehyde is essential since it is known that $\alpha$-haloaldehydes react with trialkyphosphites according to the Perkow reaction yielding dialkyl vinylphosphates isomeric with the expected phosphonates. ${ }^{12}$ Subsequent treatment of the phosphorylated acetal 5 by acid hydrolysis leads to $\mathbf{4}$. The reaction was first carried out by Dawson and Burger with stoichiometric quantities of each reagent to give a compound in $53 \%$ yield which was identified later as the diethyl 2-ethoxyvinylphosphonate 6. ${ }^{13}$ Detailed studies of the reaction were made by Razumov et al. with various phosphorus(III) acid esters (phosphites, aliphatic and aromatic phosphonites and phosphinites) together with a wide range of halogenoacetals. ${ }^{14}$ It was found that the influence of various factors is determined by familiar relations typical for the MA reaction. By monitoring the reaction by ${ }^{31} \mathrm{P}$ NMR spectroscopy it has been established that temperature plays a very significant role. Formation of diethyl 2,2-diethoxyethylphosphonate $5\left(\delta^{31} \mathrm{P}(\mathrm{THF})=+27.2\right)$ takes place cleanly at $150-160^{\circ} \mathrm{C}$ and tends to be accompanied beyond $180^{\circ} \mathrm{C}$ by its degradation into the corresponding phosphorylated vinyl ether $6\left(\delta^{31} \mathrm{P}(\mathrm{THF})=+21.6\right) .15$ The tendency of phosphorylated acetals to undergo pyrolysis is also influenced by the nature of the substituents at the phosphorus atom. Formation of phosphorylated vinyl ether $\mathbf{6}$ is not an obstacle to the synthesis of $\mathbf{4}$, since the hydrolysis of both the acetal and vinyl ether leads to the formation of the expected 1-formylmethylphosphonate 4. However, while the hydrolysis of phosphorylated vinyl ether proceeds similarly to that of phosphorylated acetals, it requires more severe conditions prejudicial to the isolation of $\mathbf{4} .^{147,148}$

In the hydrolysis of the phosphorylated diethylacetal, a high concentration and a large excess of the acid should not be used to avoid the hydrolysis of the ester groups at the phosphorus atom. ${ }^{16} \mathrm{~A}$ variety of acids have been used $\left(\mathrm{HCl},{ }^{14,16-18} \mathrm{H}_{2} \mathrm{SO}_{4},{ }^{19} \mathrm{HCO}_{2} \mathrm{H},{ }^{17,20} \mathrm{HClO}_{4}{ }^{16}\right.$ and $\left.\mathrm{CF}_{3} \mathrm{CO}_{2} \mathrm{H}^{17}\right)$ with various results. It is quite sufficient to use the theorical amount of $1 \mathrm{M} \mathrm{HCl}$ at $80-90^{\circ} \mathrm{C}$ to obtain a complete hydrolysis of the diethylacetal without degradation of the ester groups. ${ }^{14}$ A prolonged reaction at this temperature has a negative effect $\left(81 \%\right.$ of 4 after $1.5 \mathrm{~h}$ at $90^{\circ} \mathrm{C}$ with $1 \mathrm{M} \mathrm{HCl}$ and $72 \%$ after $\left.6 \mathrm{~h}\right) .{ }^{17}$ In the milder hydrolysis of diethylacetal in the presence of ion exchangers (Dowex $\left.50 \mathrm{H}^{+}\right),{ }^{21,22}$ the yield of phosphonoacetaldehyde increases $(93 \%){ }^{21}$ During the distillation of $\mathbf{4}$, a small amount of viscous product remains in the flask, attributed to the trimer of 4. ${ }^{14 a}$ This method of phosphorylation of chloro- or bromoacetaldehyde diethyl acetals coupled with a smooth hydrolysis of the acetals has been applied with success to the preparation of $\mathbf{4}^{13,14 a, 17-19}$ and extended on large scale. ${ }^{23}$ However, it is limited to 1 -formylmethylphosphonates unsubstituted at the $\alpha$-carbon.

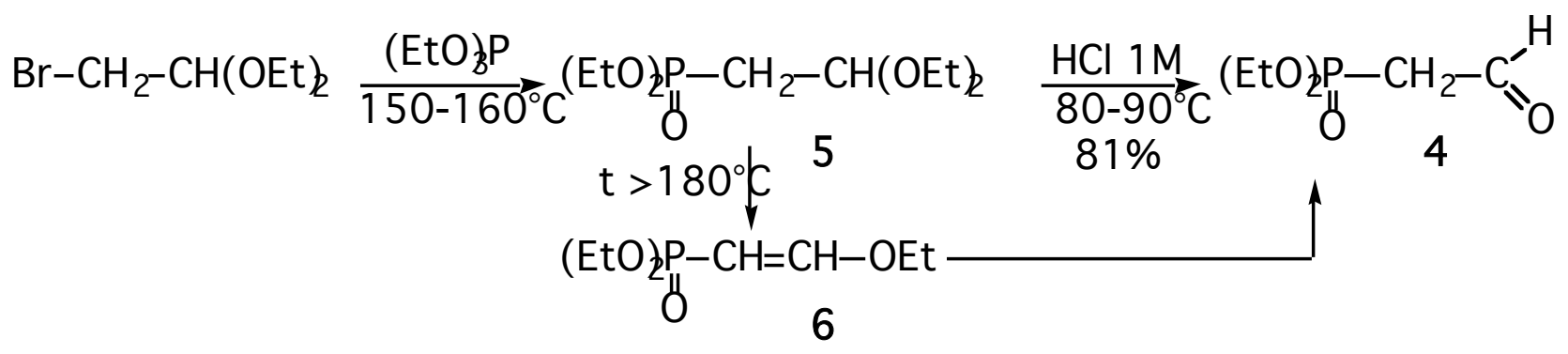

Fig. 3. Synthesis of diethyl 1-formylmethylphosphonate via the MA reaction ${ }^{17}$.

A further example of the acetal route utilizes phosphorylated acetal $\mathbf{8}$ and enolic ether $\mathbf{9}$ derived from diisopropyl ethynylphosphonate 7 (Fig. 4). According to the conditions employed, either one or two molecules of ethanol can be added across the triple bond to give, respectively, diisopropyl 2-ethoxyvinylphosphonate 9 and 2,2-diethoxyethylphosphonate 8. As above both compounds give $\mathbf{1 0}$ on acid hydrolysis. However, 
development of the method remains limited by the availability of diisopropyl ethynylphosphonate 7 on large scale. ${ }^{24}$

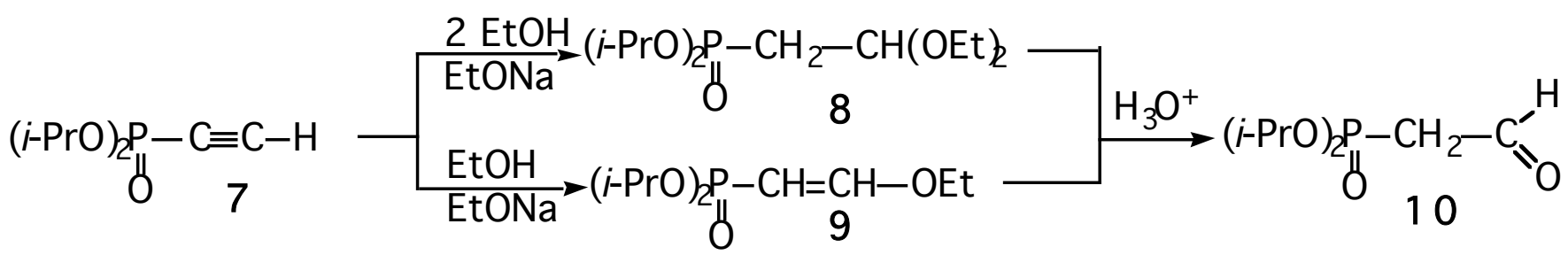

Fig. 4. Synthesis of diisopropyl 1-formylmethylphosphonate from ethynylphosphonate ${ }^{24}$.

A variation of the MA reaction utilized the chloromethyloxazine as masked formyl group instead of diethyl acetal (Fig. 5). Chloromethyloxazine underwent a smooth reaction with trialkyl phosphites at reflux for $24 \mathrm{~h}$ to furnish the oxazine phosphonates $11(\mathrm{R}=\mathrm{Me}, 40 \%$ and $\mathrm{R}=\mathrm{Et}, 80 \%) .25$

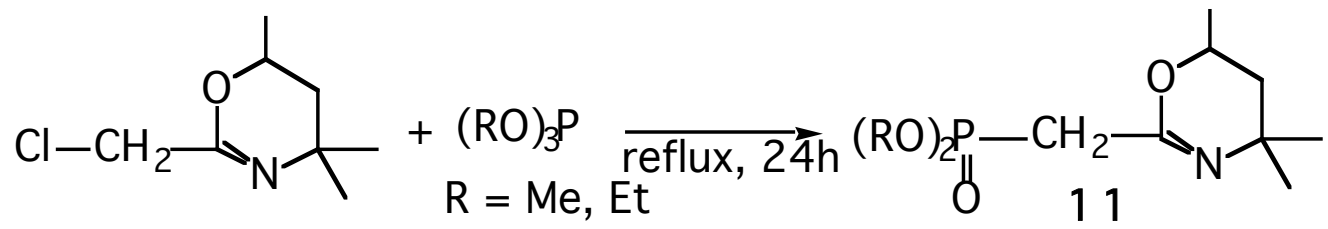

Fig. 5. Synthesis of oxazine phosphonates 25

Employing the oxazine phosphonates 11 provided a route to $\alpha$-substituted phosphonoacetaldehydes. For instance the 1,1-dimethyl oxazine phosphonate 12 was obtained in high yield (93\%) by treating the sodium derivative of $11(\mathrm{R}=\mathrm{Et})$ in DME with methyl iodide in excess. The conversion of 12 into the diethyl 1,1-dimethyl-1-formylmethylphosphonate 13 was accomplished in $62 \%$ overall yield by the standard reductionhydrolysis technique using sodium borohydride at $-45^{\circ} \mathrm{C}$ followed by heating in oxalic acid (Fig. 6). Thus the use of oxazine phosphonates $\mathbf{1 1}$ constitutes an entry into $\alpha$-substituted phosphonoacetaldehydes. 25

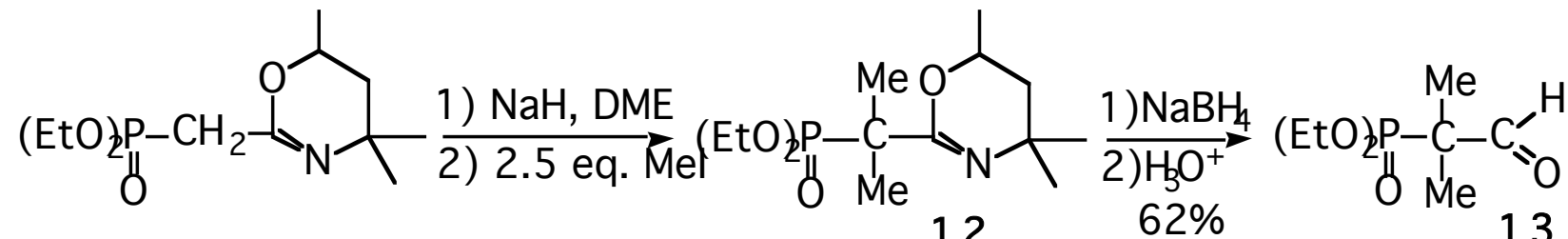

Fig. 6. Synthesis of diethyl 1,1-dimethyl-1-formylmethylphosphonate using the oxazine phosphonate 25 .

Another variation of the protecting reagent for the formyl group utilizes vinyl acetates. Thus diethyl 1-formylmethylphosphonate 4 was obtained in 66\% yield through the hydrolysis of diethyl 2-acetoxy-2-chloroethylphosphonate 14. Preparation of $\mathbf{1 4}$ was achieved by successive reaction of vinyl acetate with phosphorus pentachloride at $7-8^{\circ} \mathrm{C}$ in $\mathrm{CCl}_{4}$, treatment of the unisolated adduct at the same temperature with $\mathrm{SO}_{2}$ and alcoholysis of the (2-acetoxy-2-chloroethyl)phosphonic dichloride with ethanol at $0^{\circ} \mathrm{C}$ in $\mathrm{Et}_{2} \mathrm{O}$ in the presence of pyridine (Fig. 7). Deprotection of the formyl group, in acetone or dioxane, was a slow operation. ${ }^{26}$ 


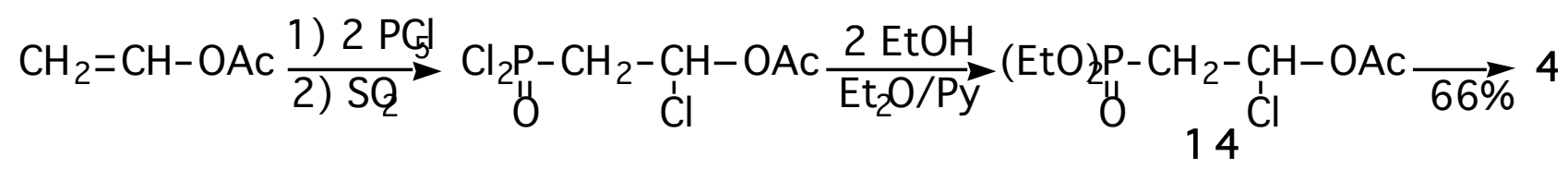

Fig. 7. Synthesis of diethyl 1-formylmethylphosphonate from vinyl acetates 26

A recently introduced method is the palladium-catalysed MA reaction of allyl acetates with (EtO) ${ }_{3} \mathrm{P}$, which provided diethyl allylphosphonates in reasonable yield (65\%). This reaction was been applied to the synthesis of diethyl 1-formylmethylphosphonate 4 on a preparative scale (crude $78 \%$, pure $52 \%$ ) by reductive ozonolysis of diethyl allylphosphonate in $\mathrm{CH}_{2} \mathrm{Cl}_{2}$ at $-70^{\circ} \mathrm{C}$ over 4 h (Fig. 8). ${ }^{27}$

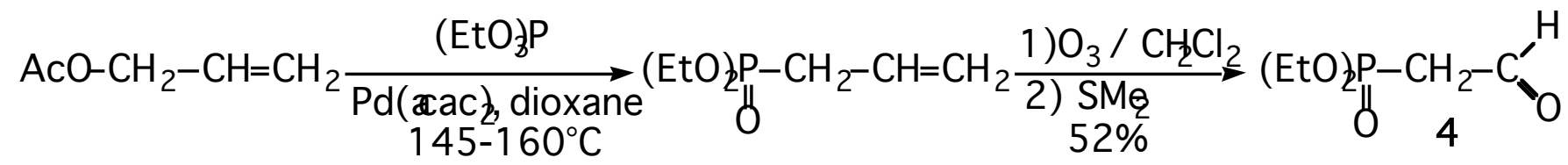

Fig. 8. Synthesis of diethyl 1-formylmethylphosphonate by reductive ozonolysis 27

The preparation on a large scale of dialkyl 1-formylethylphosphonates was achieved in good yield (66\%) by hydroformylation of several dialkyl vinylphosphonates in the presence of catalytic amounts of $\mathrm{Rh}(\mathrm{COD}) \mathrm{Cl}$ dimer in toluene with $1: 1 \mathrm{CO}-\mathrm{H}_{2}$ ratio. ${ }^{188}$

Decisive progress was made with the formylation of organophosphorus compounds containing an active methylene group. This methodology is the procedure of choice for preparing both unsubstituted and $\alpha$ substituted phosphonoacetaldehydes with or without a functional group next to the formyl group. The aldehydes synthesised include, together with the phosphorus-containing groups, alkyl, aryl and electron withdrawing groups in the $\alpha$-position.

Two complementary procedures have been successfully developed. One employs a carbanionic route with $\mathrm{HCO}_{2} \mathrm{Et}, 28,29,30,33 \mathrm{~b}$ DMF,31,149 $\mathrm{N}$-formylmorpholine ${ }^{32}$ or orthoformic esters $33 \mathrm{a}, 42,43$ as formylating agents, the other employs a thermal route with dimethylformamide dialkyl acetal or aminals ${ }^{34,35}$

In the carbanionic procedure, $n$-BuLi deprotonated the methylene group of $\mathbf{1 5}$ to give $\alpha$-lithioalkylphosphonates 16, which reacted with DMF or $N$-formylmorpholine to give a transient lithium $\beta$-aminoalkoxide 17. After treatment of the reaction mixture by aqueous acid $(3 \mathrm{M} \mathrm{HCl})$ the dialkyl 1-formylalkylphosphonates $\mathbf{1 8}$ were isolated in near quantitative yield (Fig. 9). 31,32 By a similar procedure $\mathbf{1 6}$ reacted with $\mathrm{HCO}_{2} \mathrm{Et}$ to give 18 in comparable yield. This formylation reaction using lithio anions and $\mathrm{HCO}_{2} \mathrm{Et}$ has been applied to the synthesis of several phosphonates containing an active methylene group including allyl-, 36 benzyl-, 30 chloromethyl-,37 bromomethyl-,29 3,3-diethoxybutyl-38 and thioethylmethylphosphonate. ${ }^{30}$ Yields of functional dialkyl 1-formyl-alkylphosphonates 18 were high and the only byproduct was the unreacted starting phosphonate. 


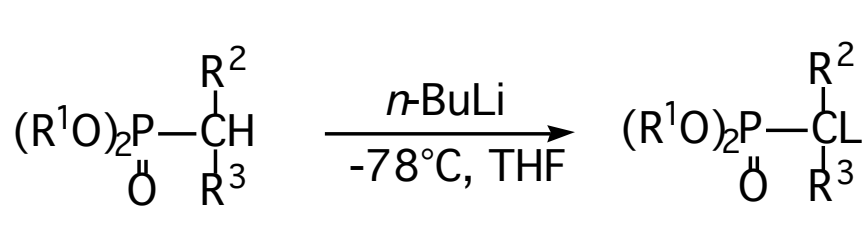

15

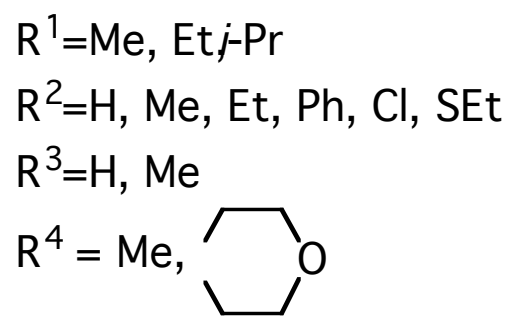

16

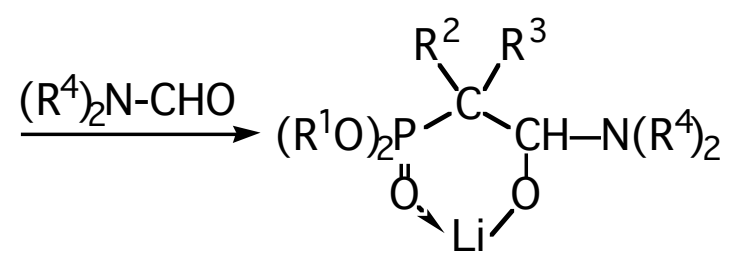

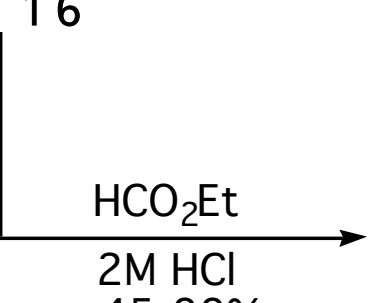

$45-88 \%$

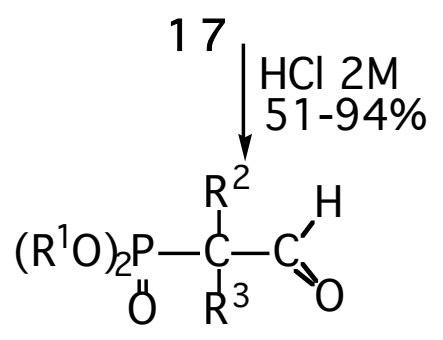

18

Fig. 9. Synthesis of 1,1-dialkyl-1-formylmethylphosphonates by the carbanionic route ${ }^{31,32}$.

The ethyl formate approach was combined with the phosphate-phosphonate conversion reaction to provide a useful one-pot transformation of triethylphosphate to the corresponding diethyl 1formylalkylphosphonates 19 in good overall yield (94\% with $\mathrm{R}=n$-Pr) (Fig. 10). 39,40 Generation of 19 from triethylphosphate renders this methodology a viable alternative to methods which require the preparation of diethyl alkylphosphonates $(\mathrm{EtO})_{2} \mathrm{P}(\mathrm{O}) \mathrm{CH}_{2} \mathrm{R}$. Thus, triethylphosphate serves as a reagent for the direct phosphorylation of alkyl groups.
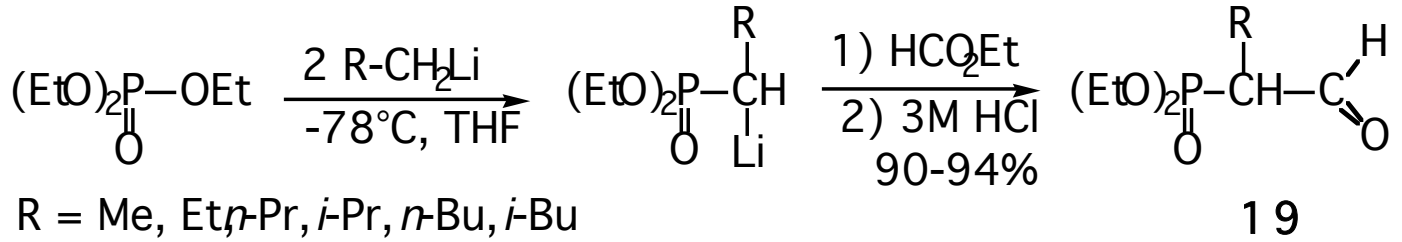

Fig. 10. One pot synthesis of diethyl 1-formylalkylphosphonates from triethylphosphate 39,40 .

Through a halogen-metal exchange reaction, the diethyl trichloromethylphosphonate $\mathbf{2 0}$ proved to be a useful reagent for the one-pot synthesis of diethyl 1-formylalkylphosphonates 19 (Fig. 11). In the presence of $n$-BuLi (2 eq.), 20 reacted readily at low temperature with TMSCl to give the 1-lithio-1-chloro-1(trimethylsilyl)-methylphosphonate 21, which provided 22 on treatment with alkyl halides. A third halogenmetal exchange reaction gaves the 1-lithio-1-(trimethylsilyl)alkylphosphonates $\mathbf{2 3}$, which were converted into the mixed acetals 24 by treatment with $\mathrm{HCO}_{2} \mathrm{Et}$ and an excess of TMSCl. Hydrolysis with $2 \mathrm{M} \mathrm{HCl}$ to diethyl 1-formyl-alkylphosphonates 19 usually as a mixture of aldehyde and enol in a good overall yield (70\%). ${ }^{41}$ 
$(\mathrm{EtO})_{2 \mathrm{P}}-\mathrm{Cl}_{\mathrm{Cl}}^{\mathrm{Cl}}-\mathrm{Cl} \frac{\begin{array}{c}2 n-\mathrm{BuLi} \\ \mathrm{TMSCl}\end{array}}{-78^{\circ} \mathrm{C}, \mathrm{THF}}$

20<smiles>[R]C(=CO[R16]([H])([H])C)[P+](=O)OCC</smiles>

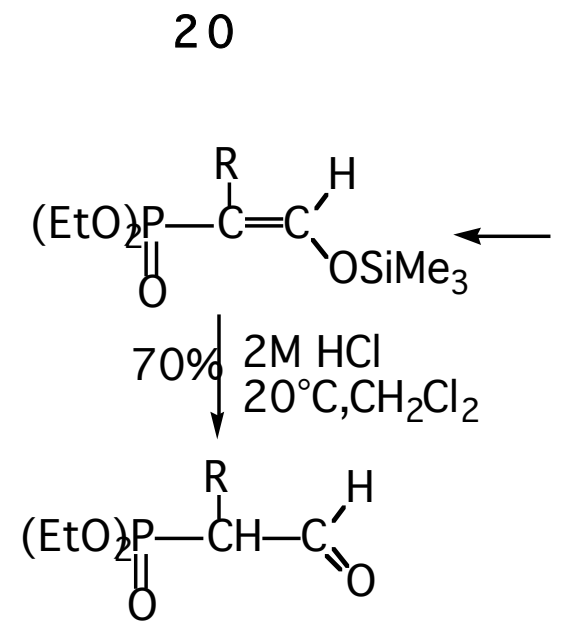<smiles>CCOP(=O)(OCC)C(Cl)(Cl)[AsH3]</smiles>

21

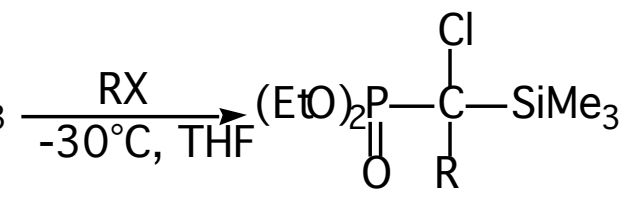

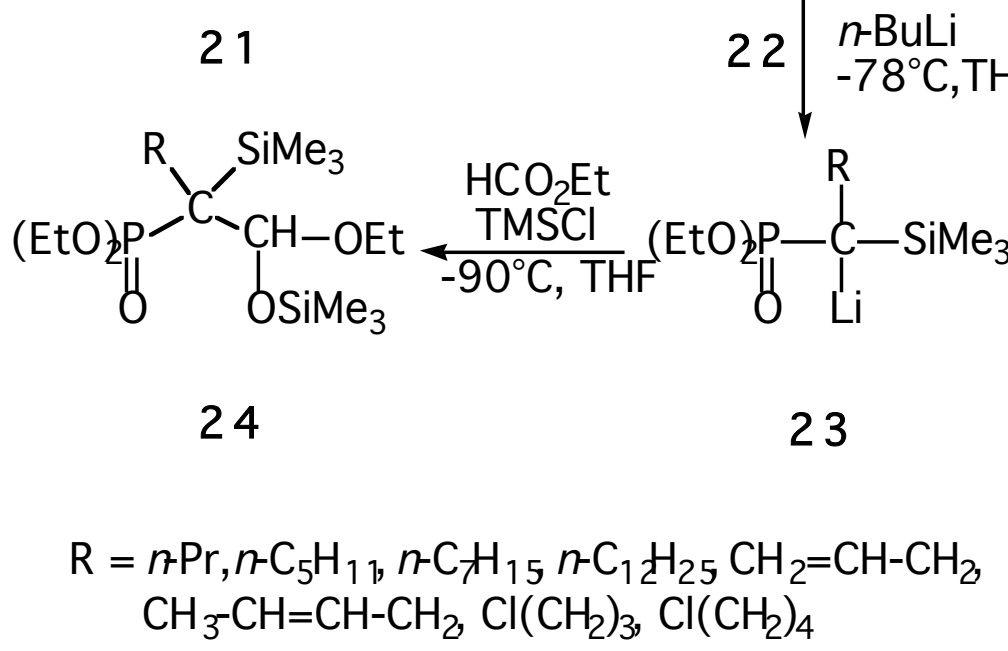

19

Fig. 11. Synthesis of diethyl 1-formylalkylphosphonates from diethyl trichloromethylphosphonate ${ }^{41}$

Formylation of methylene group with orthoformic esters is a more limited reaction. In the presence of sodium in $\mathrm{Et}_{2} \mathrm{O}$ at room temperature, orthoformic esters effect a formylation reaction with a number of relatively acidic $\left(\mathrm{Z}=\mathrm{Cl},{ }^{33 \mathrm{a}} \mathrm{Br},{ }^{33 \mathrm{a}} \mathrm{Ph}^{33 \mathrm{a}, 42}\right)$ or very acidic phosphonates $25\left(\mathrm{Z}=\mathrm{CN},{ }^{33 \mathrm{~b}} \mathrm{CO}_{2} \mathrm{R}, 33 \mathrm{~b}\right.$ $\mathrm{COR}^{29,33 a, 43}$ ). Yields of functionalized diethyl 1-formylmethylphosphonates $\mathbf{2 7}$, after aqueous acid treatment of the diethyl acetals or enol ethers, are relatively modest (32 to 50\%), which renders this methodology not competitive with methods that use formylating agent at low temperature.

When phosphonates $\mathbf{2 5}$ containing powerful electron withdrawing groups $\mathrm{Z}$ are subjected to formylation by $\mathrm{HCO}_{2} \mathrm{Et}$, the corresponding phosphorylated aldehydes $\mathbf{2 7}$ are obtained in low yields ( 25 to $30 \%$ ). $28,29,30$ Full utilization of this carbanionic route is handicapped by the $\mathrm{Z}$ groups, which promote a stabilisation of the anionic form unfavourable to the reaction. This may be overcome by use of a thermal route (Fig. 12). In the thermal procedure, an aminomethylene fragment is introduced on the methylene group by the reaction of the phosphonates $\mathbf{2 5}$ with a N,N-dimethylformamide dialkyl acetal to produce phosphorylated enamines $\mathbf{2 6}$ in pure form. The phosphorylated enamines $\mathbf{2 6}$ are then converted to the 1-formyl-methylphosphonates $\mathbf{2 7}$ by further acid or basic hydrolysis. ${ }^{34,35}$ By contrast to the carbanionic route, the electron withdrawing effect of the $\mathrm{Z}$ group appears as a favourable factor in the thermal route. 


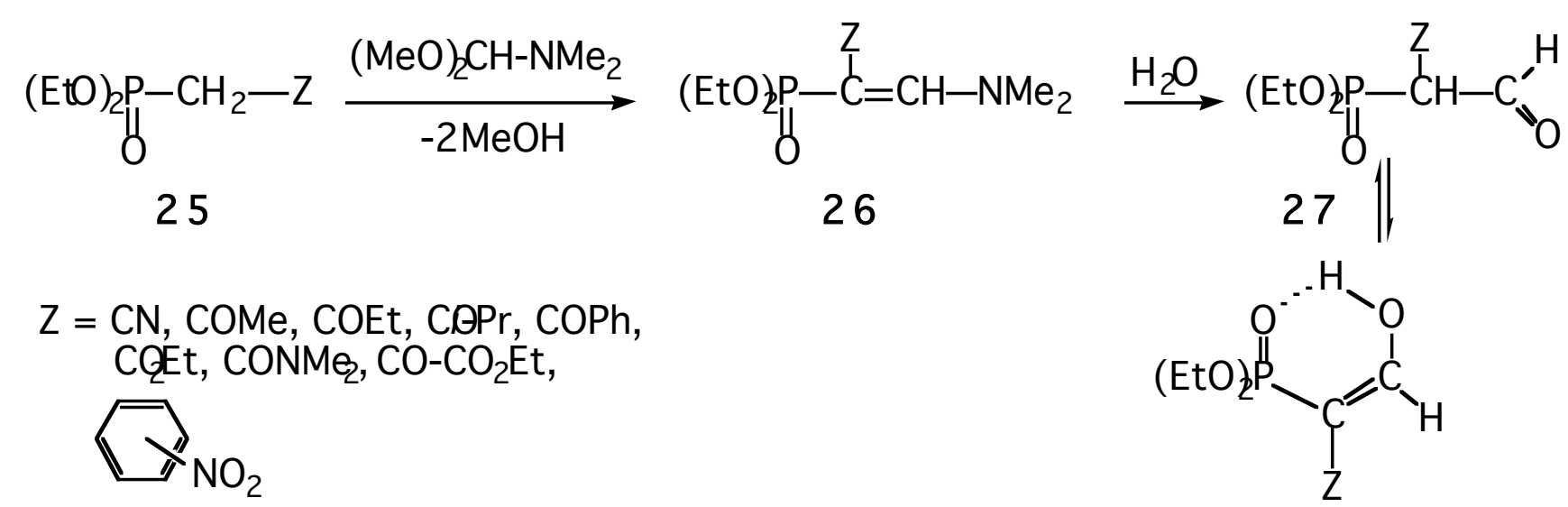

Fig. 12. Synthesis of diethyl 1-formylalkylphosphonates by thermal route 35

A large variety of $\mathrm{N}, \mathrm{N}$-dimethylformamide dialkyl acetals are commercially available. They have a greater reactivity than the orthoformate esters and they offer the advantages of neutral conditions and greater yields than those obtained by other methods. The N,N-dimethylformamide dimethyl acetal and tert-butoxybis(dimethylamino)methane have been shown to be useful in reaction with phosphonates bearing a good electron withdrawing group $\mathrm{Z}$. On reaction with functionalized phosphonates 25, N,N-dimethylformamide dimethyl acetal undergoes spontaneous elimination of methanol at room temperature when $\mathrm{Z}=\mathrm{CN}$ and $\mathrm{CO}-\mathrm{CO}_{2} \mathrm{R}$; with $\mathrm{Z}=\mathrm{CONR}_{2}, \mathrm{CO}_{2} \mathrm{R}$ and $\mathrm{COR}$ the reaction requires $2 \mathrm{~h}$ at reflux and when $\mathrm{Z}=\mathrm{C}_{6} \mathrm{H}_{4} \mathrm{NO}_{2} 8 \mathrm{~h}$ at reflux is necessary. The enamine phosphonates $\mathbf{2 6}$ are always obtained in nearly quantitative yield. However, the number of compatible functional groups is limited since phosphonates with $\mathrm{Z}=\mathrm{CH}(\mathrm{OEt})_{2}, \mathrm{Cl}, \mathrm{CH}=\mathrm{CH}_{2}, \mathrm{CH}=\mathrm{CHCl}, \mathrm{C}_{6} \mathrm{H}_{5}$, $o-\mathrm{ClC}_{6} \mathrm{H}_{4}, p-\mathrm{ClC}_{6} \mathrm{H}_{4}$ and $\mathrm{SEt}$ are inert. Formyl deprotection can be realized at room temperature either by treatment with $3 \mathrm{M} \mathrm{HCl}$ in biphasic medium $\left(\mathrm{Z}=o\right.$ - or $\left.p-\mathrm{NO}_{2} \mathrm{C}_{6} \mathrm{H}_{4}, \mathrm{CO}_{2} \mathrm{R}, \mathrm{CONR}_{2}\right)$ or with $2 \mathrm{M} \mathrm{NaOH}$. The yields are generally excellent (83-90\%) and the phosphonates containing a formyl group next to the $\mathrm{Z}$ group are isolated mainly in the enol form. 35

Another attractive preparation of 1-formylphosphonates includes the rearrangement of epoxides to carbonyl compounds, which is a well established reaction offering a true synthetic utility. An advantageous synthesis of diethyl 1,1-disubstituted 1-formylmethylphosphonates 29 has been developed using readily available diethyl 1,2-epoxyphosphonates 28 and catalytic isomerisation induced by Lewis acids (Fig. 13). The boron trifluoride etherate is an effective catalyst in the rearrangement of $\mathbf{2 8}$. The $[1,2]$ migration of the phosphoryl group is conducted with high selectivity and in good yield. Both symmetrical and unsymmetrical aliphatic and cyclic phosphorylated aldehydes $\mathbf{2 9}$ can be obtained by this way. $44-48$

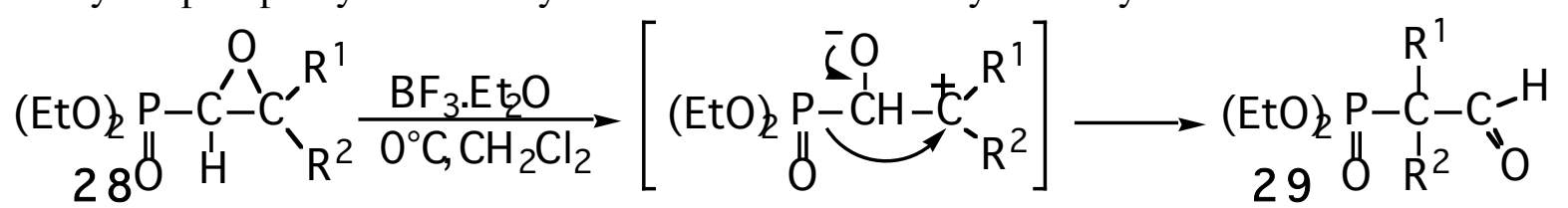

Fig. 13. Synthesis of diethyl 1,1-dialkyl-1-formylmethylphosphonates from 1,2-epoxyphosphonates ${ }^{48}$.

Table 1. Synthesis of diethyl 1,1-dialkyl-1-formylmethylphosphonates ${ }^{48}$.

\begin{tabular}{||c|cccccccccccc||}
\hline \hline $\mathbf{2 9}$ & $\mathbf{a}$ & $\mathbf{b}$ & $\mathbf{c}$ & $\mathbf{d}$ & $\mathbf{e}$ & $\mathbf{f}$ & $\mathbf{g}$ & $\mathbf{h}$ & $\mathbf{i}$ & $\mathbf{j}$ & $\mathbf{k}$ & $\mathbf{1}$ \\
\hline $\mathrm{R}^{1}$ & $\mathrm{Me}$ & $\mathrm{Me}$ & $\mathrm{Me}$ & $\mathrm{Me}$ & $\mathrm{Me}$ & $\mathrm{Me}$ & $\mathrm{Me}$ & $\mathrm{Me}$ & $\mathrm{Et}$ & $n$-Pr & $i$-Pr & $i$ - $\mathrm{Bu}$ \\
\hline $\mathrm{R}^{2}$ & $\mathrm{Me}$ & $\mathrm{Et}$ & $i$-Pr & $n-\mathrm{Pr}$ & $\longrightarrow$ & $t$-Bu & $n$-Pent & $\mathrm{Ph}$ & $\mathrm{Et}$ & $n$-Pr & $i$-Pr & $i$-Bu \\
\hline
\end{tabular}




\begin{tabular}{|c|ccccccccccccc||}
\hline $\begin{array}{c}\text { Yield } \\
(\%)\end{array}$ & 76 & 78 & 75 & 75 & 72 & 62 & 68 & 68 & 78 & 75 & 76 & 76 \\
\hline
\end{tabular}

It has been found that there are limitations in this rearrangement. For example, the 1,2-epoxyphosphonates prepared from cyclic ketones ( $m=1-3$, Fig. 14), upon treatment with boron trifluoride etherate undergo a competing proton migration and consequently give a mixture of diethyl 1,1-disubstituted-1formylphosphonates 30 (major product, 25-71\%) and diethyl 1-hydroxyallylphosphonates 31 (minor product, $10-15 \%)$ (Fig.14). ${ }^{48}$
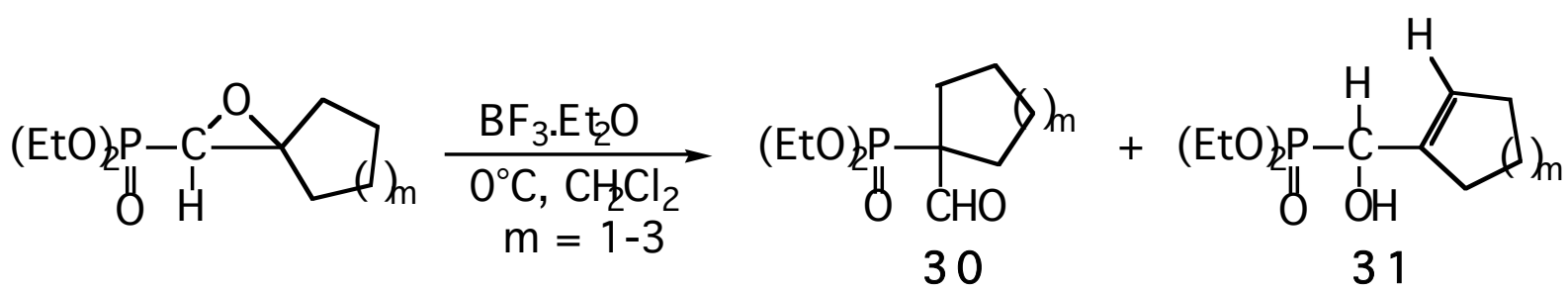

Fig. 14. Side reactions in the rearrangement of 1,2-epoxyphosphonates ${ }^{48}$.

In some cases 1,2-epoxyphosphonates undergo thermal isomerisation at high temperature $\left(170-300^{\circ} \mathrm{C}\right)$ to produce, as a result of the phosphoryl group migration, substituted 1-formylmethylphosphonates. In fact, the rearrangement products themselves can be thermally labile undergoing dephosphorylation. ${ }^{44,49}$

The ring opening of diethyl 1,2-epoxyphosphonates $\mathbf{3 2}$ has been effected by refluxing $\mathbf{3 2}$ with an ethanolic solution of sodium dialkylphosphite (Fig. 15), which attacks the $\beta$-carbon atom of the epoxide via the equilibrium sodium phosphite salt-alcoholate intermediate. The ring opened compound easily undergoes a phosphite anion elimination producing dialkyl 1-formylethylphosphonates $\mathbf{3 3}$ in $50-85 \%$ yields. 50

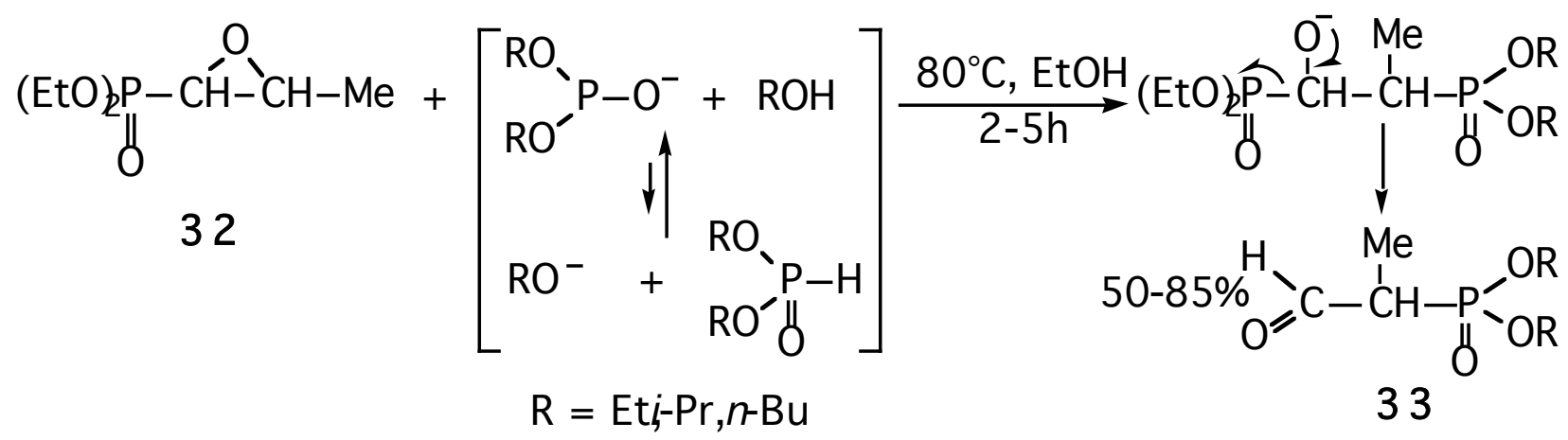

Fig. 15. Rearrangement of dialkyl 1,2-epoxyphosphonates in basic medium ${ }^{50}$.

The treatment with singlet oxygen of a methanolic solution of dimethyl 2-nitroethylphosphonate also containing $\mathrm{MeONa}$ and a sensitizer, Rose Bengal, affords dimethyl 1-formylalkylphosphonates in yields ranging from 64 to $90 \%$. Temperature dependence of the yield has been observed. The higher yield at low temperature may be attribuable to increasing stability of the intermediate dioxazetidine. ${ }^{51}$

\section{3. $\mathbf{n}=\mathbf{2}$.}

The conventional MA reaction of $(\mathrm{EtO})_{3} \mathrm{P}$ and halogenoacetals has been applied to the synthesis of diethyl 3,3-diethoxypropylphosphonates 34.14a,17a,18a,c The reaction can be realized in good yield (65\%) with linear or branched primary halogenoacetals (Fig. 16). Of significant synthetic importance is the easy formation 
of $\alpha$-substituted 3,3-diethoxy-propylphosphonates 35 by treatment of 34 with $n$-BuLi in THF at $-50^{\circ} \mathrm{C}$ and subsequent alkylation of the stable $\alpha$-lithiophosphonate carbanion. The yields of $\mathbf{3 5}$ are moderate to good (62$70 \%)$. The acetals are hydrolyzed in the same conditions as above $(1 \mathrm{M} \mathrm{HCl})$ to give diethyl 2-alkyl-2formylethylphosphonates $36\left(\mathrm{R}^{1} \neq \mathrm{H}\right)$ and 2-formylethylphosphonate $36\left(\mathrm{R}^{1}=\mathrm{H}\right)$ in yields ranging from 50 to $85 \%$. Distillation of these compounds is frequently accompanied by extensive polymerisation. ${ }^{17 \mathrm{~b}}$

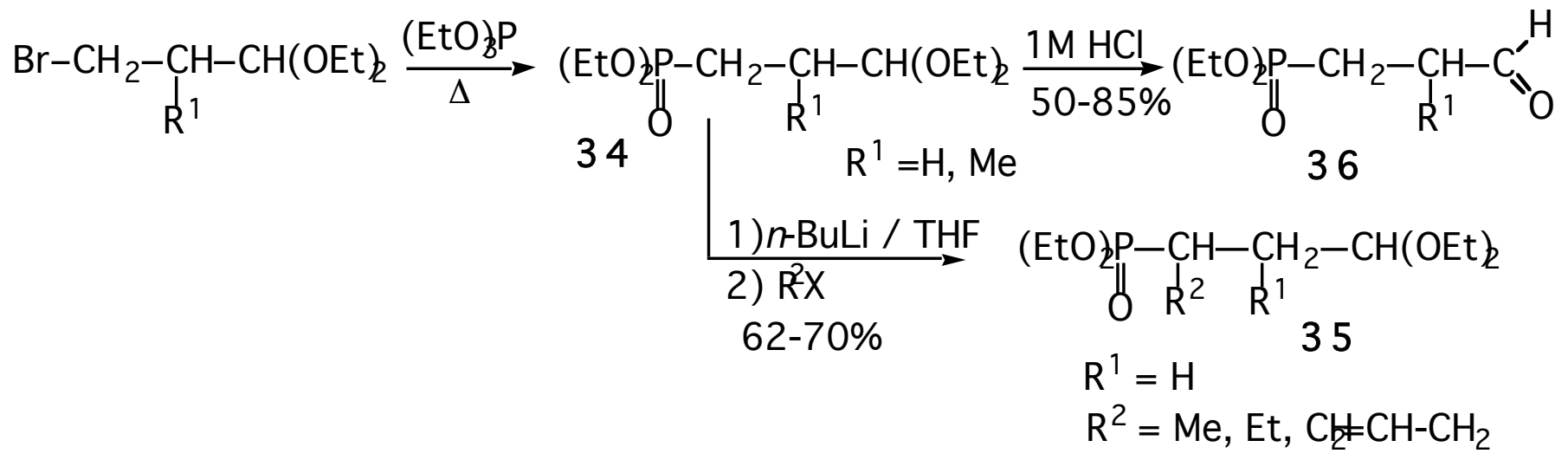

Fig. 16. Synthesis of diethyl 2-formylethylphosphonate via the MA reaction ${ }^{17 b}$.

Reaction of $(\mathrm{EtO})_{3} \mathrm{P}$ with dihalogenoalkenes at $120-140^{\circ} \mathrm{C}$ provides the diethyl 3-halogeno-propen-2ylphosphonates 37 (56 to 90\% yield) which upon treatment with alcoholates or thiolates in ethanol at room temperature results in the only formation of the substitution products in the $\gamma$-position (Fig. 17). The enol- 38 and thioenolether 39 were converted by hydrolysis with $5 \mathrm{M} \mathrm{HCl}$ at reflux to the corresponding diethyl 2-alkyl2-formylethylphosphonate $36\left(\mathrm{R}^{1} \neq \mathrm{H}\right)$ or 2 -formylethylphosphonate $36\left(\mathrm{R}^{1}=\mathrm{H}\right)$ thus giving an entry into $\beta$ substituted phosphonopropionaldehydes. ${ }^{52}$

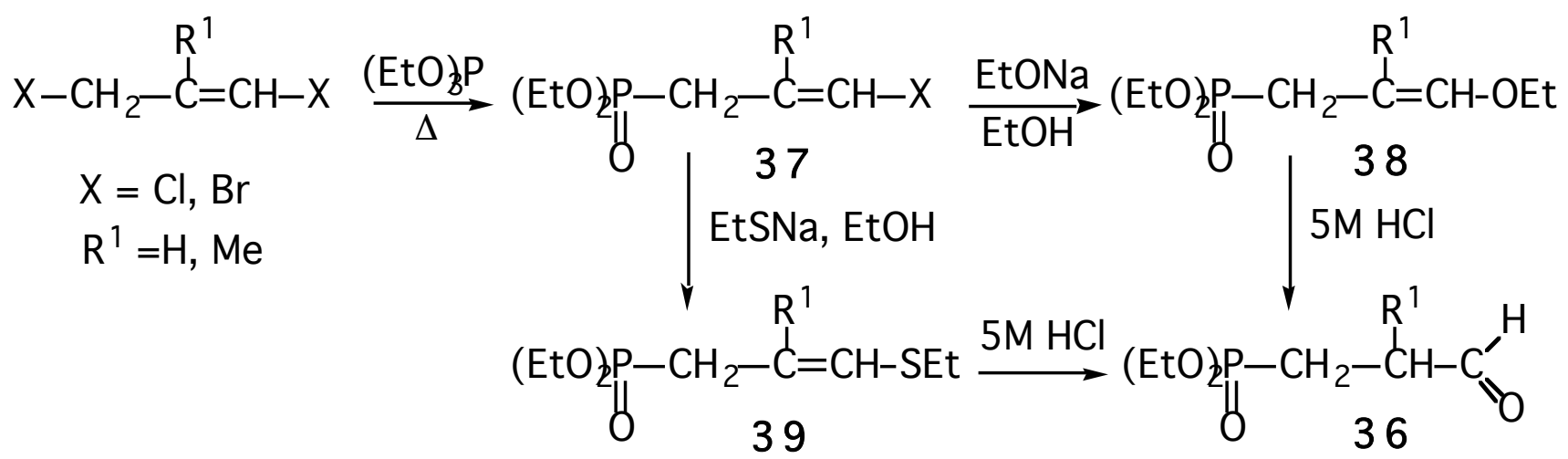

Fig. 17. Synthesis of diethyl 2-alkyl-2-formylethylphosphonates via the MA reaction ${ }^{52}$.

Unsaturated dialkyl 2-formylphosphonates have been obtained via alkoxyacetals 41. These were prepared from the reaction of $\mathrm{PCl}_{5}$ with alkyl allyl ethers at $7^{\circ} \mathrm{C}$ in $\mathrm{C}_{6} \mathrm{H}_{6}$. On treatment with $\mathrm{RONa}$ in $\mathrm{Et}_{2} \mathrm{O}$, the (3-alkoxy-3-chloropropenyl)phosphonic dichlorides $\mathbf{4 0}$ resulting from decomposition of the adduct with $\mathrm{SO}_{2}$ ( $41 \%$ yield for $\mathrm{R}^{1}=\mathrm{Et}$ and $24 \%$ for $\mathrm{R}^{1}=n$-Pr) produced a number of dialkyl 3,3-dialkoxy-propenylphosphonates 41 in yields ranging from 56 to $82 \%$ (Fig. 18). However, in experiments aimed at the isolation of the corresponding dialkyl 2-formylvinylphosphonates by hydrolysis of $\mathbf{4 1}$, only clear viscous, undistillable resins were obtained. In view of their instability, phosphonoacroleins were not isolated in a free state but were identified as their 2,4-dinitrophenylhydrazones derivatives. ${ }^{54}$ 


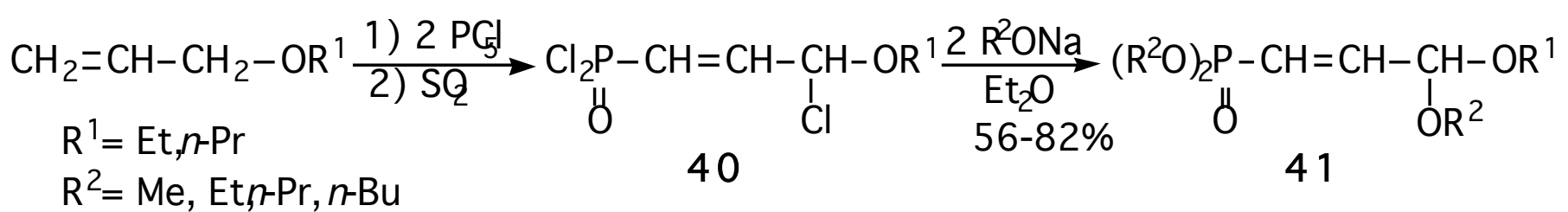

Fig. 18. Synthesis of dialkyl 3,3-dialkoxypropenylphosphonates from alkyl allyl ethers ${ }^{54}$.

In contrast, the diethyl 2-formylethynylphosphonate $\mathbf{4 3}$ is a distillable colorless liquid, which proved to be stable when stored for several months at $0^{\circ} \mathrm{C}$. It is obtained on preparative scale in high yield by hydrolysis with $97 \% \mathrm{HCO}_{2} \mathrm{H}$ of the diethyl 3,3-diethoxypropynylphosphonate 42 . Catalytic hydrogenation of 42 (5\% $\mathrm{Pd} / \mathrm{CaCO}_{3}$ ) gave a mixture $Z$ - and $E$ - of acetals, from which the $Z$ - isomer 44 was isolated in $60 \%$ yield. Formolysis of pure 44 using $97 \% \mathrm{HCO}_{2} \mathrm{H}$ gave a mixture of $Z$ - and $E$ - aldehydes from which the $Z$ - diethyl 2-formylvinylphosphonate 45 Z- was isolated in $60 \%$ yield by distillation (Fig. 19). 55<smiles>CCOC(C)C=CC(=O)O[Pb](=O)OCC</smiles>

$4460 \%$
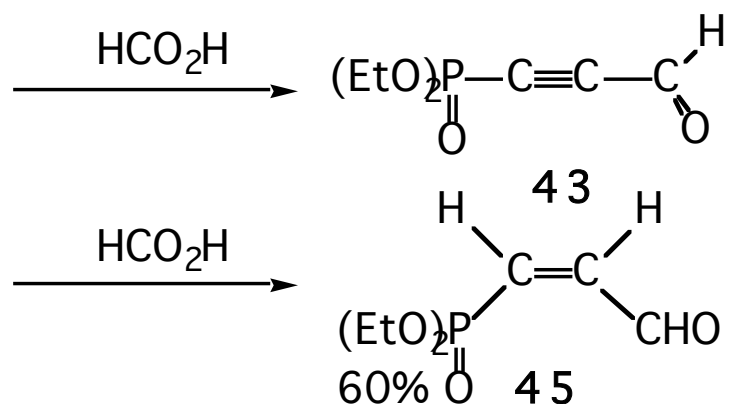

Fig. 19. Synthesis of diethyl 2-formylethynyl- and Z-2-formylvinylphosphonates 55 .

Preparation of pure $E$ - diethyl 2-formylvinylphosphonate $\mathbf{4 5}$ in $52 \%$ yield involved the oxidation with pyridinium chlorochromate ( $\mathrm{PCC}$ ) in $\mathrm{CH}_{2} \mathrm{Cl}_{2}$ at room temperature of diethoxyphosphinylallyl alcohol 47, which was prepared from the diethyl 2,3-epoxyprop-1-ylphosphonate 46. Compound 46 underwent ring opening at $0^{\circ} \mathrm{C}$ with sodium methoxide in methanol followed by treatment with Dowex $\left(\mathrm{H}^{+}\right)$resin to give the crude allylic alcohol in quantitative yield (Fig. 20). ${ }^{56}$<smiles>CC[Pb](=O)CC1CO1</smiles>

46<smiles></smiles>

47

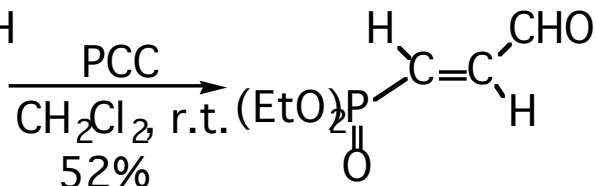

45

Fig. 20. Synthesis of E-diethyl 2-formylvinylphosphonate 56 .

Very recently the preparation of diethyl 3,3-diethoxy-2-hydroxypropylphosphonate $\mathbf{4 8}$ was reported with $38 \%$ yield through the condensation of lithium diethylphosphite with D-glycidaldehyde diethyl acetal at $80^{\circ} \mathrm{C}$ in THF in the presence of $\mathrm{BF}_{3} \cdot \mathrm{Et}_{2} \mathrm{O}$ (Fig. 21). Deprotection of the aldehyde was accomplished with $0.1 \mathrm{M}$ $\mathrm{HCl}$ at $40^{\circ} \mathrm{C}$ to give $49.57,58$

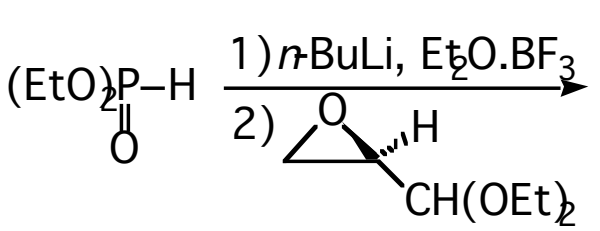

Fig. 21. Synthesis of diethyl 2-formylphosphonate by epoxide ring opening 57 .

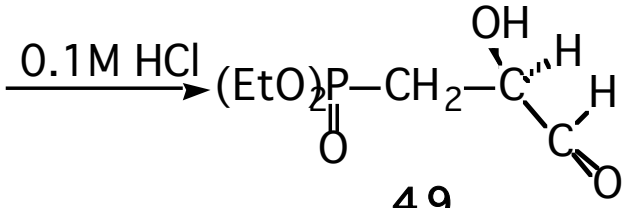

49 
The method of converting vinyl to carbonyl groups by reductive ozonolysis has received much attention and has been applied with success to a variety of phosphonates containing homoallyl groups, including $\alpha$-functionalized phosphonates. ${ }^{59-61}$ The homoallyl group is often introduced by condensation of allylbromide with diethyl 1-lithioalkylphosphonates. ${ }^{60,61}$ For instance, a convenient preparation of 52 (Fig. 22) was achieved by ozonolysis of diethyl 1-allyl-1,1-difluoromethylphosphonate 51, which itself was prepared in 64\% yield from 50 after treatment of diethyl difluoromethylphosphorylcadmium bromide intermediate with allyl bromide. 62
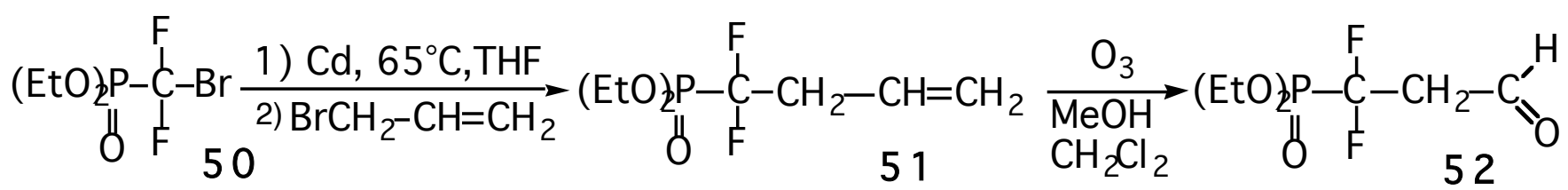

Fig. 22. Synthesis of diethyl 1,1-difluoro-2-formylethylphosphonate by reductive ozonolysis 62 .

Lactols have appeared as effective precursors in the synthesis of phosphorylated aldehydes. They have been utilized as starting materials for the conversion of phosphorylated 1,2-glycols to corresponding aldehydes via an oxidation with $\mathrm{NaIO}_{4}$ in basic medium (Malaprade reaction). The lactol oxidative opening provided the diethyl 2-formyl-2-(hydroxymethyl)ethylphosphonate, which eliminated water during purification by chromatography on silica to produce diethyl 2-methylene-2-formylethylphosphonate. ${ }^{63}$

A reaction of significant synthetic importance for the generation of dialkyl 2-formylethylphosphonates $36\left(\mathrm{R}^{1}=\mathrm{H}\right)$ is the addition of trivalent phosphorus reagents to $\alpha, \beta$-unsaturated aldehydes. ${ }^{64}$ This Michael / Michaelis-Arbuzov strategy (Fig. 23) is the method of choice for incorporating substituents at any position between the phosphoryl and formyl groups. Addition was observed to occur under quite mild conditions in a conjugate manner with a wide range of Michael type substrates. ${ }^{53,65}$ The reaction of $(\text { EtO })_{3} \mathrm{P}$ with $\alpha, \beta$-unsaturated aldehydes in the presence of a proton source was first investigated.

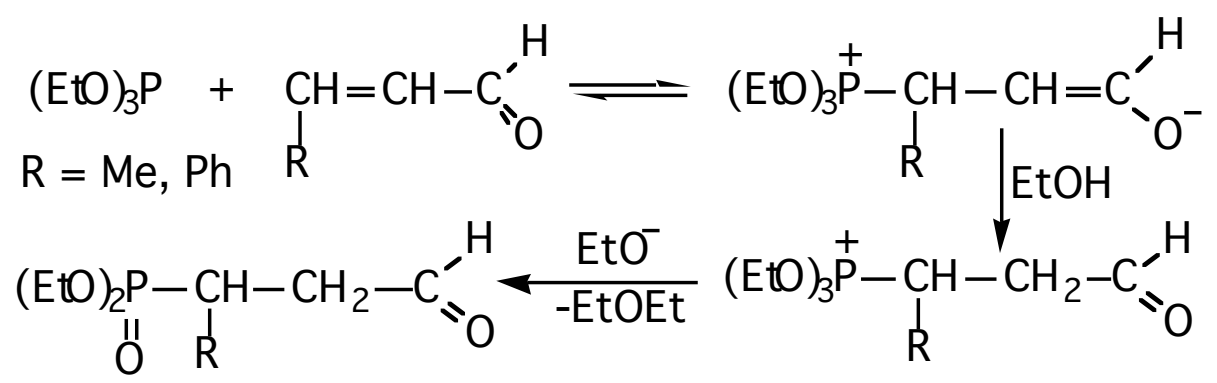

Fig. 23. Addition of (EtO) $)_{3} \mathrm{P}$ to $\alpha, \beta$-unsaturated aldehydes in the presence of ethanol ${ }^{66 \mathrm{a}}$.

The use of a protic solvent such as an alcohol or a phenol provides not only a source of a proton for the anionic site of the zwitterionic adduct, but also a nucleophile for the required dealkylation step. Further efforts demonstrated that better yields were obtained using phenol (82\% with crotonaldehyde) rather than simple alcohols. 66

Besides alcohol or phenol, a variety of associated reagents including dialkyl chlorophosphates ${ }^{67}$ and silyl halides 68 have also been added as a trap in the reaction medium. Frequently, the use of these different reagent systems gave conjugate addition products. ${ }^{64}$ In recent years, some striking developments with conjugate addition reactions have been accomplished using either phosphorus reagents bearing silyl ester 
linkages such as $\mathrm{X}_{2} \mathrm{POSiR}_{3}$ or $\mathrm{X}_{2} \mathrm{POR}$ and $\mathrm{R}_{3} \mathrm{SiCl}$. Reactions with $\alpha, \beta$-unsaturated aldehydes were carried out with 1 equivalent of each reagent either neat or in a solvent at ambient temperature (Fig. 24). A comparison of different reagents reveals that the reaction of acrolein, methacrolein and cinnamaldehyde proceeds quite readily, but with some complications. Although in certain instances low yield of conjugate addition products can be isolated, the major product formed is the product of addition at the carbonyl carbon (Abramov product). ${ }^{68}$

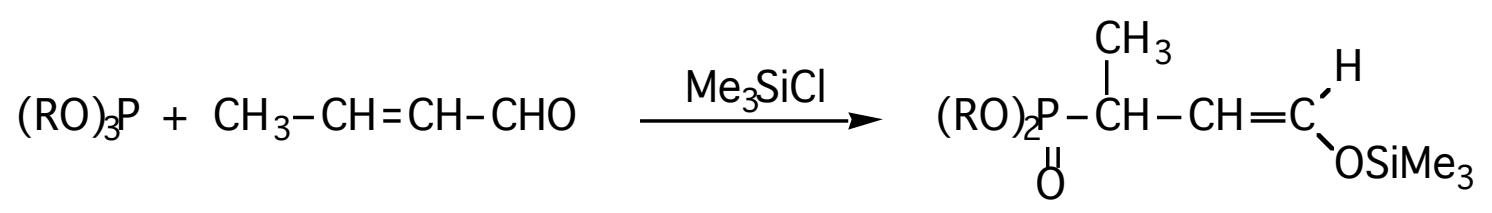

Fig. 24. Addition of trialkylphosphite to crotonaldehyde in the presence of $\mathrm{Me}_{3} \mathrm{SiCl}^{68}$.

The conjugate addition has been observed in the reaction of arylmethylenemalonaldehydes with trimethylphosphite. The reaction proceeds via an unstable intermediate, whose existence has been proven on the basis of spectral and chemical evidence, and which is easily hydrolysed to give a phosphonomethylenemalonaldehyde. 69

Full utilization of $\alpha, \beta$-unsaturated aldehydes is often handicapped by the complications reported above. These disadvantages are overcome when the unprotected $\alpha, \beta$-unsaturated aldehyde is replaced with an aldimine 53, which is activated as an imminium salt (Fig. 25).

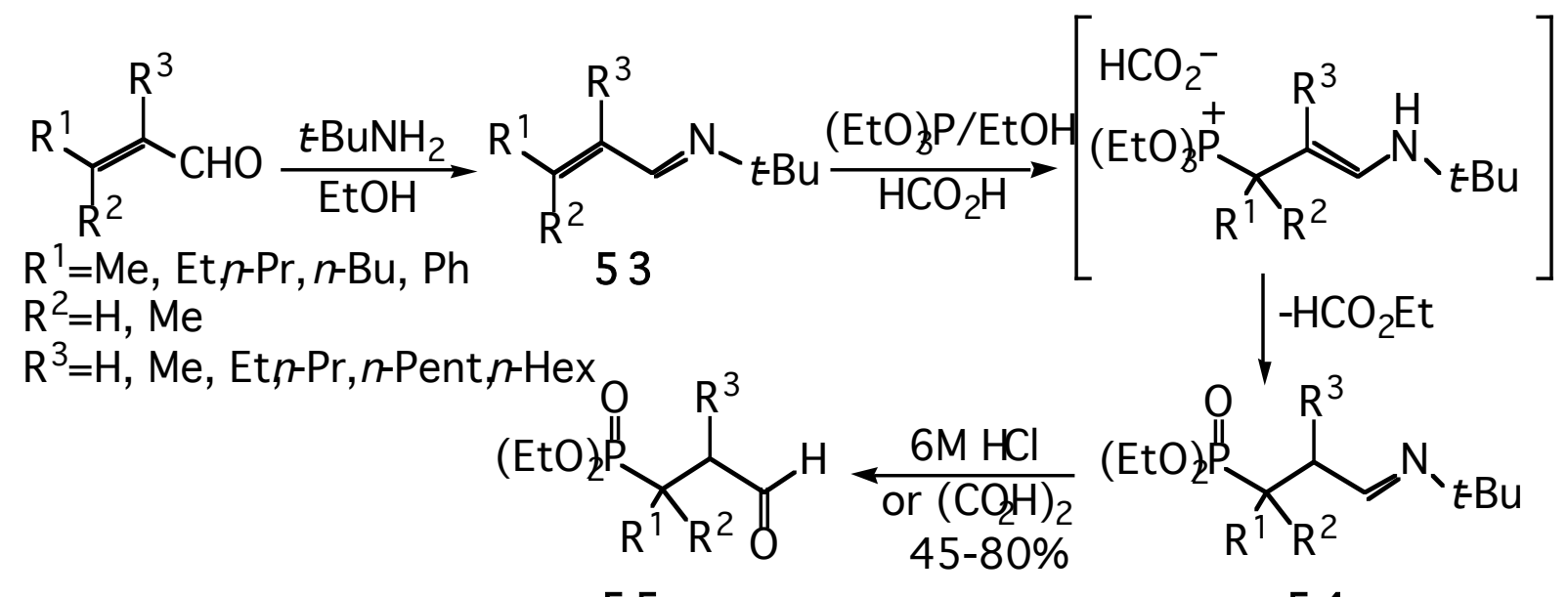

55

54

Fig. 25. Synthesis of diethyl 2-formylalkylphosphonates from aldimines ${ }^{70}$.

$(\mathrm{EtO})_{3} \mathrm{P}$ does not react with aldimines in ethanol. By contrast, the addition of 1 equivalent of $\mathrm{HCO}_{2} \mathrm{H}$ to the mixture $(\mathrm{EtO})_{3} \mathrm{P} / \mathrm{EtOH} /$ aldimine induces an exothermic reaction resulting in the exclusive formation of $\mathbf{5 4}$. Undoubtedly, the 1,4 -addition of $(\mathrm{EtO})_{3} \mathrm{P}$ is promoted by initial protonation at nitrogen thus activating the double bond (Michael addition) and generating the formate for the dealkylating step (MA reaction). The dialkyl-substituted formylphosphonates $\mathbf{5 5}$ are obtained by hydrolysis of the imine function with $6 \mathrm{M} \mathrm{HCl}$ or $1 \mathrm{M}$ oxalic acid. The method provides a ready and convenient access to a broad range of substituted diethyl 2formylalkylphosphonates $\mathbf{5 5}$ in satisfactory yields $(45-80 \%) .{ }^{70}$

\section{4. $\mathbf{n}=3$.}


The MA reaction for the synthesis of diethyl 3-formylpropylphosphonate has been realized from 4bromobutyraldehyde diethyl acetal and 2-(3-bromopropyl)-1,3-dioxolane (Fig. 26). The latter reacts with $(\mathrm{EtO})_{3} \mathrm{P}$ at $110^{\circ} \mathrm{C}$ for $10 \mathrm{~h}$ to give the cyclic acetal 56 in $83 \%$ yield. Hydrolysis of acetal with $0.35 \mathrm{M} \mathrm{HCl}$ in dioxane at $100^{\circ} \mathrm{C}$ for $2 \mathrm{~h}$ produces the diethyl 3 -formylpropylphosphonate $\mathbf{5 7}$ in nearly quantitative yield. ${ }^{18 \mathrm{a}}$

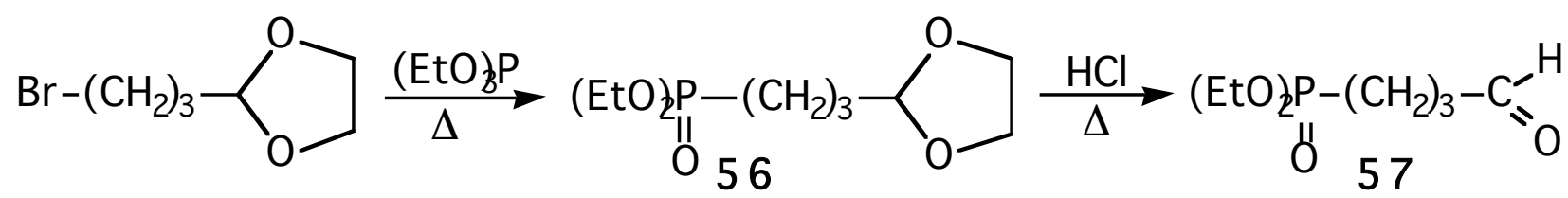

Fig. 26. Synthesis of diethyl 3-formylpropylphosphonate via the MA reaction ${ }^{18 a}$.

Since the double bond is an ideal precursor for the generation of a cyclopropyl ring an attractive procedure involving the addition of the carbenoid followed by transformation of an ester group into an aldehyde has been developed (Fig. 27). For example, the $\mathrm{CuSO}_{4}$-induced addition of ethyl diazoacetate to diethyl allylphosphonate in cyclohexane at reflux produced diethyl cyclopropylmethylphosphonate $\mathbf{5 8}$ in $30 \%$ yield as a 1:3 mixture of cis-and trans- isomers. The ester was hydrolysed to the acid which was treated with borane to give the alcohol 59. Subsequent oxidation of the intermediate 59, using PCC, afforded the aldehyde 60 in $83-86 \%$ yields respectively. ${ }^{71}$ The method has been extended (vide infra) to the preparation of higher analogs ( $\mathrm{n}=4$ and 5$).{ }^{71}$

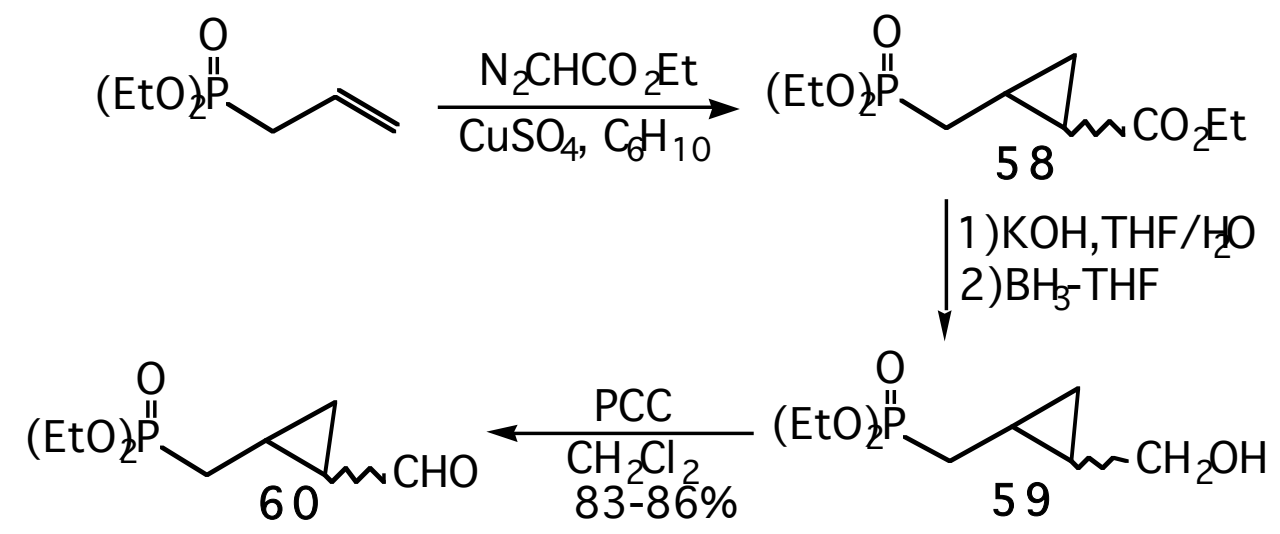

Fig. 27. Synthesis of diethyl 3-formylalkylphosphonate via addition of carbenoid to allylphosphonate ${ }^{71}$.

Unsaturated 3-formylphosphonates have been obtained by a MA reaction using 1,1-diethoxy-4-bromo2-butene ${ }^{72 a}$ or 1-acetoxy-4-chloro-2-butene ${ }^{72 b, c}$ as masked formyl group (Fig. 28). The former reacts with $(\mathrm{EtO})_{3} \mathrm{P}$ at $135^{\circ} \mathrm{C}$ to give the diethyl 4,4-diethoxy-2-butenylphosphonate in $50 \%$ yield; deprotection was accomplished in $98 \%$ using a cold-saturated aqueous solution of tartaric acid. ${ }^{72 \mathrm{a}}$ The latter reacts with $(\mathrm{EtO})_{3} \mathrm{P}$ or $(i-\mathrm{PrO})_{3} \mathrm{P}$ at $125-140^{\circ} \mathrm{C}$ in the presence of catalytic amount of $\mathrm{NaI}$ to give the corresponding phosphoryl acetates 61 in $81 \%(\mathrm{R}=\mathrm{Et})$ and $54 \%(\mathrm{R}=i-\mathrm{Pr})$ with $E: Z=90: 10$ in both cases. By refluxing $\mathbf{6 1}$ for $20 \mathrm{~h}$ in ethanol or methanol with a catalytic amount of $p$-toluenesulfonic acid, the alcohols 62 were smoothly obtained in almost quantitative yield (95-97\%) $E: Z=90: 10$. The Jones reagent proved to be the best reagent (65-68\% yield) for the oxidation of the alcohols 62 to the aldehydes 63. The dialkyl 3-formylallylphosphonates 63 are reasonably stable if stored under argon at $-20^{\circ} \mathrm{C} .{ }^{72 \mathrm{c}}$ Preparation of diethyl 3-formyl-2-methyl-allylphosphonate 64 is an example of the above process using the 1-bromo-2-methyl-4-acetoxy-2-butene as starting material and was accomplished in $86 \%$ yield $E: Z=55: 45$. 
<smiles>[X]CC([R])=CCOC(C)=O</smiles>

$\mathrm{X}=\mathrm{Cl}, \mathrm{Br}$<smiles>[R]/C(=C/C=O)CP([R6])(=O)O</smiles>

$63 \mathrm{R}^{1}=\mathrm{H}, 65-68 \%$

$6 \mathbb{4 R}^{1}=\mathrm{Me}, 86 \%$

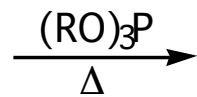

$\mathrm{R}=\mathrm{Et}, \dot{\mathrm{PPr}}$<smiles>[R20]OC/C=C(\[R])CP([R20])(=O)O[Na]</smiles>

61 $\mathrm{TsOH}$ $\mathrm{EtOH}$ or $\mathrm{MeOH}$<smiles>[R]O[R10](=O)O</smiles><smiles></smiles>
$\checkmark R^{1}$ $\mathrm{H}_{2} \mathrm{SO}_{4}$, acetone 62

Fig. 28. Synthesis of dialkyl 3-formylallylphosphonates via the MA reaction ${ }^{72 c}$.

By contrast, the 3-formyl-3-methyl-allylphosphonate 67 was prepared from diethyl crotylphosphonate 65, incorporating the formyl group by a carbanionic route (Fig. 29). Compound 65, on treatment with 3 equivalents of LDA, underwent successively silylation with $\mathrm{TMSCl}$ and formylation with $\mathrm{HCO}_{2} \mathrm{Et}$ to give the oxoanion 66, which after acid hydrolysis lead exclusively to the $E$-diethyl 3-formyl-3-methyl-allylphosphonate 67 in $78 \%$ yield. ${ }^{73}$

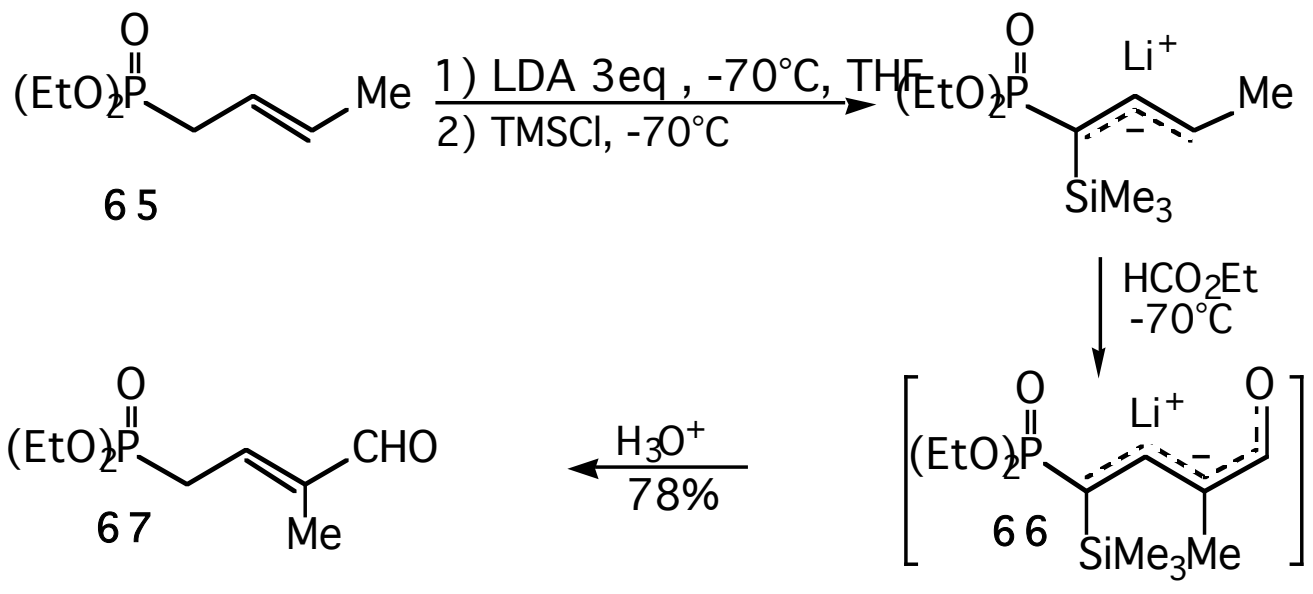

Fig. 29. Synthesis of diethyl 3-formyl-3-methyl-allylphosphonate ${ }^{73}$.

The synthetically useful diethyl 2-oxopropylphosphonate $\mathbf{6 8}$ is known to give a stable dianion 69 at ambient temperature. In the presence of 2 equivalents of LDA this dianion was smoothly reacted at low temperature with $\mathrm{HCO}_{2} \mathrm{Et}$ to provide a stabilized bis-enolate 70, which was soluble in water. Acidification with 4M HCl produced the diethyl 3-formyl-2-oxo-propylphosphonates 71 in high yields (81-89\%). This "one-pot" procedure offers a short and efficient means for obtaining a variety of compounds from readily available starting materials 68 (Fig. 30). ${ }^{74}$ Recently, another preparation of $71\left(\mathrm{R}^{1}=\mathrm{R}^{2}=\mathrm{H}\right)$ was reported and involves a multi-step route using diethyl 2-oxo-propylphosphonate $68\left(\mathrm{R}^{1}=\mathrm{R}^{2}=\mathrm{H}\right)$ as starting material. ${ }^{75}$ 


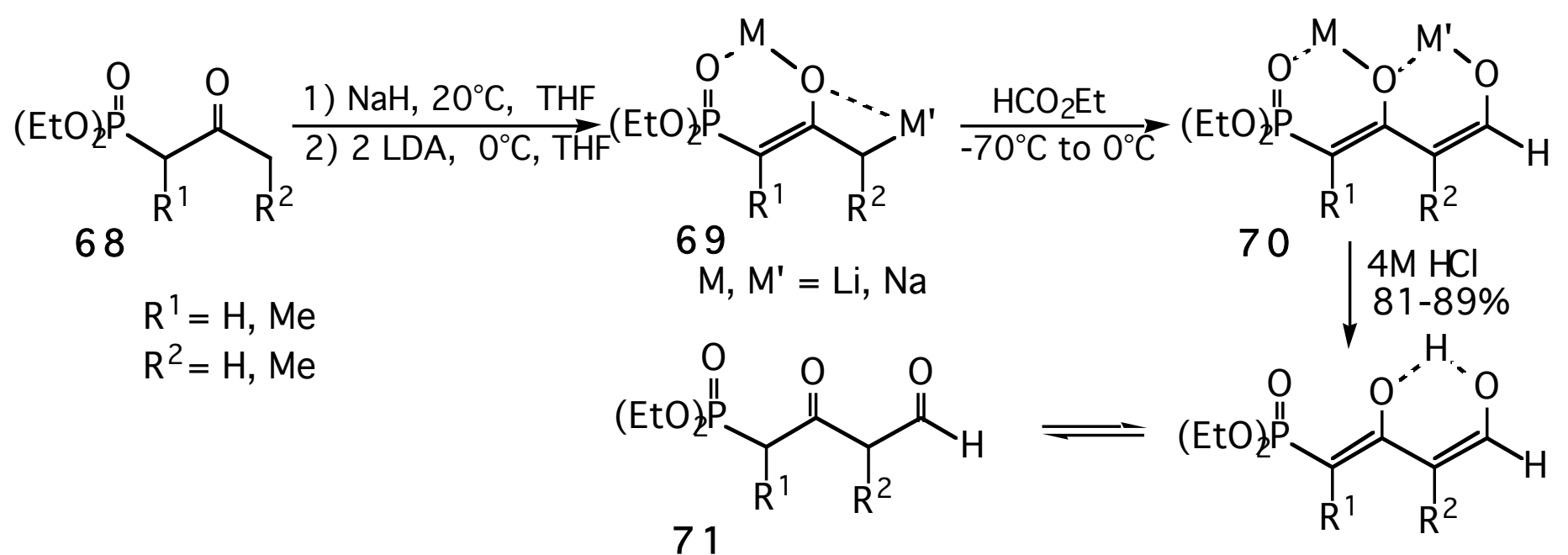

Fig. 30. Synthesis of diethyl 3-formyl-2-oxo-propylphosphonate ${ }^{74}$.

The ring opening reaction of D-glycidaldehyde diethyl acetal at $-80^{\circ} \mathrm{C}$ in $\mathrm{THF}$ by the diethyl 1-lithiomethylphosphonate in the presence of boron trifluoride etherate provided a convenient preparation of diethyl 4,4-diethoxy-3-hydroxybutylphosphonate $\mathbf{7 2}$ in $\mathbf{7 8 \%}$ yield. Unmasking of the aldehyde functionality was accomplished using $0.1 \mathrm{M} \mathrm{HCl}$ at $40^{\circ} \mathrm{C}$ to give the diethyl 3-hydroxy-3-formylpropyl-phosphonate 73 (Fig. 31). 57,76

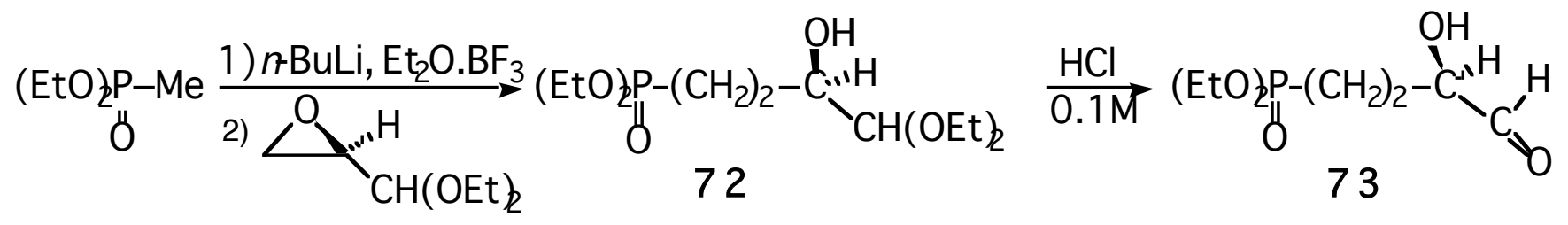

Fig. 31. Synthesis of diethyl 3-hydroxy-3-formylpropylphosphonate by epoxide ring opening 57 .

An attractive application of the oxidative cleavage of phosphorylated 1,2-glycols 75 with sodium metaperiodate (Malaprade reaction) has been demonstrated in the synthesis of diethyl 3formylalkylphosphonates 76 (Fig. 32). It was accomplished on preparative scale using the 1,2:5,6-di-Oisopropylidene- $\alpha$-D-glucofuranose 74. This mild method is advantageous and the resulting aldehyde was obtained in almost quantitative yield. ${ }^{77}$

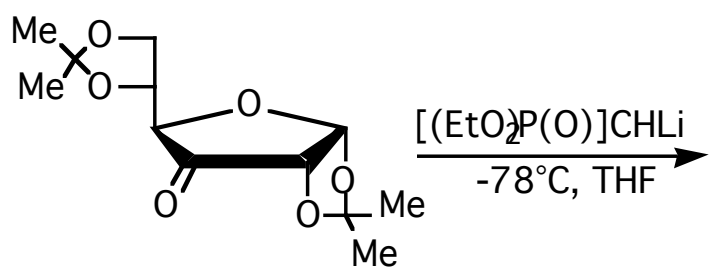

74
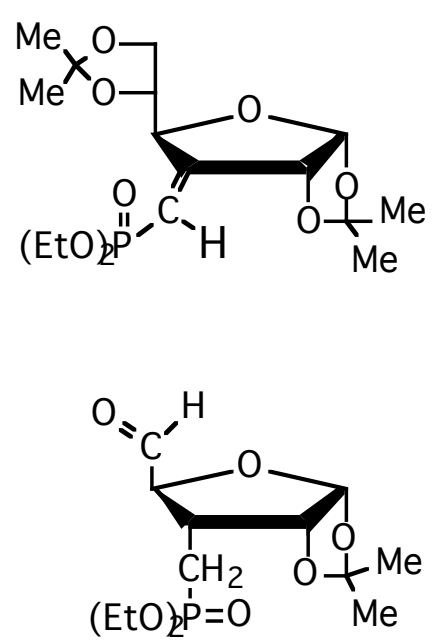

76
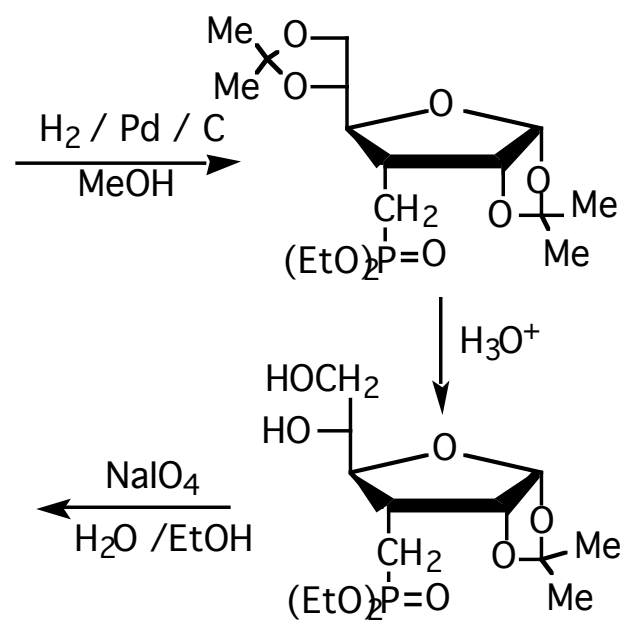

75

Fig. 32. Synthesis of diethyl 3-formylphosphonate $\mathbf{7 6}$ by oxidation of 1,2-glycols 77 . 
Several variations on the preparation of phenylphosphonates containing a formyl group in the $\gamma$-position have been reported. They are based on the phosphorylation, via Michaelis-Arbuzov or Michaelis-Becker reactions, of aromatic substrates 77 containing a protected primary alcohol (Fig. 33). Further oxidation of the alcohol into aldehyde $\mathbf{7 8}$ was accomplished under a wide range of conditions using activated $\mathrm{MnO}_{2}$ in $\mathrm{CHCl}_{3}$ at room temperature $(53 \%),{ }^{78} \mathrm{PCC}$ in $\left.\mathrm{CH}_{2} \mathrm{Cl}_{2}(83-86 \%)\right)^{71}$ or the Swern reaction (>95\%). ${ }^{79}$

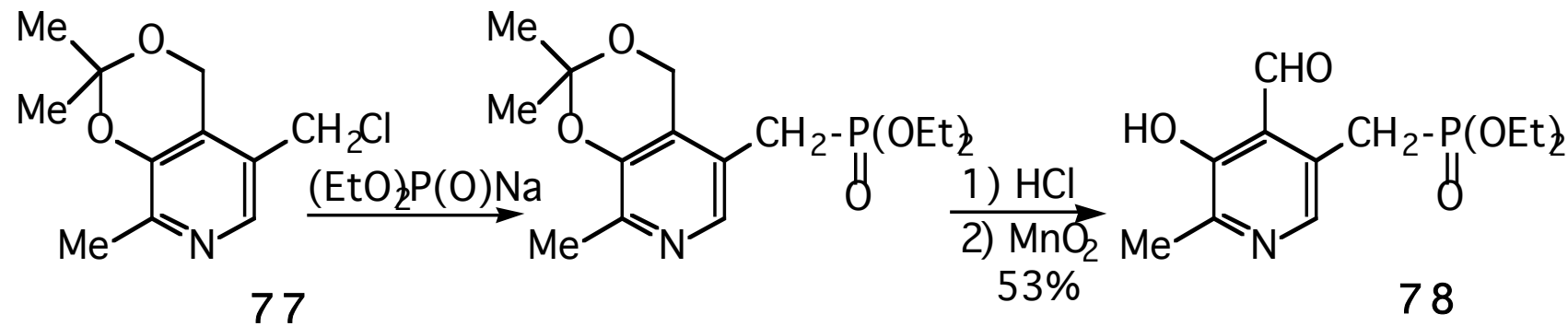

Fig. 33. Synthesis of diethyl 3-formylphosphonate by primary alcohol oxidation ${ }^{78}$.

The preparation of the configurationally unstable diethyl 3-(S)-tert-butoxycarbonylamino-3formylpropyl-phosphonate has also been reported, and involves reduction of a methyl ester group with DIBAL$\mathrm{H}$ in toluene at $-78^{\circ} \mathrm{C} .80$

An interesting procedure for the preparation of arylphosphonates bearing a formyl group is the phosphate-phosphonate rearrangement of the protected phosphorylated 4-hydroxybenzyl alcohol 79. On treatment with LDA in THF at $-78^{\circ} \mathrm{C}$, compound 79 underwent an $o$-metallation with spontaneous migration of the phosphoryl group to give the phenylphosphonate $\mathbf{8 0}$ in $77 \%$ yield. Subsequent benzylation of the phenolic $\mathrm{OH}$ and desilylation afforded $\mathbf{8 1}$, which was oxidized with activated $\mathrm{MnO}_{2}$ in THF at room temperature to give the dimethyl $m$-formylphenylphosphonate 82 in $96 \%$ yield (Fig. 34). ${ }^{81}$

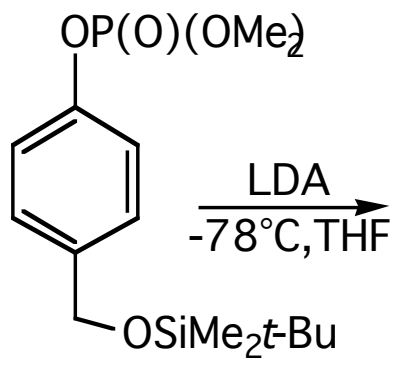

79

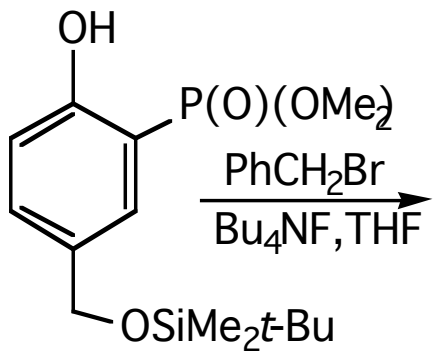

80

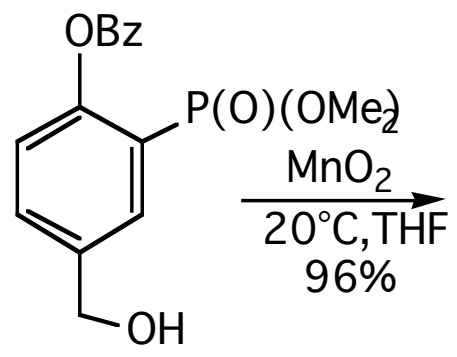

81

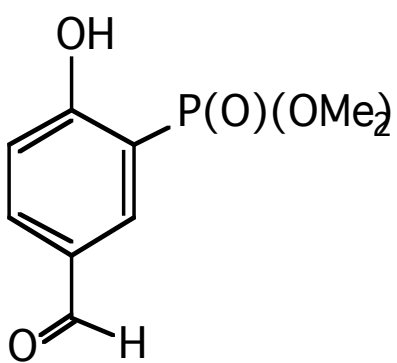

82

Fig. 34. Synthesis of dimethyl 3-formylphosphonate by phosphate-phosphonate rearrangement ${ }^{81}$.

An efficient synthesis of a variety of arylmethylphosphonates bearing electron-withdrawing groups $\left(\mathrm{CO}_{2} \mathrm{Et}, \mathrm{CN}, \mathrm{SO}_{2} \mathrm{Me}\right)$ at the $\alpha$-carbon and a formyl group on the aromatic ring has been reported. They were prepared by treatment of diethylphosphoryl-stabilized carbanions with aryl halides in DMF or HMPA in the presence of $\mathrm{CuI}$ at $100^{\circ} \mathrm{C}$ for $5 \mathrm{~h}$. In the case of protected $o$-formyliodobenzene, the coupling reaction with the sodium derivative of triethyl phosphonocarboxylate gave, after acid work-up, the corresponding diethyl $o$ formylbenzylphosphonate in $75 \%$ yield. ${ }^{82}$

\section{5. $\mathbf{n}=4$.}

Two reactions were found to be best suited to the synthesis of diethyl 4-formylalkylphosphonates. The first one is a straightforward method to diethyl 4-formylalkylphosphonates $84(\mathrm{~m}=1)$ from unprotected 
aldehyde functionality, as demonstrated by experiments involving $(\mathrm{EtO})_{3} \mathrm{P}$ and bromoaldehydes 83. At $100-110^{\circ} \mathrm{C}$, the MA reaction provided the diethyl 4-formylalkylphosphonate $84(\mathrm{~m}=1)$. However, the yields were much lower for the cis-cyclopropylaldehydes compared to those of the trans isomers (27\% versus $62 \%$ ). Presumably, this can be attributed to unwanted condensation with the cis-disposed aldehyde group (Fig. 35). ${ }^{71}$ The reaction has been extended to the preparation of $\mathbf{8 4}(\mathrm{m}=2)$ with comparable results $(12$ and $58 \%) .{ }^{71}$

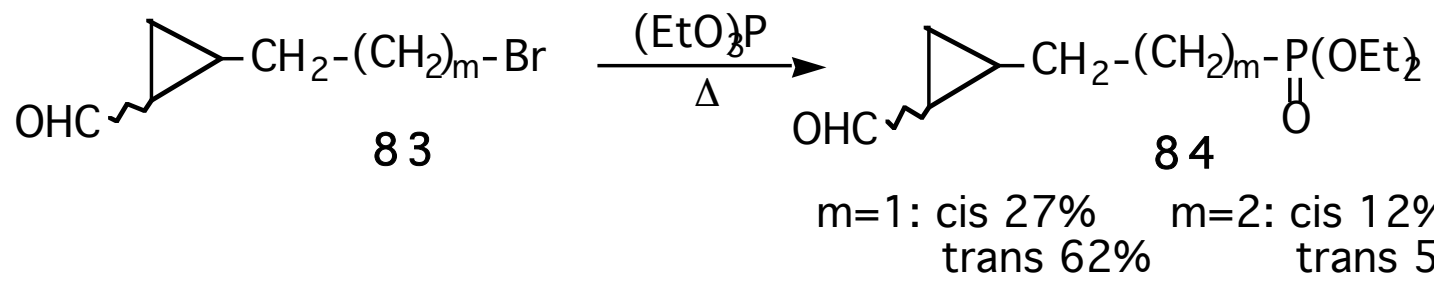

Fig. 35. Synthesis of diethyl 4-formylalkylphosphonate from unmasked aldehydes ${ }^{71}$.

In search for a flexible route to a wide range of variously substituted arylidene cyclopropanes, the carbene derived by metallic copper-induced decomposition of diethyl diazomethylphosphonate was added to an unsaturated acetal to give the diethyl 2-(3,3-dialkoxy-2,2-dimethylpropyl)cyclopropylphosphonate in 53-73\% yields. It was found that cuprous trifluoromethanesulfonate was a particularly effective catalyst for this reaction. ${ }^{191}$

The second reaction has been observed with lactones which have been shown to be useful in several synthetic schemes. The reaction is phosphorus reagent dependent. When submitted to diethyl 1-lithiomethylphosphonate, the $\gamma$-lactone $\mathbf{8 5}$ underwent a ring opening reaction to give an hydroxyphosphonate $\mathbf{8 6}$ retaining the carbonyl group in $\beta$-position to phosphorus (Fig. 36). Subsequent Swern oxidation of the hydroxyphosphonate $\mathbf{8 6}$ provided the diethyl 4-formyl-2-oxobutylphosphonate $\mathbf{8 7} .84$

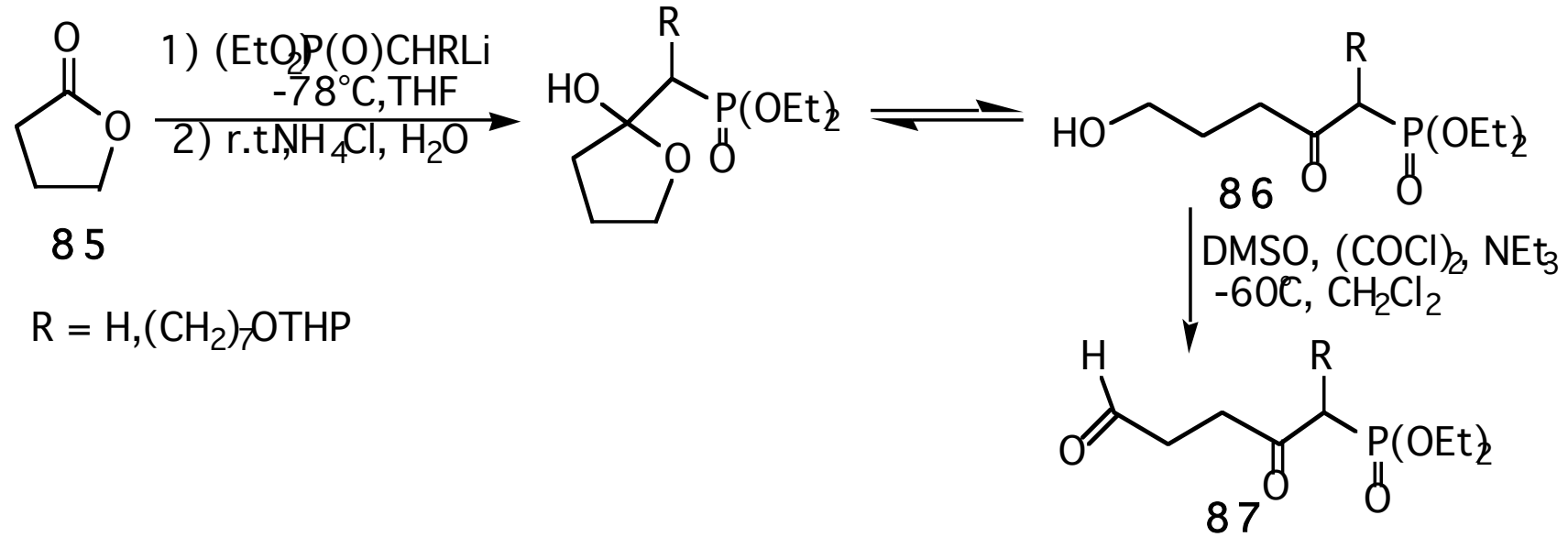

Fig. 36. Synthesis of diethyl 4-formyl-2-oxobutylphosphonates from $\gamma$-lactones ${ }^{84}$.

By contrast, reduction of the lactone to the lactol followed by reaction with the sodium derivative of tetraethyl methylenediphosphonate gives an hydroxyphosphonate $\mathbf{8 8}$ containing a double bond $\alpha, \beta$ to phosphorus. Catalytic hydrogenation of the double bond followed by Swern oxidation of the hydroxyphosphonate 89 lead to the aldehyde 90 (Fig. 37). The alcohol 89 was also oxidized using $\mathrm{SO}_{3} \cdot$ Py complex in DMSO and $\mathrm{NEt}_{3}$. This procedure allows the use of higher temperatures than the Swern protocol and provide 
the aldehyde in good yield. Thus lactones appear to be valuable synthetic intermediates wellsuited to the preparation of a variety of phosphorylated aldehydes. ${ }^{85}$

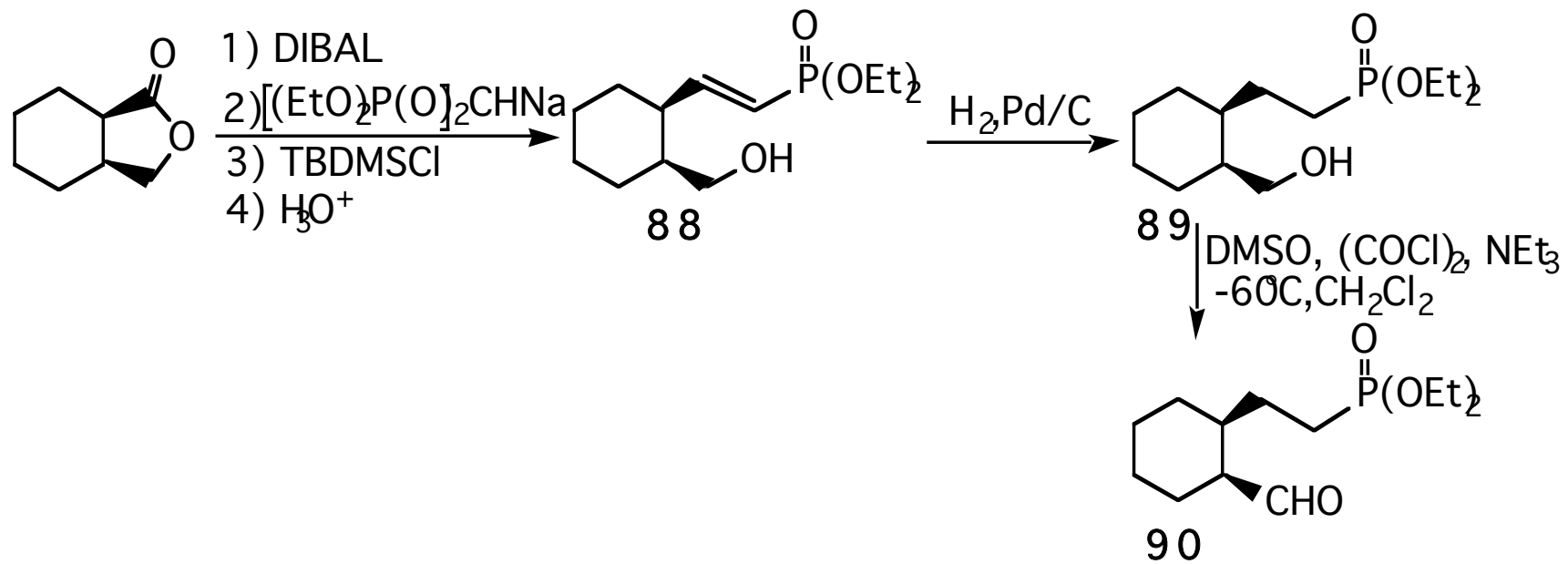

Fig. 37. Synthesis of diethyl 4-formylalkylphosphonate from $\gamma$-lactones ${ }^{85}$.

A quite similar process was used in the preparation of phosphonic acid analogs of pyridoxal phosphate (Fig. 38). The sodium derivative of tetraethyl methylenediphosphonate was condensed with $\alpha^{4}, 3-O$ isopropylidene-isopyridoxal 91 to give diethyl $\alpha^{4}, 3-O$-isopropylidene- $\alpha^{5}$-pyridoxylidenemethylphosphonate 92 in yields up to $65 \%$. Selective acid hydrolysis with $10 \% \mathrm{HCO}_{2} \mathrm{H}$ at reflux gave the key intermediate diethyl 2-(3-hydroxy-4-hydroxymethyl-2-methyl-5-pyridyl)vinylphosphonate in 98\% yield. After catalytic hydrogenation of the double bond using $5 \% \mathrm{Pd} / \mathrm{C}$ in $\mathrm{EtOH}$, several oxidation methods were studied, including $\mathrm{MnO}_{2}$ in water, $\mathrm{CrO}_{3} \cdot \mathrm{Py}$ and DMSO-DCC. Finally, oxidation with activated $\mathrm{MnO}_{2}$ in $\mathrm{CHCl}_{3}$ proceeded smoothly to give the diethyl 2-(4-formyl-3-hydroxy-2-methyl-5-pyridyl)ethylphosphonate $\mathbf{9 3} .86$

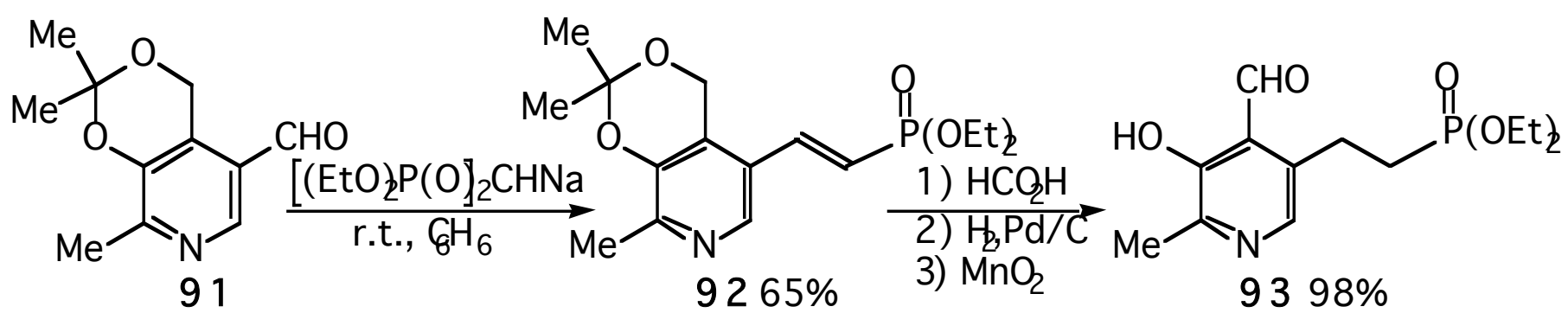

Fig. 38. Synthesis of phosphonic analog of pyridoxal phosphate ${ }^{86}$.

The vinylic and acetylenic analogs of $\mathbf{9 3}$ are known. The former was prepared as a cis-trans mixture by Peterson reaction between 91 and the lithium anion of diethyl trimethylsilylmethylphosphonate. Isolation of the cis- derivative and subsequent deprotection of the alcohol followed by oxidation with $\mathrm{MnO}_{2}$ in $\mathrm{CHCl}_{3}$ lead to the diethyl 2-(4-formyl-3-hydroxy-2-methyl-5-pyridyl)vinylphosphonate. The latter was prepared by reaction of the lithium ethynyl analogue of pyridoxal with diethyl chlorophosphate in $\mathrm{Et}_{2} \mathrm{O}$ at $-74^{\circ} \mathrm{C}$. The corresponding diethyl 2-(4-formyl-3-hydroxy-2-methyl-5-pyridyl)ethynylphosphonate was obtained in 26\% yield after deprotection of the alcohol by brief heating with $10 \%$ aqueous trifluoroacetic acid and oxidation with $\mathrm{MnO}_{2} \cdot 87$ 
The Michael addition, using an activated vinylphosphonate 94 and the magnesium derivative of the 2-(2-bromoethyl)-1,3-dioxolane, has been found to be a good method for chain-lengthening of formylphosphonates (Fig. 39). Unmasking of the aldehyde functionality produced 95.88

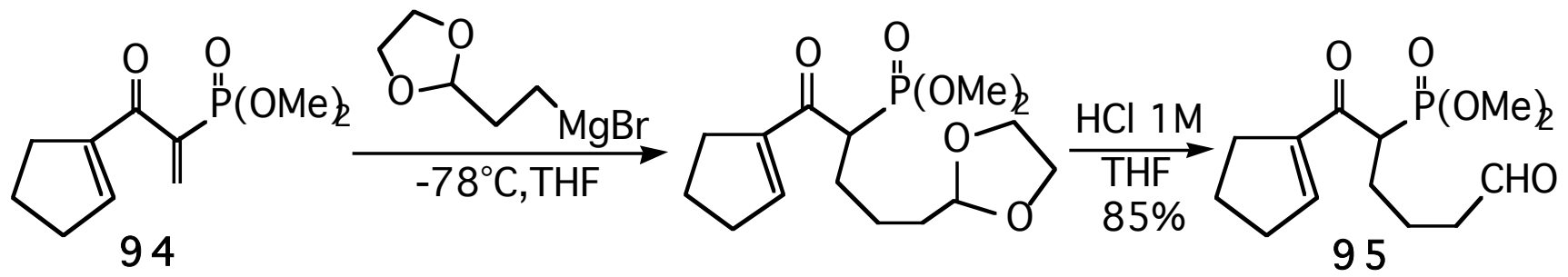

Fig. 39. Synthesis of dimethyl 4-formylalkylphosphonate via Michael addition ${ }^{88}$.

Two routes to diethyl 4-formylalkylphosphonates from 1,2-glycols and lactols demonstrated once more the importance of these substrates. The first route provided diethyl 4-formylalkylphosphonates in almost quantitative yield (98\%) from the mild oxidation of phosphorylated 1,2-didesoxy-3,4:5,6-di- $O$-isopropylidenD-arabinose with $\mathrm{NaIO}_{4}$ at $0^{\circ} \mathrm{C}$ in $\mathrm{H}_{2} \mathrm{O}$ or in a $\mathrm{H}_{2} \mathrm{O} / \mathrm{EtOH}$ mixture. ${ }^{89}$ In the second route, diethyl 4formylalkylphosphonates were obtained by opening of the unprotected 5-phosphorylated-D-ribofuranose with EtSH in $\mathrm{HCl}$ to give a dithioacetal. Subsequent acetylation followed by removal of the thioethyl groups generated the aldehyde. 90

The aromatic version of the MA reaction between $(i \text {-PrO })_{3} \mathrm{P}$ and $p$-bromobenzaldehyde at $160^{\circ} \mathrm{C}$, catalyzed by $\mathrm{NiCl}_{2}$, afforded the diisopropyl $p$-formylphenylphosphonate in $54 \%$ yield. The reaction has been extensively studied and it has been shown that electron-donor substituents facilitate reaction, while electronacceptor substituents make reaction with P(III) compounds more difficult, regardless of their position in the aromatic nucleus. ${ }^{189}$

Several other preparative procedures have been reported including the phosphorylation of aromatic substrates containing a free formyl group, a protected formyl group or a potential formyl group. The first procedure was used for the preparation of diethyl 4- or 6-methoxy-3-formylbenzylphosphonates in 83 and $74 \%$ yields by a MA reaction between $(\mathrm{EtO})_{3} \mathrm{P}$ and corresponding methoxyformylbenzyl chlorides at $170-180^{\circ} \mathrm{C} .{ }^{83}$ The second procedure used the $\mathrm{Pd}\left(\mathrm{PPh}_{3}\right)_{4}$-catalyzed coupling reaction between diethylphosphite and $m$ bromobenzaldehyde protected as 1,3-dioxolane with ethylene glycol.91 In the third procedure the phosphorylation of substrates was achieved according to a Michaelis-Arbuzov or a Michaelis-Becker reaction, followed by generation of the formyl group. The latter operation is usually based on typical formylation reaction using $\mathrm{HCO}_{2} \mathrm{Et}$ in basic medium ${ }^{92}$ or by oxidation of benzylic bromide for example. ${ }^{93} \mathrm{~A}$ single case of generation of aldehyde group by hydrolysis of a dibromomethylthiophene with diluted $\mathrm{H}_{2} \mathrm{SO}_{4}$ in dioxane at reflux for $1.5 \mathrm{~h}$ in $95 \%$ yield was recently reported. ${ }^{186}$

Under the modified Heck reaction conditions $\left(\mathrm{Ag}_{2} \mathrm{CO}_{3} / \mathrm{Pd}(\mathrm{OAc})_{2} / \mathrm{PPh}_{3}\right)$, the coupling of diethyl (Z)-2-iodovinylphosphonate with acrolein in $\mathrm{MeCN}$ at room temperature for $24 \mathrm{~h}$ afforded the diethyl $(1 Z, 3 E)$ dienylphosphonate with high stereoselectivity in $94 \%$ yield. ${ }^{94}$

\section{6. $\mathbf{n}=5$ to 9}

The previously reported preparation of diethyl 4-formylalkylphosphonates $84(\mathrm{~m}=1)$ from unprotected aldehyde functionality (Fig. 35) has been extended to provide one of the few known methods for the 
transformation of a bromo aldehydes moiety to the corresponding diethyl 5-formylalkylphosphonates 84 $(\mathrm{m}=2){ }^{71}$ By a similar procedure to that described for $\mathbf{n = 3}$, the copper-mediated coupling reaction of diethylphosphoryl stabilized carbanions with aryl halides was applied to protected $p$-formyliodobenzene to produce diethyl $p$-formylbenzylphosphonate in $68 \%$ yield. ${ }^{82}$

Most of the diethyl 5- and 6-formylalkylphosphonates containing an $o$-substituted aromatic ring with a masked aldehyde group were obtained by direct displacement of an alkyl halide or mesylate by a MichaelisBecker reaction. For example, the masked aldehyde group was introduced on 2-methylbenzyl alcohol 96 by treatment with $n$-BuLi and alkylation of the resulting carbanion for $48 \mathrm{~h}$ by 2-(2-bromoethyl)-1,3-dioxolane $(18 \%)$ or bromoacetaldehyde dimethylacetal $(8.41 \%)$. The benzylic alcohols 97 were mesylated and displaced with sodium diethylphosphite to introduce the phosphoryl group (83\% and 51\%). The aldehydes 98 were unmasked by treatment with a $1: 1 \mathrm{THF} / 3 \mathrm{M} \mathrm{HCl}$ at $25^{\circ} \mathrm{C}$ for $5 \mathrm{~h}(93 \%$ and $100 \%)$ (Fig. 40). 93

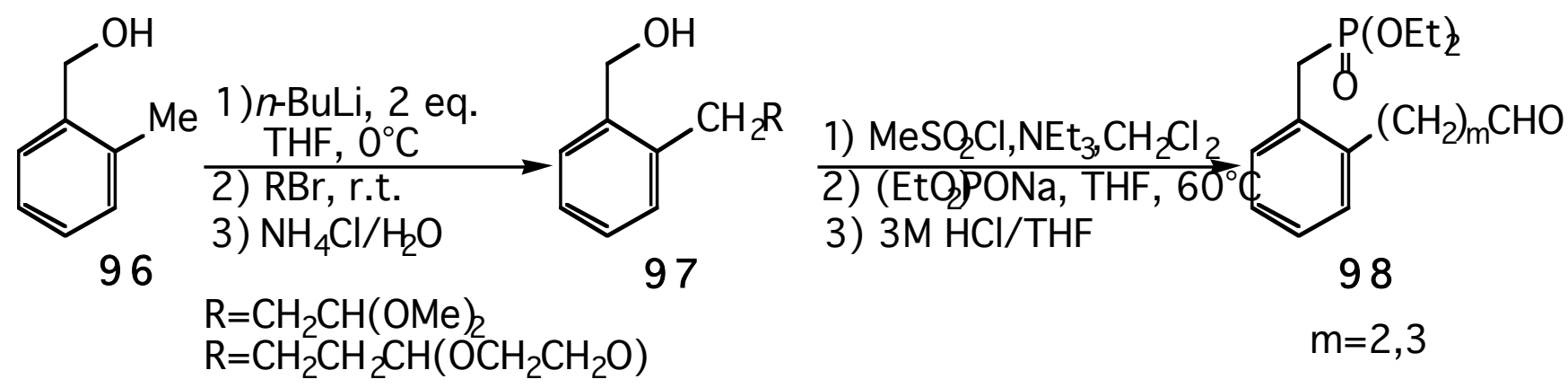

Fig. 40. Synthesis of diethyl 5- and 6-formylalkylphosphonates.

An interesting gap has been realized with the use of $\alpha$-hydroxyphosphonates, as illustrated by the synthesis of 102 (Fig. 41). Treatment of terephthalaldehyde, containing monoprotected aldehyde function, with the readily acid labile di-tert-butylphosphite (Pudovik reaction) in the presence of basic alumina oxide has allowed the facile synthesis of the $\alpha$-hydroxyphosphonate 99. Radical deoxygenation of the secondary alcohol 99 was achieved in a two step process through the intermediacy of xanthate $\mathbf{1 0 0}$ with $n$-Bu $3 \mathrm{SnH}$ to provide 101. The diethyl acetal was converted to $\mathbf{1 0 2}(29 \%)$ by further treatment with $\mathrm{CHCl}_{3}$ saturated with $1 \mathrm{M} \mathrm{HCl} .{ }^{95}$

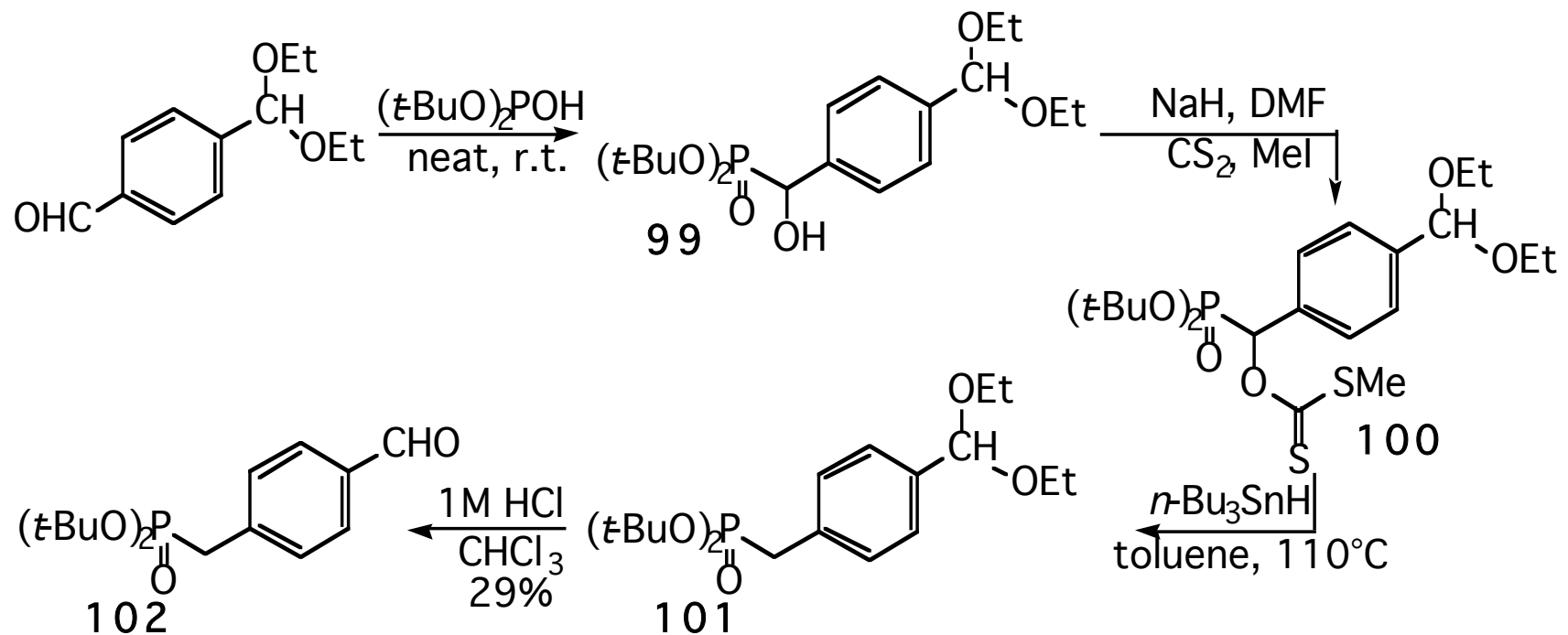

Fig. 41. Synthesis of di-tert-butyl 5-formylalkylphosphonate from $\alpha$-hydroxyphosphonate 95 . 
Readily accessible diethyl 2-oxo-3-alkenylphosphonates 103 are effective heterodienes in the DielsAlder reaction. Cycloaddition reactions with vinyl ethers in benzene in a sealed tube at $85^{\circ} \mathrm{C}$ or above $130^{\circ} \mathrm{C}$ gave satisfactory yields (57-88\%) of dihydro-2H-pyrans 104. All these reactions were regioselective, however, the stereoselectivity was poor. The isolated products were always the mixture of 2,4-trans- and 2,4-cisisomers. The hemiacetal moiety of $\mathbf{1 0 4}$ was readily hydrolysed when treated with $4 \mathrm{M} \mathrm{HCl}$ in $\mathrm{THF}$ to provide diethyl 5-formyl-2-oxo-pentylphosphonates 105 in excellent yields (72-92\%) (Fig. 42). It was found that aldehydes $105\left(\mathrm{R}^{1}=\mathrm{R}^{2}=\mathrm{H}\right)$ underwent smooth cyclisation leading to diethyl 2-oxocyclohexenephosphonate 106. 96

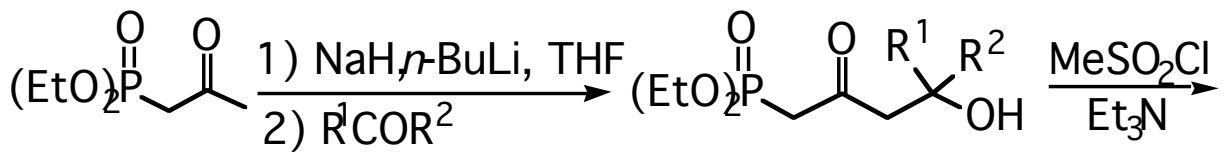<smiles>[R]C([R])=CC(=O)CP(=O)(OC)OCC</smiles>

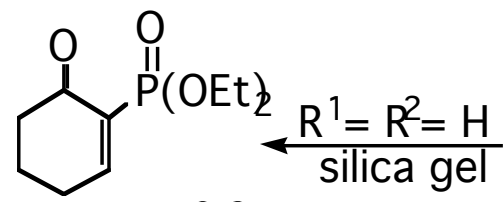

106<smiles>[R]C([R])(CC=O)CC(=O)C[P+]([O-])=CC</smiles>

105

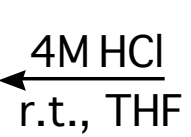

$72-92 \%$

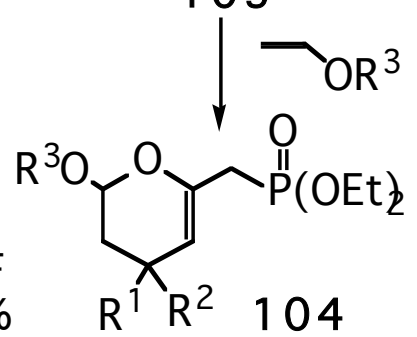

Fig. 42. Synthesis of diethyl 5-formyl-2-oxo-pentylphosphonate from 2-oxo-propylphosphonate 96 .

A recently introduced method is the ring opening reaction by oxygen of furans $\mathbf{1 0 7}$ bearing a diethyl ethyl- or propylphosphonate moiety in position 2 (Fig. 43). The reaction occurred in methanol at $0^{\circ} \mathrm{C}$ under irradiation followed by reaction with dimethyl sulphide thus providing the corresponding diethyl 5-formyl3-oxo-pent-4-enylphosphonate 108 and 6-formyl-4-oxo-hex-5-enylphosphonate 109. By reduction of the double bond compounds 108 and 109 were converted to diethyl 5-formyl-3-oxopentylphosphonate 110 and 6formyl-4-oxo-hexylphosphonate 111 in excellent yield (92-96\%). ${ }^{97}$

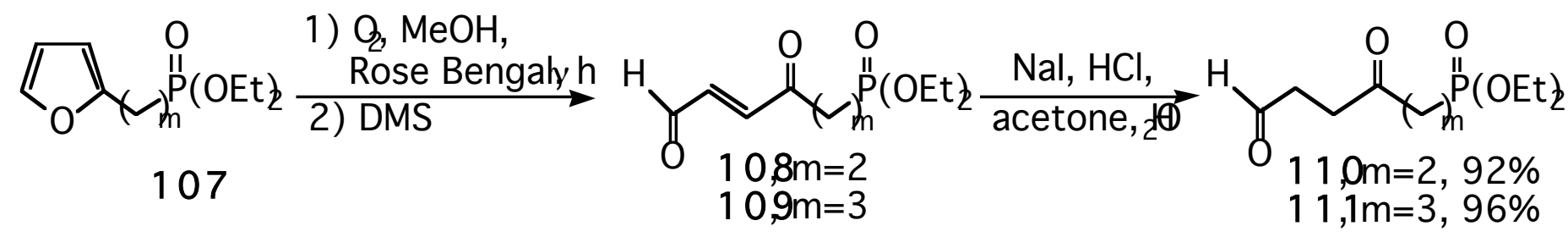

Fig. 43. Synthesis of diethyl 5- or 6-formyl-3 or 4-oxo-alkylphosphonates 97.

In a series of experiments, it has been found that the ene reactions of trimethyl phosphonoacrylate with alkenes was catalyzed by $\mathrm{EtAlCl}_{2}$ and occurred at $25^{\circ} \mathrm{C}$ (Fig. 44). Lewis acid catalysis offers significant advantages over the corresponding thermal ene reactions that occur at $200-300^{\circ} \mathrm{C}$. This property has been applied with success to the synthesis of dimethyl 6-formylalkylphosphonates 114. Reaction of the alcohol 112 with trimethyl 2-phosphono-acrylate in $\mathrm{CH}_{2} \mathrm{Cl}_{2}$ at $0^{\circ} \mathrm{C}$ for $1 \mathrm{~h}$ gave the ene adduct 113 in $40 \%$ yield. Oxidation of 113 with pyridinium dichromate (PDC) gave the dimethyl 6-formylalkylphosphonate 114 in $68 \%$ yield, which can undergo an intramolecular HWE reaction. ${ }^{98}$ 

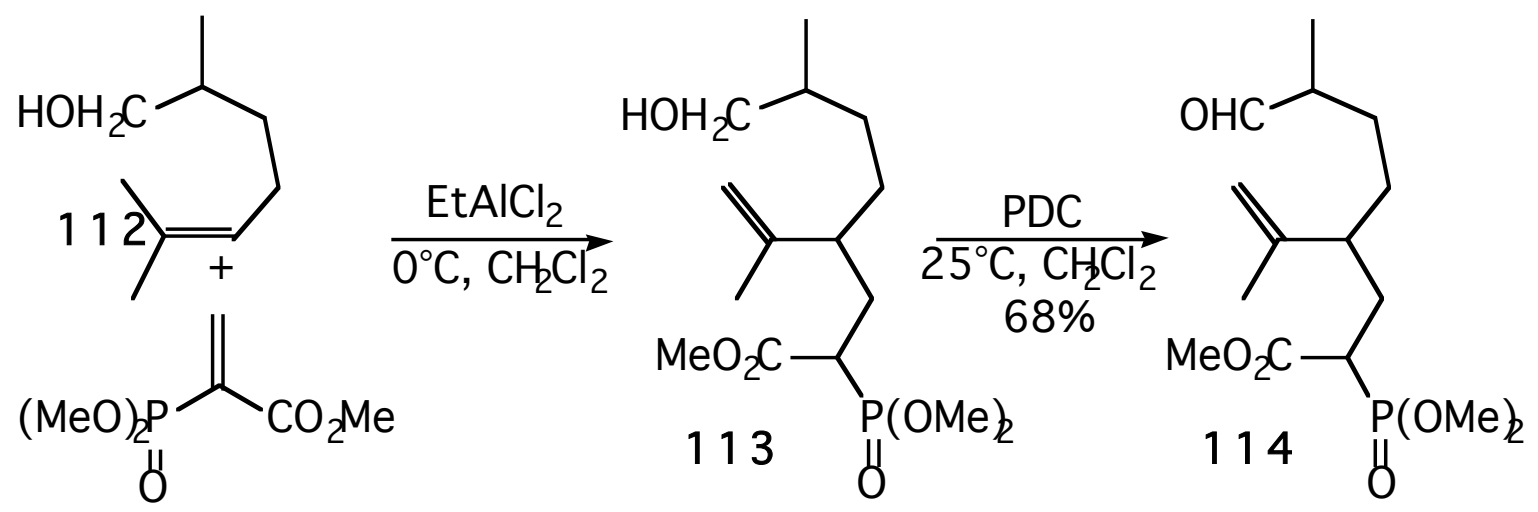

Fig. 44. Synthesis of dimethyl 6-formylalkylphosphonate via ene reaction ${ }^{98}$.

The palladium-catalyzed arylation of diethyl vinylphosphonate with $p$-bromobenzaldehyde $(\mathrm{MeCN}$, $100^{\circ} \mathrm{C}, 4 \mathrm{~h}$ ) afforded diethyl $p$-formylstyrylphosphonate in $60 \%$ yield. 99

Once more the methodology using lactones has been developed with success. The mixed anhydride $\mathbf{1 1 5}$, stemming from the opening of a $\delta$-lactone, was treated, after suitable protection, with diethyl $\alpha$-cupromethylphosphonate to produce the $\beta$-ketophosphonate 116 in good yield (69\%). Finally, the ozonolysis of 116 gave the diethyl 7-formylalkylphosphonate 117 in high yield (Fig. 45). ${ }^{100}$

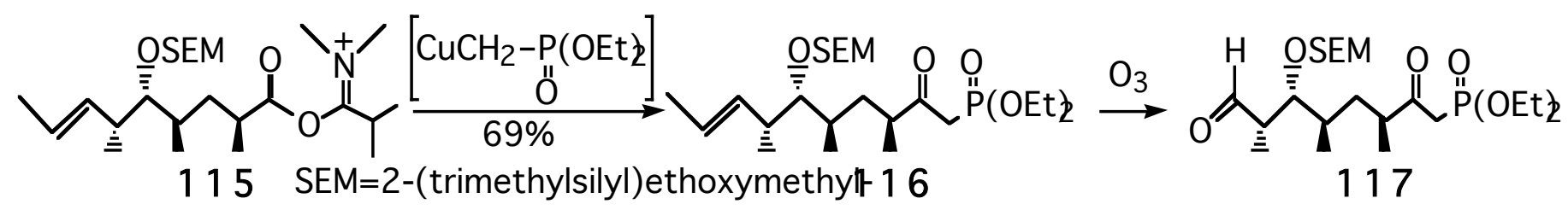

Fig. 45. Synthesis of diethyl 7-formylmethylphosphonate from $\delta$-lactone ${ }^{100}$.

Similarly, a lactam was submitted to a ring opening reaction using dimethyl 1-lithiomethylphosphonate in $\mathrm{THF}$ at $-78^{\circ} \mathrm{C}$. On work-up, the $\mathrm{N}$-methyl imine generated the dimethyl 6-formylalkylphosphonate, which in turn gave perhydroazulenone on treatment with tert-BuOK/tert-BuOH. ${ }^{162}$

In an approach to the central eight-membered ring of ceroplastol I, the use of an intramolecular HWE reaction was explored starting from a diethyl 7-formylalkylphosphonate. This $\mathrm{C}_{7}$ aldehyde, protected as a 1,3dioxolane, was obtained in $20 \%$ yield as a 1:1 mixture of keto acetals by Michael addition in $\mathrm{THF}$ at $-78^{\circ} \mathrm{C}$ of an alkenyllithium to the 2-(diethoxyphosphinyl)cyclopentenone. Hydrolysis of the acetal in refluxing acetone $/ \mathrm{H}_{2} \mathrm{O}$, TsOH afforded $89 \%$ of the desired phosphorylated keto / aldehyde. 101

Phosphonates containing an aldehyde group at $\mathrm{C}_{9}$ are important intermediates have been employed in the incorporation of a $\mathrm{C}_{1}-\mathrm{C}_{9}$ fragment into macrolide antibiotics (pikronolide, 102 carbonolide $\mathrm{B}, 103$ erythromycin $\mathrm{A}^{104}$ ). They were prepared by treatment of a $\mathrm{C}_{7}$ dialdehyde, protected at one extremity (double bond or tert-butyldimethylsilyl (TBS) ether), with the dimethyl 1-lithiomethylphosphonate at $-80^{\circ} \mathrm{C}$ in $\mathrm{THF}$, which gave the $\beta$-hydroxyphosphonates in 74-79\% yield. Subsequent oxidation (PDC/DMF102 or TPAP/NMO/ $\mathrm{CH}_{2} \mathrm{Cl}_{2}{ }^{103,104}$ ) produced the corresponding $\beta$-ketophosphonate in excellent overall yield. Generation of the terminal aldehyde at $\mathrm{C}_{9}$ was performed by oxidation of the primary alcohol with TPAP/NMO 103 or of the double bond with $\mathrm{OsO}_{4} / \mathrm{NMO} /$ acetone followed by cleavage with $\mathrm{NaIO}_{4} \cdot{ }^{102}$

\section{7. $\quad \mathrm{n}=\mathbf{1 1}$ to $\mathbf{1 6}$.}


The phosphorylated aldehydes reported in the previous sections can participate, as reagents or substrates, in several useful synthetic schemes including HWE reaction, Strecker and related reactions, reductive amination and formation of heterocycles. By contrast, the phosphorylated aldehydes 118 described in the present section are almost exclusively prepared to achieve formation of macrocycles 119 (11- to 17membered carbon chain) via an intramolecular HWE reaction (Fig. 46). This widely used cyclisation step represents the best way for preparing macrocyclization products.

The phosphonate group is frequently incorporated at one extremity of the chain using a carbanionic approach. The more widely used method involves the displacement of halogenated derivatives with phosphoryl stabilized carbanions $\left(\mathrm{Z}=\mathrm{CN}, \mathrm{CO}_{2} \mathrm{R}, \mathrm{COR}\right){ }^{105-109}$ The others are accomplished by displacement of chlorine from diethyl chlorophosphate with lithiated functional derivatives, ${ }^{110}$ or by treatment of a carboxylate with the lithium derivative of a dialkyl methylphosphonate. ${ }^{111,112,163}$ At the other extremity of the chain oxidation of a primary alcohol generates the aldehyde group.

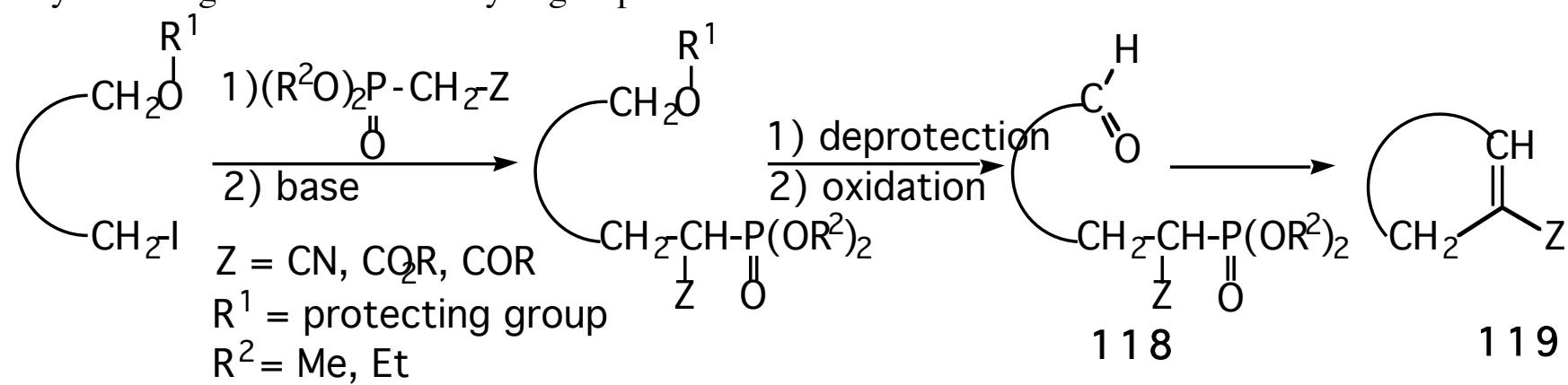

Fig. 46. Formation of macrocycles by intramolecular HWE reaction.

\section{REACTIONS OF PHOSPHORYLATED ALDEHYDES}

As a consequence of their ready accessibility coupled with their versatile chemical properties, phosphorylated aldehydes represent now an important class of compounds in organic and organophosphorus chemistry. As synthetic intermediates, these compounds owe their interest to the presence in the same molecule of a phosphoryl and a formyl group which govern their chemical reactivity. The purpose of this section is to provide a general overview of the important synthetic reactions which have been designed and developed from phosphorylated aldehydes.

\subsection{Reactions of the carbonyl group}

Several properties of the formyl group have been demonstrated in the past. For instance, the reaction of phosphorylated acetals with diols yielded phosphorylated 1,3-dioxolanes, ${ }^{113}$ 1,3-dioxans, ${ }^{114}$ and polymethylene acetals. 115 The reaction is carried out by heating equimolar amounts of the reactants with simultaneous distillation of the alcohol liberated. The reduction of phosphorylated aldehydes over a platinum catalyst $^{42 \mathrm{a}}$ or by sodium borohydride ${ }^{116}$ leads to the corresponding hydroxy derivatives in high yields. Phosphorylated aldehydes are oxidized by peracids ${ }^{117}$ or by alkaline potassium permanganate ${ }^{118}$ to the corresponding phosphorylated carboxylic acids. The dimethylhydrazones of $\mathbf{4}$ are known and prepared at room temperature in $40-98 \%$ yields. ${ }^{195}$ At $110^{\circ} \mathrm{C}$, $p$-toluenesulfonamide adds to 6 to give an adduct which eliminates ethanol when strongly heated to give in $68-80 \%$ yields the corresponding phosphorylated vinylsulfonamide, also available from $p$-toluenesulfonamide and 4.119 The aldolase-catalysed reaction of $\mathbf{4}$ with dihydroxyacetone phosphate (DHAP) gives a diphosphorylated sugar in $90 \%$ yield. ${ }^{193}$ In chloroform solution phosphorylated 
acetaldehydes are in equilibrium with the enol form and when treated with $\mathrm{HNO}_{2}$ they afford the nitrosoenols, which are dimeric in aqueous solution. ${ }^{120,121}$ Although the phosphorylated acetaldehydes condense with sodium derivatives of nitroalkanes to give mainly the phosphonylnitroalcohols, there is also detectable a second sequence, leading to a dienol. ${ }^{122}$ Because of the resultant tautomerism, the course and end-point of the reaction between phosphonylacetaldehydes and active methylene compounds (acetylacetone, cyanoacetic ester, dimedone) can vary. For acidic active-methylene compounds, further reaction with the initial condensation product can occur. The final position of tautomeric equilibrium depends on the nature of the dicarbonyl compound and of the substituents on phosphorus. ${ }^{123}$ Diethyl 1-formylmethylphosphonate 4 reacts with $n$-BuLi at low temperature in THF to give a lithium enolate. By contrast, the reaction of 4 with $n$-BuLi or $\mathrm{Zn}(\mathrm{OCOMe})_{2}$ at room temperature for several days preferentialy yields the metal complexes of the diphosphorylated butadienolate or the free $E$-enol via aldol condensation (Fig. 47). ${ }^{124}$ The self-condensation of 4 in basic media has been the subject of several reports. ${ }^{192}$
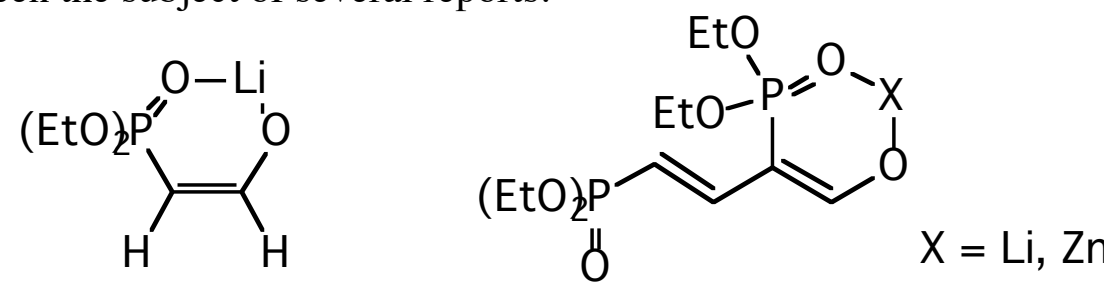

Fig. 47. Reaction of 4 with $n$-BuLi ${ }^{124}$.

The transformation of diethyl 1-formyl- or 1-alkyl-1-formylmethylphosphonates (4 or 19) into diethyl 2-oxoalkylphosphonates via diethyl 2-dialkylaminovinylphosphonates has been reported with moderate to good yields $(22-85 \%) .125$

Starting with diethyl 1-formylalkylphosphonates, the synthetically attractive trans-2,3-epoxy-4oxoalkyl-phosphonates are easily available by two methods. The first method employs the Wittig reaction of diethyl 1-formylalkylphosphonates 4, 19 or 29 with 2-oxoalkylidene-triphenylphosphoranes and subsequent epoxidation of the resulting E-4-oxo-2-alkenyl derivatives with $\mathrm{H}_{2} \mathrm{O}_{2} / \mathrm{Na}_{2} \mathrm{CO}_{3}$ in $\mathrm{MeOH}$. ${ }^{126 a}$ The second procedure involves the $\mathrm{Sn}(\mathrm{OTf})_{2}$-mediated aldol reaction of 4, 19 or 29 with bromomethylketones and subsequent cyclization of the bromohydrins. These epoxides are readily isomerized into 2,4-dioxoalkylphosphonates (49 to 81\%) on heating in toluene in the presence of catalytic amounts of $\mathrm{Pd}_{(}\left(\mathrm{PPh}_{3}\right)_{4}$ and 1,2-bis(diphenylphosphino)ethane (dppe). ${ }^{126 \mathrm{~b}}$

\subsection{Preparation and reactions of diethyl chloroformyl- and dichloroformylmethyl-phosphonates}

Reaction of dialkyl 1-formylmethylphosphonates 120 with $\mathrm{Cl}_{2} / \mathrm{CCl}_{4}$ results in formation of either chloromethyl 121 or dichloromethyl 122 derivatives (Fig. 48). Several variations on the preparation of these two compounds have been reported. It was shown that chlorination at the $\alpha-\mathrm{CH}$ bond of dialkyl 1-formylmethylphosphonates with $\mathrm{Cl}_{2}$ was selective and temperature dependent, namely: a) in $\mathrm{CCl}_{4}$ between 10 and $-15^{\circ} \mathrm{C}$ the monochlorinated aldehydes were formed in $70-80 \%$ (appearance of a yellow colour indicates the completion of monochlorination), while b) raising the temperature to $0^{\circ} \mathrm{C}$ resulted in dichlorination $(80$ 90\%). Raising the temperature to r.t. can lead to the cleavage of the $\mathrm{P}-\mathrm{C}$ bond under the action of $\mathrm{HCl}$ with the formation of phosphorochloridates. Full utilization of gaseous chlorine being handicapped by the sensitivity of the $\mathrm{P}-\mathrm{C}$ bond in acid medium, an alternative procedure for the preparation of $\mathbf{1 2 1}$ in $90 \%$ yield is the chlorination of 2-ethoxyvinylphosphonates 6 in $\mathrm{CCl}_{4}$ at r.t. followed by hydrolysis. ${ }^{127}$ Preparation of 
compound $\mathbf{1 2 1}$ has also been accomplished in high yield by reaction between the dialkyl 1-lithio-1chloromethylphosphonates and $\mathrm{HCO}_{2} \mathrm{Et}$ at low temperature (70-85\%). 37 By carefully choosing the experimental conditions, it has been found that dialkyl 2,2-diethoxyethylphosphonates react in a similar manner with chlorine in refluxing $\mathrm{CCl}_{4}$ to provide dichloro acetals. ${ }^{127 \mathrm{f}}$

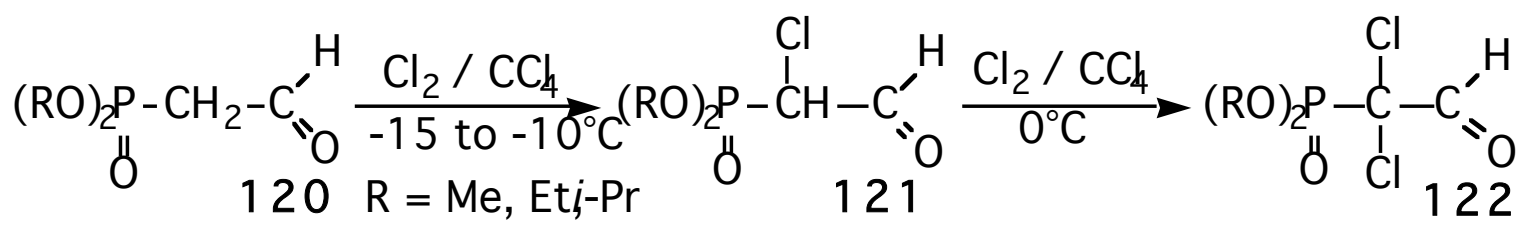

Fig. 48. Synthesis of chloroformyl- and dichloroformylmethylphosphonates ${ }^{127}$.

Systematic studies on the chemistry of the chloroformyl- $\mathbf{1 2 1}$ and dichloroformyl- 122 methylphosphonates showed their high reactivity and extensive synthetic possibilities. For example, the nitration of $\mathbf{4}$ with acetyl nitrate gives a low yield of nitromethylphosphonate. ${ }^{194}$ The nitrosation of 121 with $\mathrm{HNO}_{2} / \mathrm{HCl}$ below $0^{\circ} \mathrm{C}$ results in hydrolytic rupture of the $\mathrm{C}-\mathrm{C}$ bond in the initially formed 1-nitroso compound, loss of the formyl group and formation of the oximes of the dialkoxyphosphinylformyl chloride in $95 \%$ yield. With increasing reaction temperature, however, loss of chlorine and formation of the $\alpha$-nitroso derivative of 1formylmethylphosphonate takes over. ${ }^{127 e, 128}$ The oximes react with 1,4-phenylenediamine, 4-aminoantipyrine, benzhydrazide or thiosemicarbazide as a result of nucleophilic attack by a nitrogen atom on the electrophilic carbon center of the halo oxime to give products of amino- or thiosemicarbazide-oxime structure. ${ }^{129}$ In the presence of $\mathrm{NEt}_{3}$, these oximes can serve as a source of nitrile oxide, which easily enter into dipolar cycloaddition with terminal acetylenes at $20^{\circ} \mathrm{C}$ to give 3-phosphorylated isoxazoles in good yields (6994\%). ${ }^{18 \mathrm{~b}, 130}$ It has also been found that in the reactions between 121 and aryldiazonium salts (chlorides or tetrafluoroborates) in $\mathrm{AcONa} / \mathrm{H}_{2} \mathrm{O}$, the formyl group is split off and the corresponding arylhydrazones of 121 are formed. ${ }^{131} \mathrm{~A}$ study of the kinetics of these reactions has been realized. ${ }^{132}$ The arylhydrazones react with a variety of nucleophiles $\left(\mathrm{NH}_{4} \mathrm{OH}, \mathrm{R}-\mathrm{NH}_{2}, \mathrm{~N}_{2} \mathrm{H}_{4} \cdot \mathrm{H}_{2} \mathrm{O}, \mathrm{Na}_{2} \mathrm{~S}, \mathrm{Na}_{2} \mathrm{SO}_{3}, \mathrm{Na}_{2} \mathrm{~S}_{2} \mathrm{O}_{3}, \mathrm{NaSCN},\left(\mathrm{H}_{2} \mathrm{~N}\right)_{2} \mathrm{CS}\right)$ with replacement of the halogen by the nucleophile. ${ }^{133}$

The diethyl 1,1-dichloro-1-formylmethylphosphonate $\mathbf{1 2 2}$ readily takes part in the Abramov reaction with diethyl phosphite to form the 1,1-dichloro-2-hydroxyethyldiphosphonate in $70 \%$ yield. ${ }^{127 d}$ Under the action of alcoholic solutions of alkalis or secondary amines, $\mathbf{1 2 2}$ undergoes decomposition in the manner of the haloform reaction with the formation of diethyl dichloromethylphosphonate ( $88 \%$ or $72 \%) .127 \mathrm{~d}$ The diethyl 1,1-dichloro-1-formylmethylphosphonate 122 reacts with $\mathrm{HC}(\mathrm{OEt})_{3} / \mathrm{H}_{2} \mathrm{SO}_{4}$ to give the acetal in almost quantitative yield (92\%). ${ }^{127 c}$ Reaction of 122 with $\mathrm{Ph}_{3} \mathrm{P}$ in benzene or toluene results in the formation of diethyl 1,2-dichloro-vinylphosphonate (51\%). ${ }^{134}$ The reaction of $\mathbf{1 2 2}$ with isocyanates of trivalent phosphorus compounds proceeds by a [3+2] cycloaddition reaction with formation of oxazaphospholines (72-75\%). ${ }^{135}$ With iso-PrSH, 122 forms a hemithioacetal, the trimethylsilyl derivative of which, in boiling xylene, undergoes a transposition of the (original) carbonyl group to the $\alpha$-position via an epoxyphosphonate. ${ }^{136}$

\subsection{Heterocyclic systems with phosphorylated substituents}

One of the most thoroughly investigated synthetic applications of phosphorylated aldehydes is the synthesis of heterocyclic compounds containing a phosphoryl group in the side chain. ${ }^{137}$ Historically, the first attempt to synthesise the diethyl 1-formylmethylphosphonate 4 was undertaken with the aim of its subsequent 
employment in the synthesis of phosphorylated heterocycles. ${ }^{2}$ In many cases phosphorylated acetals or enamines were used instead of phosphorylated aldehydes.

Diethyl 1,1-diethoxymethylphosphonate has been utilized in condensation with amino, hydroxy or mercapto 1,2-disubstituted benzene derivatives to produce a series of benzoheterocyclic phosphorus compounds. The yields of benzoxazole and benzothiazole derivatives are acceptable (68\% and 30\%), ${ }^{138-140}$ but benzimidazoles are obtained in poor yields $(7 \%) .{ }^{141}$ The yield of benzimidazoles has been since improved to $65 \%$ by reacting the hydrazone derivative of 121 with $o$-phenylenediamine in refluxing $\mathrm{CHCl}_{3}$ for $2.5 \mathrm{~h} .{ }^{142}$ Catechol and naphthalene-2,3-diol upon reaction with diethyl 1,1-diethoxymethylphosphonate are converted into dioxolane phosphonates in a similar manner. ${ }^{143}$ Under Fischer indole synthesis conditions, diethyl 2,2diethoxyethyl-phosphonate 5 reacts with phenylhydrazine to afford the 2-indolylphosphonate in low yield. It has been postulated that the initially formed product is the indolyl-3-phosphonate, which rearranges to the 2derivative in the presence of an excess of $\mathrm{ZnCl}_{2} \cdot 14 \mathrm{f}, 144$ By a similar procedure, diethyl 1-formylmethylphosphonate 4 reacts with a variety of arylhydrazines in refluxing toluene in the presence of PPA to give the indolyl-3-phosphonates in moderate yields (35-45\%). ${ }^{145}$ A wide range of heterocycles can also be obtained by the condensation of diethyl 2,2-diethoxyethylphosphonate 5 with aromatic $o$-disubstituted compounds containing mobile hydrogen atoms such as $o$-phenylenediamine, $o$-aminophenol, $o$ aminothiophenol and others. These reactions, which are common to a large class of phosphorylated acetals, were carried out by heating equimolecular amounts of reactants at $160-180^{\circ} \mathrm{C}$, whereupon alcohol was evolved. The yields of benzimidazoles, benzoxazoles and benzothiazoles are commonly in the range 30-50\%.138-141 Further applications of the Fischer reaction have been demonstrated in the reaction of diethyl 2formylethylphosphonate $36\left(\mathrm{R}^{1}=\mathrm{H}\right)$ with a large number of arylhydrazine chlorohydrates in anhydrous ethanol at reflux for 2 to $12 \mathrm{~h}$. The indolyl-3-methylphosphonates are isolated in variable yields from 4 to $83 \% .145$ The diethyl 1-chloro-1-formylmethylphosphonate $\mathbf{1 2 1}$ is also a precursor to heterocycles via the intermediacy of the phenylhydrazones. Treatment of hydrazones of $\mathbf{1 2 1}$ with benzylamine gives the $\mathrm{N}^{3}$-benzyl-amidrazones, which on oxidation using $\mathrm{H}_{2} \mathrm{O}_{2}, \mathrm{KMnO}_{4}$ or $\mathrm{Ag}_{2} \mathrm{O}$ in biphasic medium yields the 3-phosphorylated-1,2,4-triazoles in $40-80 \% .{ }^{133 \mathrm{~d}}$ In a similar way, the oxime of $\mathbf{1 2 1}$ is a precursor of 3-phosphorylated isoxazoles via the nitrile oxide. ${ }^{130}$

Enamine phosphonates bearing a functional group $\left(\mathrm{CHO}, \mathrm{COMe}, \mathrm{COPh}, \mathrm{CO}_{2} \mathrm{Et}\right)$ in $\alpha$-position 123 have been shown to undergo similar nucleophilic cyclisation reactions with compounds containing mobile hydrogen atoms, providing the basis of another synthesis of phosphorylated heterocycles (Fig. 49). The dimethylamino group of enamine phosphonates $\mathbf{1 2 3}$ can be selectively and totally transaminated by treatment with symmetrical or unsymmetrical hydrazines, guanidine, acetamidine and methylisothiourea in refluxing ethanol. The corresponding phosphorylated pyrazolones $124\left(\mathrm{R}^{1}=\mathrm{OH}, \mathrm{R}^{2}=\mathrm{H}\right)$, pyrazoles $\mathbf{1 2 4 a}, \mathbf{b}$ and pyrimidines $\mathbf{1 2 5} \mathbf{a}, \mathbf{b}$ are isolated in excellent yield (90-95\%). ${ }^{35}$ The ethyl dialkylphosphonylformylacetates were also used as precursors of phosphorylated pyrazolones in moderate to good yields. 190 


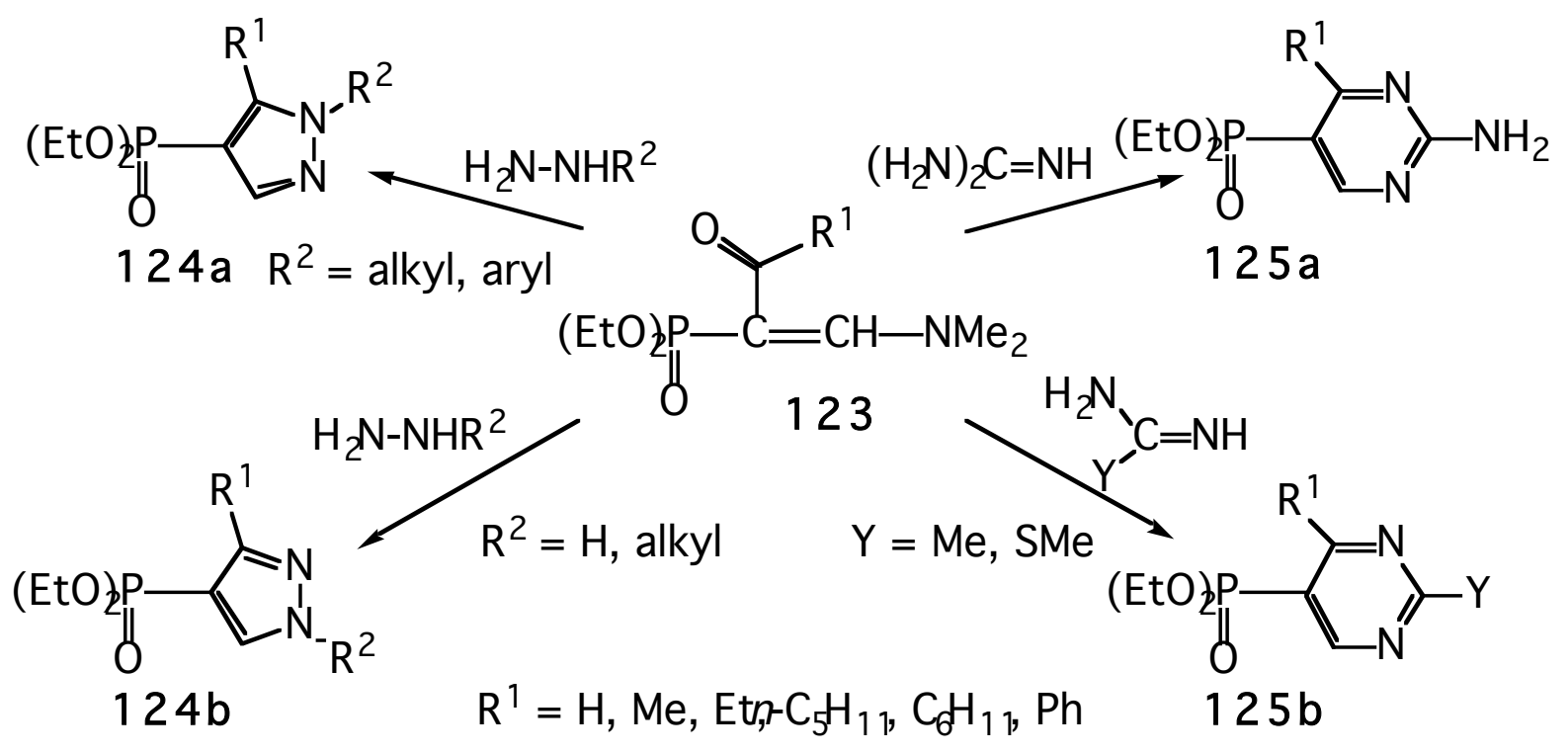

Fig. 49. Synthesis of phosphorylated pyrazoles and pyrimidines ${ }^{35}$.

Of special interest is the report of an efficient, one-pot procedure for the preparation of 3phosphorylated indole 127 in $88 \%$ yield using 126 (Fig. 50). The presence of a nitro group in the ortho position promotes, after reduction, a spontaneous transamination offering an easy approach to 3-phosphorylated indole derivatives. 35 a<smiles>CCOP(=O)(Cc1ccccc1[N+](=O)[O-])OCC</smiles>
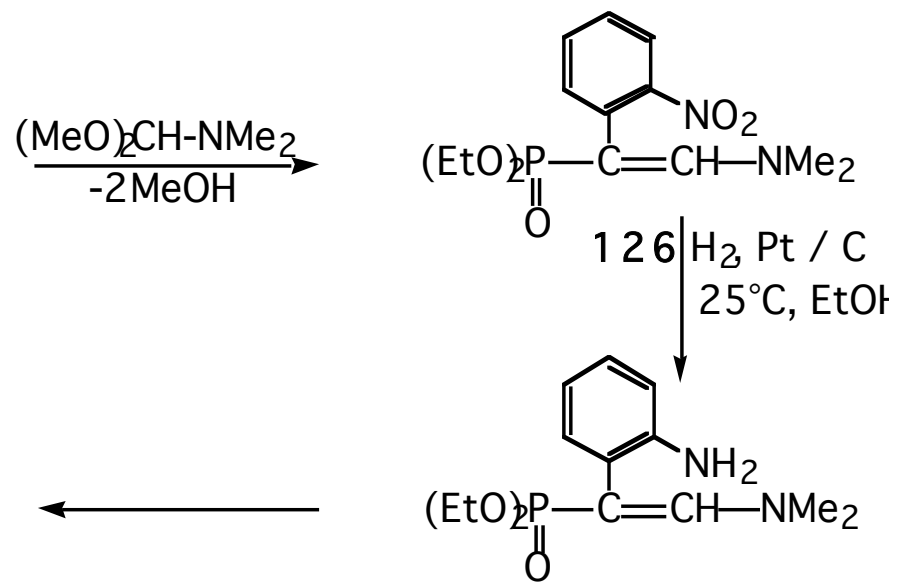

127

Fig. 50. Synthesis of 3-(diethoxyphosphinyl)indole $35 \mathrm{a}$.

The addition of tosylazide to diethyl 1-formylalkylphosphonate $\mathbf{4}$ yields the triazoline which under the reaction conditions produces the diethyl diazomethylphosphonate and the triazole, respectively, according to the nature of $\alpha$-substituent. ${ }^{146}$

\subsection{Horner-Wadsworth-Emmons (HWE) reaction}

The Wittig and the Horner-Wadsworth-Emmons reactions are among the most important reactions for the two carbon elongation of a carbonyl functional group to a more complex aldehyde or ketone. ${ }^{150}$ They can be described as a general synthetic protocol for the conversion of aldehydes and ketones into $\alpha, \beta$-unsaturated carbonyl compounds $131(\mathrm{R}=\mathrm{H}$ or $\neq \mathrm{H})$ and their derivatives. But whereas the reaction of the resonancestabilized phosphonium ylids (Wittig reaction) proceeds readily with aldehydes, the reaction with ketones is more effectively achieved using the more nucleophilic anions of phosphonate reagents (HWE reaction). ${ }^{151}$ The 
first reagent for the formylolefination of ketones as well as aldehydes, diethyl 2-(cyclohexylimino)ethylphosphonate 128 was described in 1968 (Fig. 51). ${ }^{23,152}$ The carbanion 129 is generated conveniently by treatment of 128 with $\mathrm{NaH}$ then coupled with a variety of aldehydes and ketones. Satisfactory results were obtained when hydrolysis of the intermediate aldimines $\mathbf{1 3 0}$ was carried out in a two-phase system. Other procedures were reported for the hydrolysis of imines such as dilute oxalic acid or acetate buffer and $\mathrm{SiO}_{2} /$ weak acid. Several variations on the formylolefination reaction have been reported utilizing protecting reagents for aldehydes such as oxazine (Fig. 5) ${ }^{25}$ semicarbazide ${ }^{153}$ and 1,1-dimethylhydrazine. ${ }^{154}$

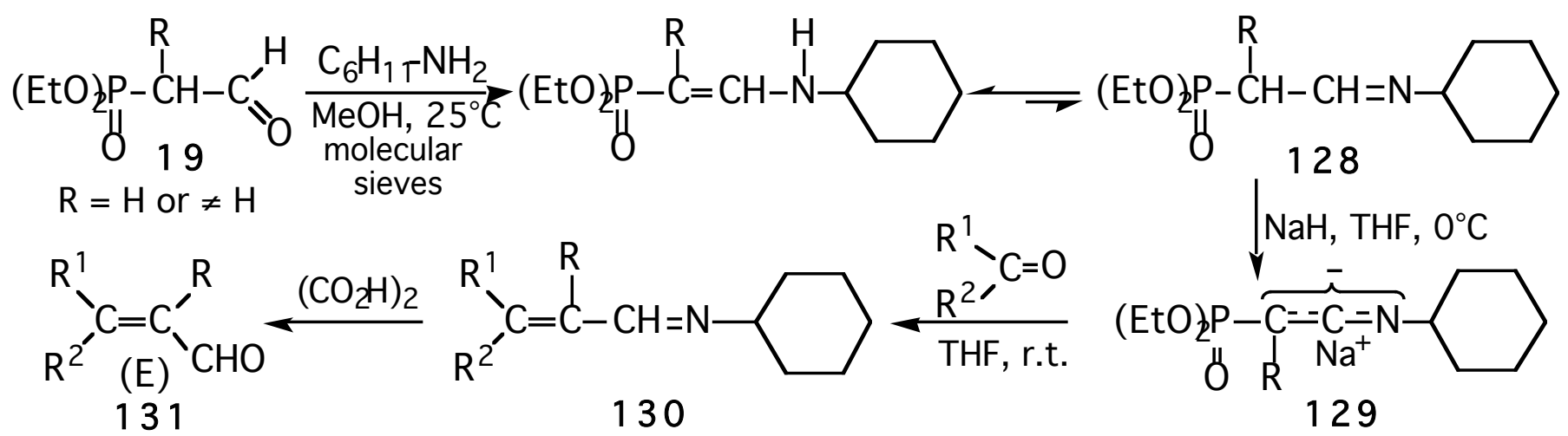

Fig. 51. Synthesis of $\alpha, \beta$-unsaturated aldehydes ${ }^{152}$.

An alternative and efficient route leading to $E$ - $\alpha, \beta$-unsaturated aldehydes $131(\mathrm{R}=\mathrm{H})$ is based upon the metallation of the N-tert-Butylacetaldimine 132 (Fig. 52). In this attractive one-pot procedure, 132 was treated with LDA and then with diethyl chlorophosphate to give the lithiated enamine phosphonate $\mathbf{1 3 3}$, thus avoiding the preparation of the phosphonate imine reagent, which required three steps from commercial materials. ${ }^{155}$

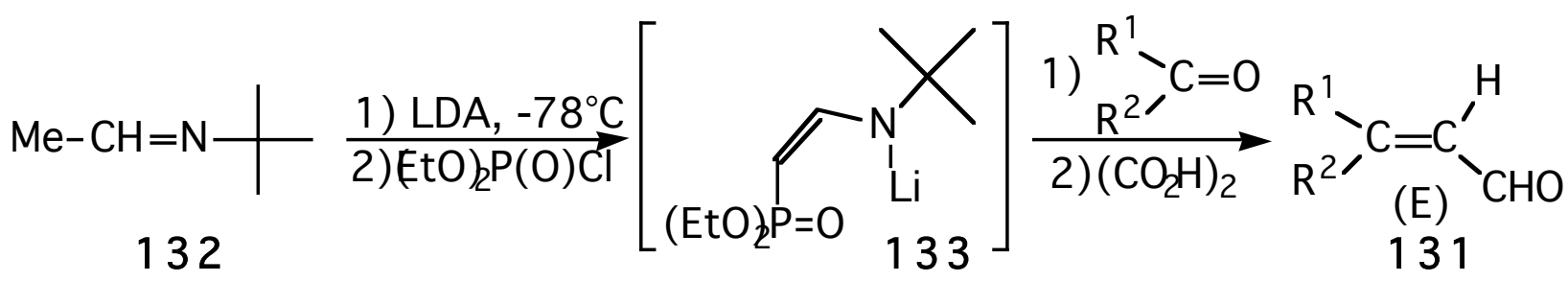

Fig. 52. One-pot synthesis of $\alpha, \beta$-unsaturated aldehydes 155 .

In addition to the previous methods for generating $E$ - $\alpha, \beta$-unsaturated aldehydes 131, an advantageous one-pot preparation of $\alpha, \beta$-unsaturated- $\alpha$-substituted aldehydes 135 was reported (Fig. 53). The procedure involves the intermediacy of the lithiated $\alpha, \beta$-enamine phosphonate $\mathbf{1 3 4}$ prepared by nucleophilic addition of diethyl $\alpha$-lithioalkylphosphonates to ethyl N-phenyl-formimidate. ${ }^{156}$ On reaction with aliphatic or aromatic aldehydes 134 produces $\alpha, \beta$-unsaturated- $\alpha$-substituted imines, which may be efficiently converted to $\alpha, \beta$ unsaturated- $\alpha$-substituted aldehydes $\mathbf{1 3 5}$ by acid hydrolysis in yields ranging from 45 to $78 \% .157$ 


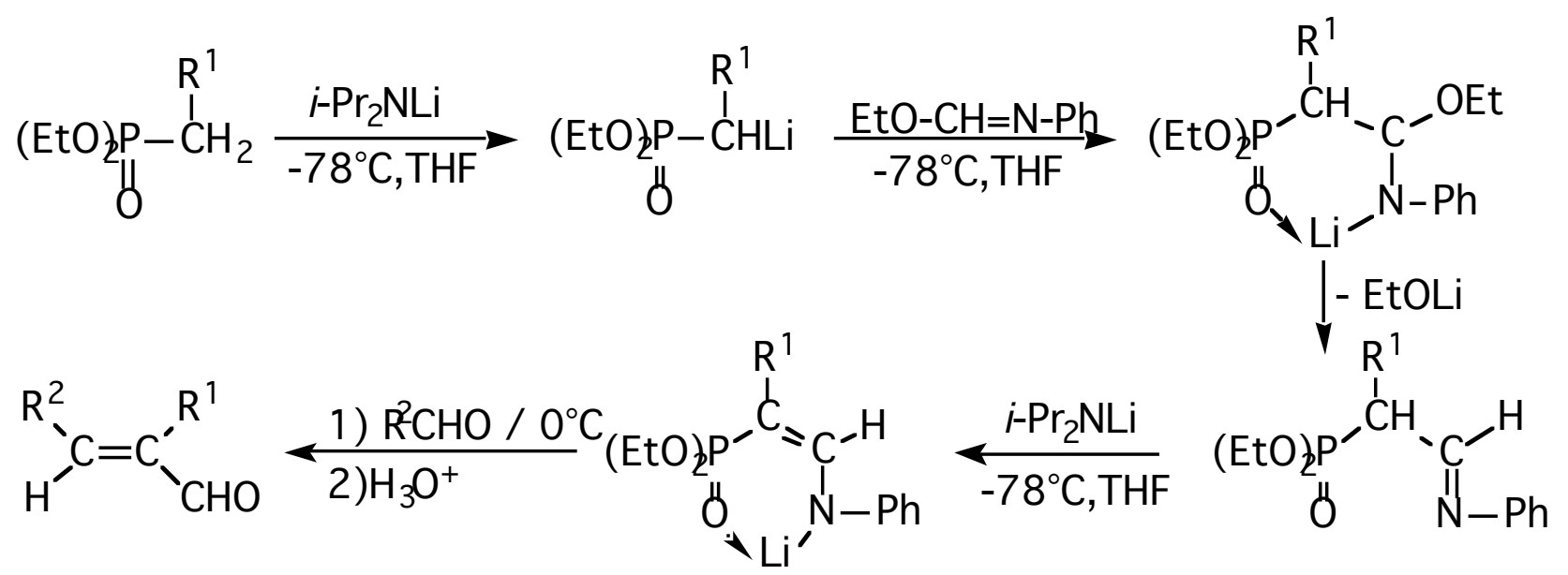

135

134

Fig. 53. One-pot synthesis of $\alpha, \beta$-unsaturated- $\alpha$-substituted aldehydes ${ }^{157}$.

Of significant synthetic importance is the intramolecular version of the HWE methodology. It has been recognized as the method of choice for preparing five-, 88 six-158-161 and seven-162 membered ring systems as well as macrocyclic ring systems, including rings containing 11, ${ }^{163} 12,{ }^{105,110} 14,{ }^{105-109,111} 15,112,16416,112$ and 1775,164 atoms. In the preparation of larger ring sizes high-dilution procedures have usually been required to achieve satisfactory yields. The use of a mild base ( $\mathrm{LiCl} / \mathrm{DBU}$ ) or crown ether catalysis has also been shown to be of importance. As an illustration of the utility of this technique, some typical macrocyclisations providing biologically active compounds (with conditions in brackets) are given : 11-membered ring (-)bertyadionol $\left(\mathrm{NaH} /\right.$ toluene $\left./ 42^{\circ} \mathrm{C}, 28-32 \%\right),{ }^{163}$ 12-membered ring (+)-cleomeolide $\left(\mathrm{K}_{2} \mathrm{CO}_{3} / 18\right.$-crown-6/ toluene / r.t., 38\%), 110 12-membered ring pseudopterane and 14-membered ring furanocembrane systems $(\mathrm{LiCl}$ / DBU / MeCN / r.t., 50\% and 42\%), 105 14-membered ring (-)-asperdiol and (+)-desepoxyasperdiol (LiCl / $\mathrm{DBU} / \mathrm{MeCN} /$ r.t., $61 \%$ and 30\%), ${ }^{106}$ 14-membered ring ( \pm )-methyl ceriferate-I $\left(\mathrm{NaH} / \mathrm{DME} / 80^{\circ} \mathrm{C}\right.$, 24\%), 107 14-membered ring anisomelic acid ( $\mathrm{LiCl} / \mathrm{DBU} / \mathrm{MeCN} /$ r.t., 71\%), 108 14-membered ring cembratrienediols and thunbergols $\left(\mathrm{LiCl} / \mathrm{DBU} / \mathrm{MeCN} / 40^{\circ} \mathrm{C}, 63 \%\right),{ }^{109}$ 14-membered ring macrocyclic trienone $\left(\mathrm{LiCl} / \mathrm{DBU} / \mathrm{MeCN} /\right.$ r.t., 63\%), ${ }^{111}$ 15-membered ring muscone precursor (NaH / DME / high dilution, 50\%), ${ }^{112}$ 17-membered ring civetone precursor (tert- $\mathrm{BuOH} / \mathrm{H}_{2} \mathrm{O} / \mathrm{KHCO}_{3} /$ reflux, 56\%) ${ }^{164}$ and 17 membered ring lankacidin $\left(\mathrm{K}_{2} \mathrm{CO}_{3} / 18\right.$-crown- $6 /$ toluene $\left./ 100^{\circ} \mathrm{C}, 37 \%\right) .75$ The stereochemistry, as well as the ease of the intramolecular reaction is largely determined by the nature of the carbon chain that forms the ring. In a paper appearing in 1987 the authors concluded that "the intramolecular ketophosphonate-aldehyde condensation reaction is a most powerful method for constructing macrorings, and, therefore, it should be placed high on the list of choices for such operations when applicable" ${ }^{165}$

\subsection{Phosphonoacetaldehyde in nature}

In 1972 it was demonstrated that not only phosphoenolpyruvate (PEP) is the immediate precursor of phosphonates in Tetrahymena, but that phosphonoacetaldehyde (PAAl) is a direct precursor of 2-aminoethylphosphonate (AEP) (Fig. 54). ${ }^{166-169}$ Phosphonoalanine (PAla) is a side product in the synthesis and apparently is not directly converted to AEP. In Tetrahymena the radioactive carbon atom in phosphonoenol [3-14C] pyruvate is incorporated into the phosphonate carbon atom in 2-aminoethylphosphonic acid (AEP) confirming that an intramolecular rearrangement of PEP takes place during the biosynthesis of AEP. The incorporation of 
label into AEP is inhibited to a greater extent by PAAl than by PAla : hence the latter may not be on the main biosynthetic pathway to AEP. The phosphonopyruvate (PnPyr) initially formed by the intramolecular rearrangement of PEP is probably decarboxylated to phosphonoacetaldehyde before amination to AEP occurs and the latter is then incorporated into phosphonolipids. Since the discovery of enzymes, PEP phosphonomutases, responsible for C-P bond formation from Tetrahymena or from Streptomyces hygroscopicus, new systems have been reported. ${ }^{170}$ Recently, another enzyme (phosphonoacetaldehyde hydrolase (phosphonatase) from Bacillus cereus), which catalyzes the dephosphonylation reaction of phosphonoacetaldehyde (PAAl) to inorganic phosphate and acetaldehyde, was highlighted. This enzymatic process involves activation of C-P bond cleavage by formation of a Schiff base between PAAl and an active site lysine in phosphonatase. ${ }^{171}$ All these results clearly demonstrate the importance of phosphorylated aldehydes in biological processes.

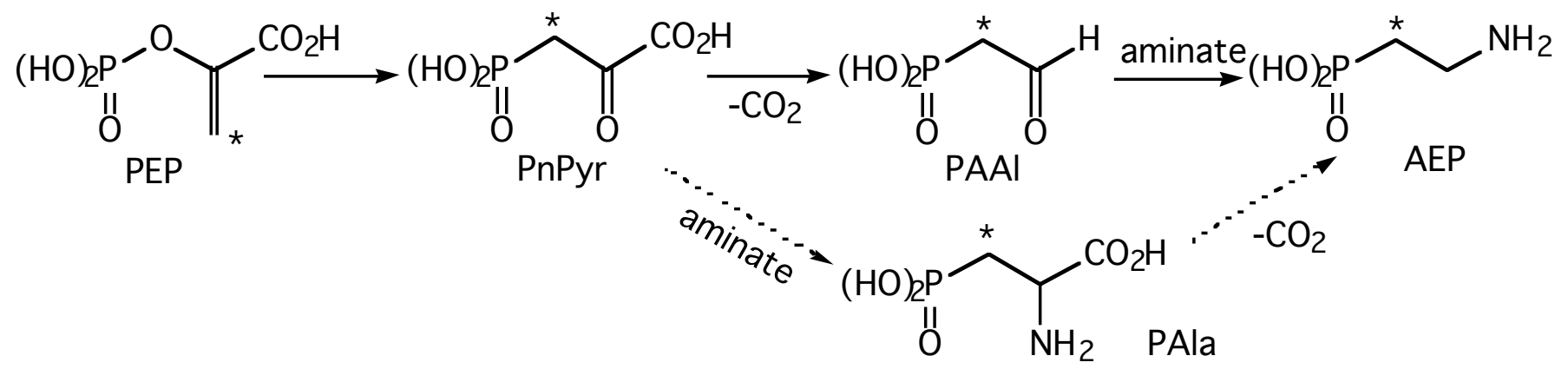

Fig. 54. Pathway for the biosynthesis of AEP.

Fosfomycin, a clinically used antibiotic, is biosynthetically derived from a $\mathrm{P}-\mathrm{C}_{2}$ unit, most likely to be phosphonoacetaldehyde, and a methyl group from L-methionine (Fig.55). As shown above for AEPA, the phosphoenolpyruvate (PEP) was suggested as the most likely precursor of carbons 1 and 2 of fosfomycin. ${ }^{172}$

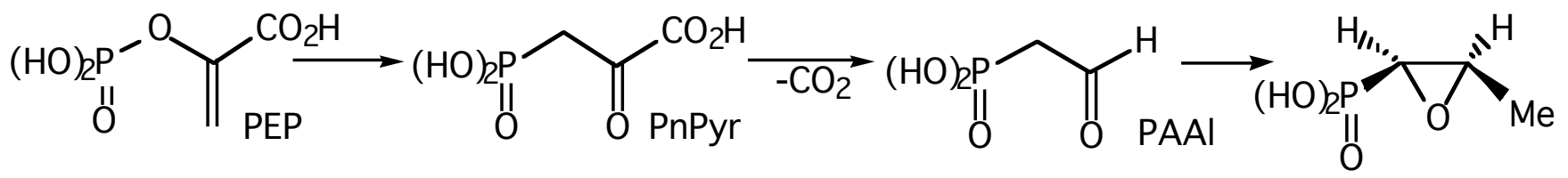

Fig. 55. Pathway for the biosynthesis of fosfomycin 172 .

\subsection{Reductive amination}

Since the phosphonoacetaldehyde is an ideal precursor for the generation of AEP, an attractive procedure for the preparation of 2-aminoalkylphosphonic acids 137 from 1-formylalkyl-phosphonates 4 $\left(\mathrm{R}^{1}=\mathrm{H}\right)$ and $19\left(\mathrm{R}^{1}=\mathrm{Me}\right)$ has been developed using reductive amination of the carbonyl in the presence of $\mathrm{NaBH}_{3} \mathrm{CN}$ (Fig. 56). This method appears to be fairly general and may be used for the preparation of 2aminoalkylphosphonates 136 containing primary, secondary or tertiary amino groups simply by treating the carbonyl compound at room temperature with a primary or secondary aliphatic or aromatic amine. ${ }^{17 a}$ When $\mathrm{AcONH}_{4}$, as a source of ammonia, was subjected to this reaction it required lengthy reaction times and produced a mixture of primary aminophosphonate (7\%) and iminobis(ethylphosphonate) (30\%). ${ }^{173}$ The primary aminophosphonate being considerably more nucleophilic than ammonia, the second attack upon the carbonyl group is an unavoidable competing side reaction. Finally, hydrolysis of $\mathbf{1 3 6}$ with $8 \mathrm{M} \mathrm{HCl}$ followed by 
purification using Amberlite IRA 410 provided the aminophosphonic acids $\mathbf{1 3 7}$ in moderate to excellent yields $(40-81 \%)$.

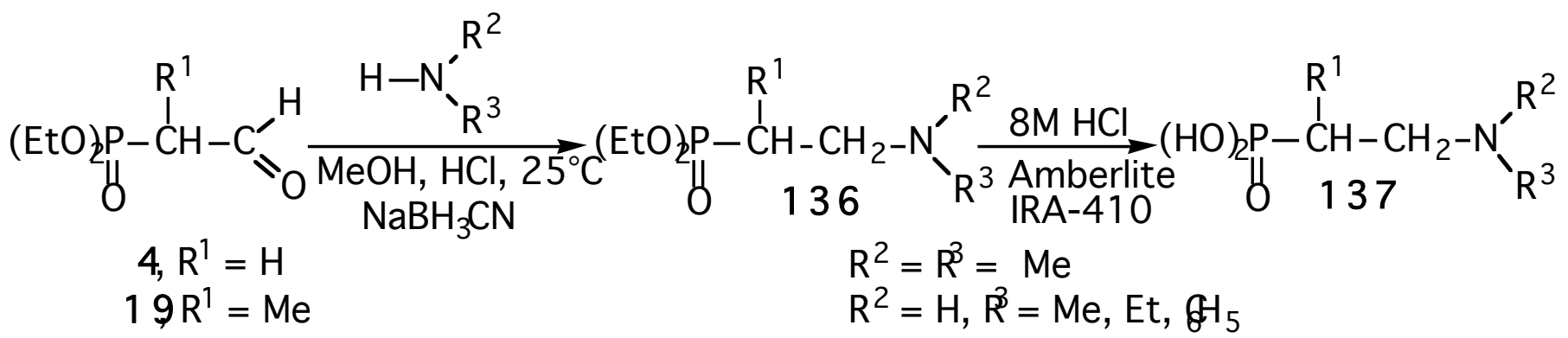

Fig. 56. Reductive amination of phosphonoacetaldehydes ${ }^{17 a}$.

The reductive amination reaction has been modified for the preparation of primary aminophosphonic acids 141 (Fig. 57). It has been observed that the use of benzylamine in reaction with phosphorylated aldehydes 138 increases chemospecificity, reaction rates and yields. Aminobenzylphosphonates $\mathbf{1 3 9}$ have been isolated in $85 \%$ yield, then converted to aminophosphonates 140 by catalytic hydrogenation followed by acid hydrolysis and purification to give aminoalkylphosphonic acids 141.174 Together with its modifications, the reductive amination is one of the most useful and general methods available for the preparation of a wide variety of aminoalkylphosphonic acids from phosphorylated aldehydes.

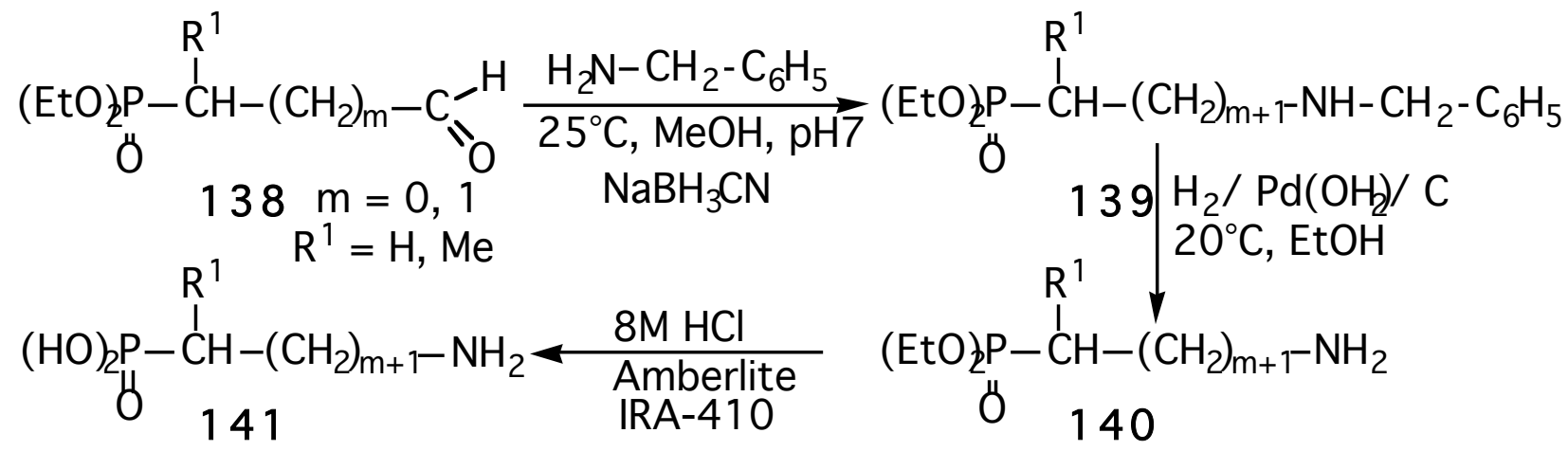

Fig. 57. Reductive amination in the presence of benzylamine ${ }^{174}$.

Of synthetic importance is the preparation of AEP via the reduction of oxime of diethyl 1-formylmethylphosphonate 4. The oxime was prepared from 4 and hydroxylamine hydrochloride in EtOH / pyridine, treated with $(\mathrm{AcO})_{2} \mathrm{O} / \mathrm{AcOH}$ and reduced using $5 \% \mathrm{Pd} / \mathrm{C} / \mathrm{H}_{2}$. After acid hydrolysis for $48 \mathrm{~h}$ using $\mathrm{HCl} 6 \mathrm{M}$ followed by Dowex $50\left(\mathrm{H}^{+}\right)$purification, AEP was isolated in $43 \%$ yield. ${ }^{118}$

The synthesis of 1-aminoalkyldiphosphonic acids 144 from phosphorylated aldehydes 142 has also been described. The preparation is based on the thioureidoalkylphosphonate method (Fig. 58). Thus, starting from phosphorylated aldehydes $142(\mathrm{~m}=1,2,3), \mathrm{N}$-phenylthiourea and diphenylphosphite, the corresponding thioureidoalkylphosphonates $\mathbf{1 4 3}$ were prepared in good yields in glacial AcOH. The hydrolytic degradation in a refluxing mixture of $\mathrm{AcOH} / \mathrm{HCl}$ led to satisfactory overall yields (50-70\%) of the 1-aminoalkyldiphosphonic acids 144. These compounds were purified by ion-exchange chromatography using acidic resin (Dowex 50). ${ }^{18 a}$ 


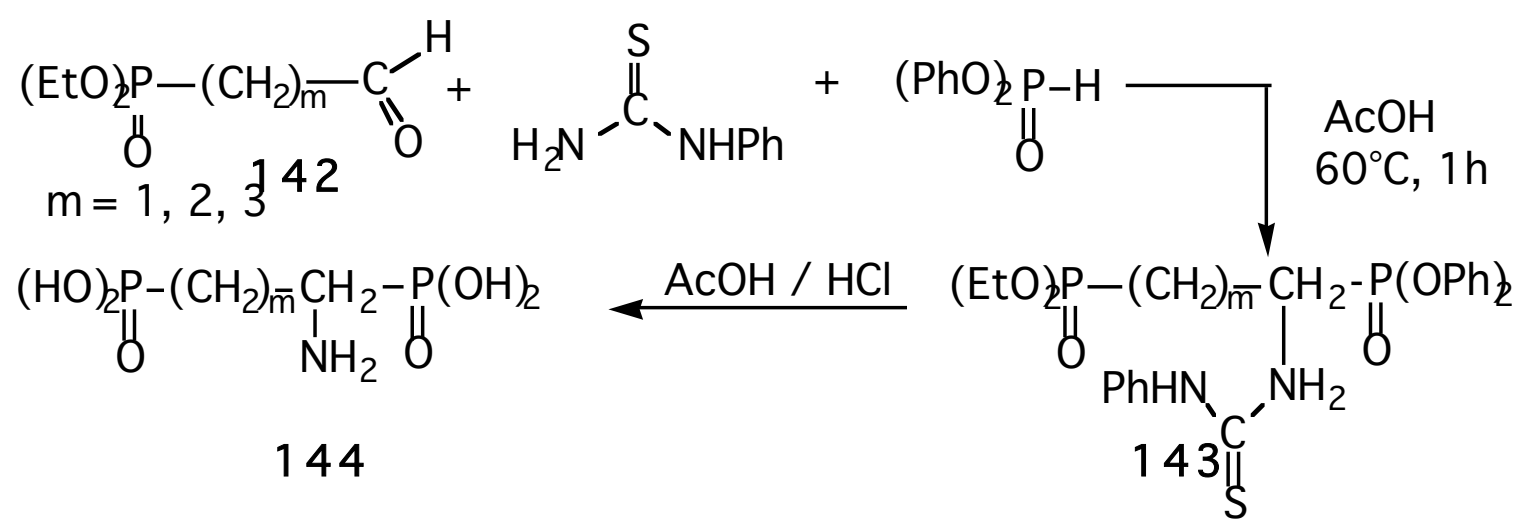

Fig. 58. Synthesis of 1-aminoalkyldiphosphonic acids ${ }^{18 a}$.

\subsection{Aminocarboxylation (Strecker and related reactions)}

Receptors for glutamic and aspartic acids ${ }^{175,176}$ have been implicated in the pathology of several neurological and neurodegenerative illnesses, including, for example, epilepsy, cerebral ischemia, hypoglycaemia, Huntington's and Alzheimer's diseases, and Parkinsonism. The growing number of these disorders, in which excitatory amino acids (EAA) have been implicated, has resulted in considerable attention being focused on the development of compounds which antagonize excitatory amino acids neurotransmission. Compounds which act selectively and competitively at the subclass of EAA receptor selectively activated by N-methyl-D-aspartate (NMDA) have received particular attention. ${ }^{177}$ Several amino phosphonocarboxylic acids have been characterized as being potent and selective competitive NMDA antagonists ${ }^{178-182}$ (Fig. 59) and have been found to be efficacious against neuronal damage. With these considerations in mind, the Strecker and Bucherer-Bergs reactions for the synthesis of $\omega$-amino- $\omega$-carboxyalkylphosphonic acids have been applied to a variety of phosphorylated aldehydes.

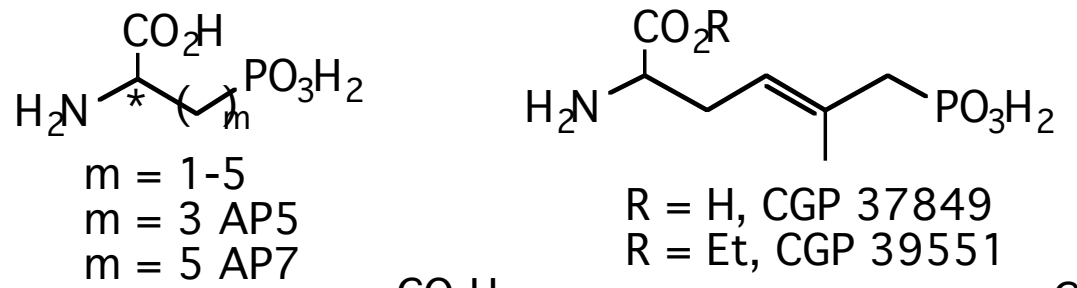

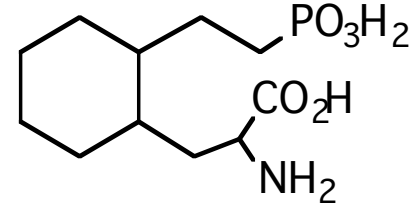

NPC 12626<smiles>NC(=O)C1C(CCC(=O)O)C1CC(=O)O</smiles><smiles>NC(C(=O)O)C1CC(P(=O)(O)O)C1</smiles>

$\mathrm{m}=1,2,3$

Fig. 59. Structures of some NMDA antagonists.

Phosphorylated aldehydes $\mathbf{1 3 8}$ are first smoothly converted to amino nitriles 145, which are further treated with concentrated $\mathrm{HCl}$ to provide the amino acids 146 (Fig. 60). In this method, treatment (in the absence of light) of freshly purified phosphorylated aldehydes at room temperature in water (or $\mathrm{MeOH} / \mathrm{water}$ or $\mathrm{MeCN}$ ) with $\mathrm{NaCN}$ (or $\mathrm{KCN}$ ) and $\mathrm{NH}_{4} \mathrm{Cl}$ (or $\mathrm{NH}_{4} \mathrm{OH}$ or $\mathrm{HCO}_{2} \mathrm{NH}_{4}$ ) (or $\left(\mathrm{NH}_{4}\right)_{2} \mathrm{CO}_{3}$ at $50-60^{\circ} \mathrm{C}$ in the Bucherer-Bergs reaction ${ }^{79,85}$ ) produces selectively the amino nitriles in moderate to high yields (44-91\%). 17b,71,72a,83,85,93,183 Improved yields have been reported through the use of alumina/ultrasound 71 or a modified Strecker reaction. ${ }^{196}$ Hydrolysis of the amino nitriles 145 with 6-8M HCl at reflux delivers the crude amino acids 146, which were purified by ion-exchange chromatography using strongly acidic resin (Dowex $18 \mathrm{x} 100)$. The Bucherer-Bergs route is not so efficacious because of difficulties in the hydrolysis of the hydantoin. $17 \mathrm{~b}$ 


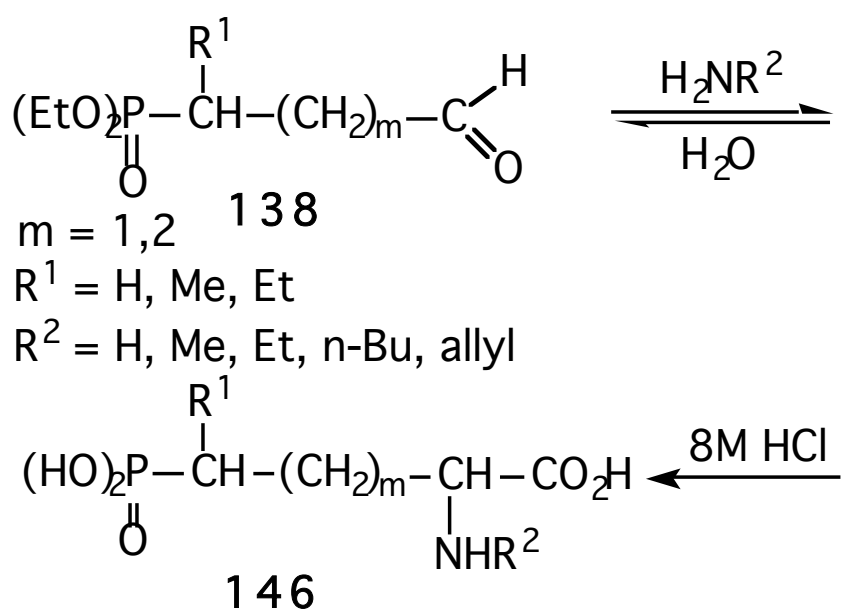<smiles>[R]C(CCC=[W])[Po](=O)CC</smiles>

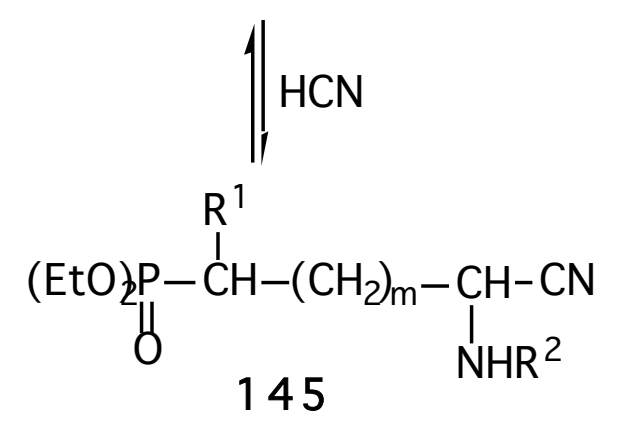

Fig. 60. Synthesis of amino carboxyalkylphosphonic acids via the Strecker reaction.

Though initially prepared and evaluated as a racemic, it was recognized that the NMDA antagonist activity was likely to reside primarily in a single enantiomer. The stereoselective nature of the NDMA receptor is well established, albeit not completely understood. Consequently, several attempts were undertaken to develop synthetic protocol which would allow to prepare optically active compounds. Early reported preparations of optically active $\omega$-amino- $\omega$-carboxyalkylphosphonic acids included a Strecker reaction using $(S)(-)$ - $\alpha$-methyl-benzylamine as the amination agent. However, the enantiomeric excess was only $50 \% .{ }^{184}$ Recently reported procedures, which use chemoenzymatic processes, offer a more convenient approach for the mild obtention of optically pure aminophosphonic acids. The enzymatic hydrolysis either of amide (using penicillinacylase, EC 3.5.1.11, from Escherichia coli) ${ }^{83}$ or ester (with Subtilisin A $^{85}$ or Carlsberg esterase ${ }^{185}$ ) groups provides a high yielding method of resolution of the racemic mixture. In the case of the hydantoin resulting from Bucherer-Bergs reaction, the resolution of two diastereomeric compounds, epimeric at the C-5 hydantoin carbon atom, was made using D-hydantoinase from Agrobacterium, in alkaline buffer. ${ }^{85}$

Another attractive route to aminocarboxylalkylphosphonic acids involves the intermediacy of the ethyl $\alpha$-azidoacetate (Fig. 61). Addition of methanolic sodium methoxide to a solution of 147 and ethyl $\alpha$ azidoacetate in methanol at $-30^{\circ} \mathrm{C}$, provides the vinyl azide 148. Hydrogenation of $148(10 \% \mathrm{Pd} / \mathrm{C} / \mathrm{MeOH})$ gives the aminoester 149, which at reflux with $3 \mathrm{M} \mathrm{HCl}$ delivers the free amino acid $\mathbf{1 5 0} .95 \mathrm{~b}, \mathrm{c}$

The copper(I) catalyzed cycloaddition of an aldehyde with ethyl isocyanoacetate 197 to form the corresponding oxazoline has also been found to be an interesting method for introducing the amino acid group. However, this procedure is not diastereoselective and the yield is moderate (33\%). ${ }^{198}$

Similarly, a promising methodology using an Horner-Wadsworth-Emmons reaction between an aldehyde and the sodium derivative of N-acyl-2-(dialkoxyphosphinyl)glycine ester has been described.199 Unfortunately, the dehydro amino acid is obtained in poor yield. ${ }^{85}$ By contrast, the use of diethyl 2,4dioxoimidazoline-5-phosphonate ${ }^{200}$ and $\mathrm{LiOH} / \mathrm{MeOH}$ leads to a rapid and high yielding conversion of aldehyde to dehydrohydantoin as a mixture of $E$ - and $Z$ - isomers. 85 


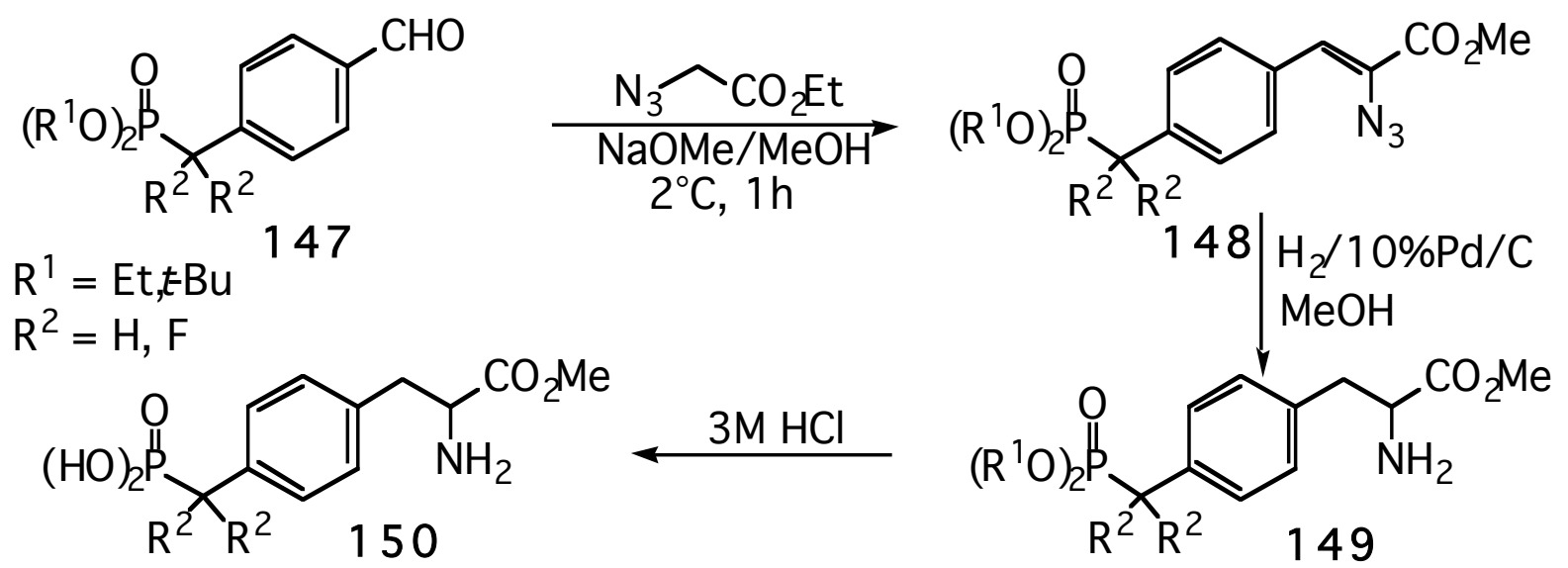

Fig. 61. Synthesis of amino carboxyalkylphosphonic acids via $\alpha$-azidoacetate ${ }^{95 b}$.

\section{CONCLUSION}

Since their discovery in 1952, phosphorylated aldehydes have found widespread prominence in organic chemistry and their popularity emanates from their efficiency and versatility. They are functionally rich molecules very useful in organic synthesis and frequently involved in biological processes. The present review highlights three major developments of this chemistry. First, significant progress in the preparation of phosphorylated aldehydes has been achieved resulting in various new reactions to arrive at a high level of structural diversity and complexity. Second, olefination reaction based on the Horner-Wadsworth-Emmons reaction is an ever-growing area and the intramolecular version has became the most powerful tool for the construction of macrorings. Finally, the utility of phosphorylated aldehydes for the synthesis of biologically active compounds has blossomed during the last ten years. The diversity of phosphono amino acid analogues prepared attests to the wide acceptance and general utility of phosphorylated aldehydes.

\section{ACKNOWLEDGEMENTS}

In collecting the literature, the authors have benefited greatly from collaboration with Mrs Françoise Girard, who is gratefully acknowledged. We are also grateful to the Centre National de la Recherche Scientifique and Ecole Polytechnique for financial support to B.I. 


\section{REFERENCES}

1. Razumov, A.I.; Liorber, B.G.; Moskva, V.V.; Sokolov, M.P. Russ. Chem. Rev. 1973, $42,538$.

2. Dawson, N.D.; Burger, A. J. Am. Chem. Soc. 1952, 74, 5312.

3. Wagenknecht, J. Synth. Inorg. Met. Org. Chem. 1974, 4, 567.

4. Firestone, R.A. Patent US 3784590; C.A. 1974, 80, 60031.

5. Vasella, A.; Voeffray, R. Helv. Chim. Acta 1982, 65, 1953.

6. Moskva, V.V.; Mavrin, V.Y.Zh.Obshch. Khim. 1987, 57, 2793; J. Gen. Chem. USSR (Engl. Transl.) 1988, 57, 2492.

7. $\quad$ (a) Mikolajczyk M.; Grzejszczak S.; Zatorski A.; Mlotkowska B.; Gross H.; Costisella B. Tetrahedron 1978, 34, 3081; (b) Mikolajczyk M.; Balczewski P. Tetrahedron 1992, 48, 8697; (c) Mikolajczyk M.; Graczyk P.P.; Wieczorek M.W. J. Org. Chem. 1994, 59, 1672.

8. $\quad$ Razumov, A.I.; Moskva, V.V. Zh. Obshch. Khim. 1964, 3125.

9. (a) Moskva, V.V.; Maikova, A.I.; Razumov, A.I. Zh. Obshch. Khim. 1969, 39, 595; C.A. 71, 50076r; (b) Diesche, W. Annalen 1968, $712,21$.

10. Balazewski, P.; Mikolajczyk, M. Heteroat. Chem. 1994, 64, 487.

11. Razumov, A.I.; Moskva, V.V. Zh. Obshch. Khim. 1965, 35, 1595; C.A. 63, 18144.

12. (a) Perkow, W.; Ullerich, K.; Meyer, F. Naturwissenschaften 1952, 39, 353; (b) Sekine, M.; Okimoto, K.; Yamada, K.; Hata, T. J. Org. Chem. 1981, 46, 2097.

13. Gryszkiewicz-Trochimowski, E.; Chemelevsky, A. Bull. Soc. Chim. Fr. 1966, 2043.

14. (a) Razumov, A.I.; Moskva, V.V. Zh. Obshch. Khim. 1964, 34, 2589; J. Gen. Chem. USSR (Engl. Transl.) 1964, 34, 2612. (b) Razumov, A.I.; Gurevich, P.A. Zh. Obshch. Khim. 1967, 37, 1615; (c) Razumov, A.I.; Gurevich, P.A. Zh. Obshch. Khim. 1967, 37, 1615; C.A. 1968, 68, 39730s; (d) Razumov, A.I.; Savicheva, G.A.; Zykova, T.V.; Sokolov, M.P.; Smirnova, G.G.; Liorber, B.G.; Salakhutdinov, R.A. Zh. Obshch. Khim. 1971, 41, 2164; (e) Razumov, A.I.; Savicheva, G.A.; Zykova, T.V.; Sokolov, M.P.; Liorber, B.G.; Salakhutdinov, R.A. Zh. Obshch. Khim. 1971, 41, 1954; (f) Razumov, A.I.; Sokolov, M.P.; Zykova, T.V.; Liorber, B.G.; Savicheva, G.A.; Salakhutdinov, R.A. J. Gen. Chem. USSR (Engl. Transl.) 1972, 42, 43; Zh.Obshch. Khim. 1972, 42, 47; (g) Razumov, A.I.; Liorber, B.G.; Sokolov, M.P.;

Moskva, V.V.; Hazvanova, G.F.; Zykova, T.V.; Chemodanova, L.A.; Salakhutdinov, R.A. Zh. Obshch. Khim. 1973, 43, 568; J. Gen. Chem. USSR (Engl.Transl.) 1973, 43, 570.

15. Iorga, B.; Eymery, F.; Mouriès, V.; Savignac, P., unpublished results.

16. Halmann, M.; Vofsi, D.; Yanai, S. J. Chem. Soc., Perkin Trans. 2 1976, 1210.

17. (a) Varlet, J.-M.; Collignon, N.; Savignac, P. Synth. Commun. 1978, 8, 335; (b) Varlet, J.M.; Fabre, G.; Sauveur, F.; Collignon, N.; Savignac, P. Tetrahedron 1981, 37, 1377.

18. (a) Kudzin, Z.H.; Kotynski, A.; Andrijewski, G. J. Organomet. Chem. 1994, 479, 199; (b) Nkusi, G.; Neidlein, R. J. Prakt. Chem. / Chem.-Ztg. 1992, 334, 278; (c) Cates, L.A.; Jones Jr., G.S.; Good, D.J.; Tsai, H.Y.-L.; Li, V.-S.; Caron, N.; Tu, S.-C.; Kimball, A.P. J. Med. Chem. 1980, 23, 300.

19. Pfeiffer, F.R.; Mier, J.D.; Weisbach, J.A. J. Med.Chem. 1974, 17, 112.

20. Gorgues, A. Bull. Soc. Chim. Fr. 1974, 529.

21. Tavs, P. Chem. Ber. 1967, 100, 1571.

22.

23. Clare, B.W.; Ferro, V.; Skelton, B.W.; Stick, R.V.; White, A.H. Aust. J. Chem. 1993, 46, 805.

Nagata,W.; Wakabayashi, T.; Hayase, Y. Org. Synth. 1973, 53, 44.

Saunders, B.C.; Simpson, P. J. Chem. Soc. 1963, 3351.

25. (a) Malone, G.R.; Meyers, A.I. J. Org. Chem. 1974, 39, 623; (b) Malone, G.R.; Meyers, A.I. J. Org. Chem. 1974, 39, 618.

26. (a) Lutsenko, I.F.; Kirilov, M. Doklady Akad.Nauk SSSR 1960, 132, 842; Dokl. Chem. (Engl. Transl.) 1960, 132, 621; (b) Lutsenko, I.F.; Kirilov, M.; Postnikova, G.B. Zh. Obshch. Khim. 1961, 31, 2034; J. Gen. Chem. USSR (Engl. Transl.)

1961, 31, 1902; (c) Lutsenko, I.F.; Kirilov, M. Zh. Obshch. Khim. 1961, 31, 3594; C.A., 1962, 8606b. (d) Lutsenko, I.F.; Kirilov, M.; Postnikova, G.B.Zh. Obshch. Khim. 1962, 32, 263; J. Gen. Chem. USSR (Engl.Transl.) 1962, 32, 257; (e) Lutsenko, I.F.; Kirilov, M. Godishnik Sofiiskiya Univ. Fak. Khim. 1960/1961, 55, 135; C.A., 1964, 61, $10701 \mathrm{f}$.

27. Malet, R.; Moreno-Manas, M.; Pleixats, R. Synth. Commun. 1992, 22, 2219.

28. Kirilov, M.; Petrov, G. Monatsch. Chem. 1968, 99, 166.

29. Yoffe, S.T.; Petrovsky, P.V.; Goryunov, Ye. I.; Yershova, T.V.; Kabachnik, M.I. Tetrahedron 1972, $28,2783$.

30.

31. Aboujaoude, E.E.; Collignon, N.; Savignac, P. J. Organomet. Chem. 1984, 264, 9. Aboujaoude, E.E.; Collignon, N.; Savignac, P. Synthesis 1983, 634.

Olah, G.A.; Ohannesian, L.; Arvanaghi, M. J. Org. Chem. 1984, 49, 3856.

(a) Yoffe, S.T.; Vatsuro, K.V.; Petrovsky, P.V.; Fedin, E.I.; Kabachnik, M.I. Izv. Akad. Nauk SSSR, Ser. Khim. 1970, 7, 1504; Bull. Acad. Sci. USSR, Div. Chem. Sci. (Engl. Transl.) 1970, 1420; (b) Yoffe, S.T.; Vatsuro, K.V.; Petrovsky, P.V.; Kabachnik, M.I. Izv. Akad. Nauk SSSR, Ser. Khim. 1971, 4, 731; Bull. Acad. Sci. USSR, Div. Chem. Sci. (Engl. Transl.) 1971, 20, 655.

34. Grassberger, M.A. Liebigs Ann. Chem. 1974, 1872.

35. (a) Aboujaoude, E.E.; Collignon, N.; Savignac, P. Tetrahedron 1985, 41, 427. (b) Aboujaoude, E.E.; Collignon, N.; Savignac, P. Phosphorus Sulfur 1987, 31, 231.

36. Al-Badri, H.; About-Jaudet, E.; Combret, J.-C.; Collignon, N. Synthesis 1995, 1401

37. Teulade, M.-P.; Savignac, P.; Aboujaoude, E.E.; Collignon, N. J. Organomet. Chem. 1985, $287,145$.

38. Truel, I.; Mohamed-Hachi, A.; Aboujaude, E.E.; Collignon, N. Synth. Commun. 1997, $27,1165$.

39. Teulade, M.-P.; Savignac, P. Tetrahedron Lett. 1987, 28, 405.

40. Savignac, P.; Patois, C. Org. Synth. 1995, 72, 241.

41. Zanella, Y.; Berté-Verrando, S.; Dizière, R.; Savignac, P. J. Chem. Soc., Perkin Trans. 1 1995, 2835.

42. (a) Tammelin,L.-E.; Fagerlind, L. Acta Chem. Scand. 1960, 14, 1353; (b) Larsson, L.; Tammelin, L.-E.Acta Chem. Scand. 1961, 15, 350 .

43. Kreutzkamp, N. Angew. Chem. 1957, 69, 393.

44. Churi, R.H.; Griffin, C.E.J. Am. Chem. Soc. 1966, 88, 1824. 
Sprecher, M.; Kost, D. Tetrahedron Lett. 1969, 703.

46. Cann, P.F.; Howells, D.; Warren, S. J. Chem. Soc., Perkin 21972, 304.

47. Ulman, A.; Sprecher, M. J. Org. Chem. 1979, 44, 3703.

48. Teulade, M.-P.; Savignac, P. Synth.Commun. 1987, 17, 125.

49. Griffin, C.E.; Kundu, S.K. J. Org. Chem. 1969, 34, 1532.

50. Baboulene, M.; Sturtz, G. Synthesis 1978, 456.

51. Yamashita, M.; Nomoto, H.; Imoto, H. Synthesis 1987, 716.

52. Lavielle, G.; Sturtz, G.; Normant, H. Bull. Soc. Chim. Fr. 1967, 4186.

53. Block, H.D. Patent 1976, Bayer AG, DE 2516341; C.A. 86, 55580.

54. (a) Tsivunin, V.S.; Kamai, G.Kh.; Kormachev, V.V.Zh. Obshch. Khim. 1966, 36, 1663; J. Gen. Chem. USSR

Transl.) 1966, 36, 1661; (b) Kormachev, V.V.; Tsivunin, V.S.; Koren, N.A.; Kutuev, A.A.; Kletsko, G. Zh.

Khim. 1969, 39, 2256; J. Gen. Chem. USSR (Engl. Transl.) 1969, 39, 2201; (c) Kormachev, V.V.; Tsivunin,

(Engl.

Obshch.

J.Gen. Chem. USSR (Engl.Transl.) 1970, 40, 1698; Zh. Obshch. Khim. 1970, 40, 1711; (d) Kormachev, V.V. Mitrasov, Y N.

Zh. Obshch. Khim. 1975, 45, 1267; J. Gen. Chem. USSR (Engl. Transl.) 1975, 45, 1244; (e) Kormachev, V.V.; Mitrasov, Y.N. Zh. Obshch. Khim. 1975, 45, 1270; J. Gen. Chem. USSR (Engl. Transl.) $1975,45,1247$

55. (a) Rudinskas, A.J.; Hullar, T.L. J. Org. Chem. 1976, 41, 2411; (b) Rudinskas, A.J.; Hullar, T.L. J. Med. Chem. 1976, $19,1367$.

56. Just, G.; Potvin, P.; Hakimelahi, G.H. Can. J. Chem. 1980, 58, 2780.

57. $\quad$ Page, P.; Blonski, C.; Périé, J. Tetrahedron 1996, 52, 1557.

58. Von Der Osten, C.H.; Sinskey, A.J.; Barbas, C.F.; Pederson, R.L.; Wang, Y.F.; Wong, C.H. J. Am. Chem. Soc. 1989, $111,3924$.

59. $\quad$ Mikolajczyk, M.; Zurawinski, R.; Kielbasinski, P. Tetrahedron Lett. 1989, 30, 1143.

60. Gijsen, H.J.M.; Wong, C.-H. Tetrahedron Lett. 1995, 36, 7057.

61. Balczewski, P.; Pietrzykowski, W.M.; Mikolajczyk, M. Tetrahedron 1995, 51, 7727

62. (a) Chambers, R.D.; Jaouhari, R.; O'Hagan, D. Tetrahedron 1989, 45, 5101; (b) Chambers, R.D.; Jaouhari, R.; O'Hagan, D. J. Fluorine Chem. 1989, 44, 275.

63. Blackburn, G.M.; Rashid, A.J. Chem. Soc., Chem. Comm. 1988, 317.

64. Engel, R. Synthesis of Carbon-Phosphorus Bonds; CRC Press, Boca Raton, 1988; pp. 137-164.

65. (a) Kamai, G.; Kukhtin, V.A. Doklady Akad. Nauk SSSR 1957, 112, 868; C.A. 51, 13742f. (b) Kamai, G.; Kuchtin, V.A. Zh. Obshch. Khim. 1957, 27, 2376.

66.

(a) Harvey, R.G. Tetrahedron 1966, 22, 2561; (b) Merger, F.; Fouquet, G. Patent 1976, BASF AG, DE 2517448; C.A. 86, 72869 .

67. (a) Okamoto, Y. Chem. Lett. 1984, 87. (b) Okamoto, Y.; Azuhata, T. Synthesis 1986, 941.

68. (a) Evans, D.A.; Hurst, K.M.; Truesdale; L.K.; Takacs, J.M. Tetrahedron Lett. 1977, 2495; (b) Evans, D.A.; Hurst, K.M.; Takacs, J.M. J. Am. Chem. Soc. 1978, 100, 3467.

vvorak, D.; Saman, D.; Budesinski, M.; Arnold, Z. Coll. Czech. Chem. Comm. 1987, 52, 2926.

Teulade, M.-P.; Savignac, P. Synthesis 1987, 1037.

Dappen, M.S.; Pellicciari, R.; Natalini, B.; Monahan, J.B.; Chiorri, C.; Cordi, A.A. J. Med. Chem. 1991, $34,161$.

(a) Natchev, I.A. Tetrahedron 1988, 44, 1511; (b) Rein, T.; Àkermark, B.; Helquist, P. Acta Chem. Scand., Ser. B 1988, 42, 569; (c) Kann, N.; Rein, T.; Åkermark, B.; Helquist, P. J. Org. Chem. 1990, 55, 5312.

Al-Badri, H.; About-Jaudet, E.; Collignon, N. Tetrahedron Lett. 1995, 36, 393.

Fouqué, D.; About-Jaudet, E.; Collignon, N.; Savignac, P. Synth. Commun. 1992, 22, 219.

Mata, E.G.; Thomas, E.J. J. Chem. Soc., Perkin Trans. 1 1995, 785.

Page, P.; Blonski, C.; Perié, J. Tetrahedron Lett. 1995, 36, 8027.

Albrecht, H.P.; Jones, G.H.; Moffatt, J.G. Tetrahedron 1984, 40, 79.

Han, C.-N. A.; Iwata, C.; Metzler, D.E. J. Med. Chem. 1983, 26, 595

Yokomatsu, T.; Nakabayashi, N.; Matsumoto, K.; Shibuya, S. Tetrahedron: Asymmetry 1995, 6, 3055.

Schick, A.; Kolter, T.; Giannis, A.; Sandhoff, K. Tetrahedron 1995, 51, 11207.

Paladino, J.; Guyard, C.; Thurieau, C.; Fauchere, J.-L. Helv. Chim. Acta 1993, 76, 2465.

Minami, T.; Isonaka, T.; Okada, Y.; Ichikawa, J. J. Org. Chem. 1993, 58, 7009.

Czekanski, T.; Witek, St.; Costisella, B.; Gross, H. J. Prakt. Chem. 1981, 323, 353.

Altenbach, H.-J.; Holzapfel, W.; Smerat, G.; Finkler, S.H. Tetrahedron Lett. 1985, 26, 6329

Hamilton, G.S.; Huang, Z.; Yang, X.-J.; Patch, R.J.; Narayanan, B.A.; Ferkany, J.W. J. Org. Chem. 1993, $58,7263$.

Hullar, T.L.J.Med. Chem. 1969, 12, 58.

Stepanova S.V.; L'vova, S.D.; Gunar, V.I. Sov. J. Bioorg. Chem. (Engl. Transl.) 1978, 4, 498.

(a) Minami, T.; Watanabe, K.; Chikugo, T.; Kitajima, Y. Chem. Lett. 1987, 2369; (b) Minami, T.; Nakayama, N.; Fujimoto, K.; Matsuo, S. Phosphorus, Sulfur, and Silicon 1993, 75, 135.

89.

90.

91.

92.

Paulsen, H.; Bartsch, W. Chem. Ber. 1975, 108, 1745.

Wolff, M.E.; Burger, A. J. Am. Pharm. Assoc. 1959, 56.

Issleib, K.; Doepfer, K.-P.; Balszuweit, A. Phosphorus Sulfur 1983, 14, 171.

Sikorski, J.A.; Miller, M.J.; Braccolino, D.S.; Cleary, D.G.; Corey, S.D.; Font, J.L.; Gruys, K.J.; Han, C.Y.; Lin, K.C.; Pansegrau, P.D.; Ream, J.E.; Schnur, D.; Shah, A.; Walker, M.C. Phosphorus, Sulfur, and Silicon 1993, 76, 115

93. Bigge, C.F.; Drummond, J.T.; Johnson, J.; Malone, T.; Probert Jr., A.W.; Marcoux, F.W.;Coughenour, L.L.; Brahce, L.J. J.Med. Chem. 1989, 32, 1580 .

94. Huang, X.; Zhang, C., Lu, X. Synthesis 1995, 769.

95. (a) Burke Jr., T.R.; Li, Z.-H.; Bolen, J.B.; Marquez, V.E. J. Med. Chem. 1991, 34, 1577; (b) Burke Jr., T.R.; Russ, P.; Lim, B. Synthesis 1991, 1019; (c) Burke Jr., T.R.; Smyth, M.S.; Nomizu, M.; Otaka, A.; Roller, P.P. J. Org. Chem. 1993, 58, 1336; (d) Burke Jr., T.R.; Smyth, M.S.; Otaka, A.; Roller, P.P. Tetrahedron Lett. 1993, 34, 4125.

Snider, B.B.; Phillips, G.B. J.Org.Chem. 1983, 48, 3685.

100. (a) Ditrich, K.; Bube, T.; Stürmer, R.; Hoffmann, R.W. Angew. Chem. Int. Ed. Engl. 1986, 25, 1028; (b) Hoffmann, R.W.; Ditrich, K. Liebigs Ann. Chem. 1990, 23; (c) Ditrich, K. Liebigs Ann.Chem. 1990, 789. 
101. Snider, B.B.; Yang, K. J. Org. Chem. 1992, 57, 3615.

102. (a) Nakajima, N.; Hamada, T.; Tanaka, T.; Oikawa, Y.; Yonemitsu, O. J. Am. Chem. Soc. 1986, 108, 4645; (b) Nakajima, N.; Tanaka, T.; Hamada, T.; Oikawa, Y.; Yonemitsu, O. Chem. Pharm. Bull. 1987, 35, 2228.

103. Keck, G.E.; Palani, A.; McHardy, S.F.J. Org. Chem. 1994, 59, 3113.

104. Nishida, A.; Yagi, K.; Kawahara, N.; Nishida, M.; Yonemitsu, O. Tetrahedron Lett. 1995, 36, 3215.

105. Marshall, J.A.; DuBay, W.J. J.Org.Chem. 1994, 59, 1703.

106. (a) Tius, M.A.; Fauq, A.H.J.Am. Chem. Soc. 1986, 108, 1035; (b) Tius, M.A.; Fauq, A.H. J. Am. Chem. Soc.

1986, $108,6389$.

107. (a) Kodama, M.; Shiobara, Y.; Sumitomo, H.; Fukuzumi, K.; Minami, H.; Miyamoto, Y. Tetrahedron Lett. 1986, 27, 2157; (b) Kodama, M.; Shiobara, Y.; Sumitomo, H.; Fukuzumi, K.; Minami, H.; Miyamoto, Y. J. Org. Chem. 1988, 53,1437 .

108. (a) Marshall, J.A.; DeHoff, B.S. Tetrahedron Lett. 1986, 40, 4873; (b) Marshall, J.A.; DeHoff, B.S. Tetrahedron 1987, $43,4849$.

109. Astles, P.C.; Thomas, E.J. J. Chem. Soc., Perkin Trans. 1 1997, 6, 845.

110. (a) Paquette, L.A.; Wang, T.-Z.; Wang, S.; Philippo, C.M.G. Tetrahedron Lett. 1993, 34, 3523; (b) Paquette, L.A.; Wang,

T.-Z.; Philippo, C.M.G.; Wang, S. J. Am. Chem. Soc. 1994, 116, 3367.

111. Roush, W.R.; Warmus, J.S.; Works, A.B. Tetrahedron Lett. 1993, 34, 4427.

112. Nicolaou, K.C.; Seitz, S.P.; Pavia, M.R.; Petasis, N.A.J. Org. Chem. 1979, 44, 4011.

113. Moskva, V.V.; Razumov, A.I. Trudy Kazan. Khim.-tekhnol. Inst. 1965, 34, 273.

114. Razumov, A.I.; Gurevich, P.A.; Moskva, V.V.Zh. Obshch. Khim. 1967, 37, 961.

115. Gurevich, P.A.; Shelepova, N.I.; Razumov, A.I. Zh. Obshch. Khim. 1968, 38, 1905.

116. Razumov, A.I.; Gurevich, P.A.; Akhmadullina, A.G.; Baigil'dina, S.Y. Patent USSR 318583; Byul. Izobret. $1971,32$.

117. Razumov, A.I.; Moskva, V.V. Zh. Obshch. Khim. 1965, 35, 1149; C.A. 63, 11605.

118. Isbell, A.F.; Englert, L.F.; Rosenberg, H. J. Org. Chem. 1969, 34, 755.

119. (a) Moskva, V.V.; Sitdikova, T.Sh.; Razumov, A.I.; Bondar, S.V. Zh. Obshch. Khim. 1979, 49, 473; J. Gen. Chem. USSR (Engl. Transl.) 1979, 49, 415; (b) Sitdikova, T.Sh.; Razumov, A.I. Zh. Obshch. Khim. 1979, 49, 473.

120. Razumov, A.I.; Liorber, B.G.; Pavlov, V.A.; Sokolov, M.P.; Zykova, T.V.; Salakhutdinov, R.A. Zh. Obshch. Khim. 1977, 47, 243; C.A.; 1977, 87, 23392.

121. Razumov, A.I.; Liorber, B.G.; Sokolov, M.P.; Pavlov, V.A.; Zykova, T.V.; Zyablikova, T.A. Zh. Obshch. Khim. 1977, 47, 1192; C.A.; 1977, 87, 135631.

122. Razumov, A.I.; Liorber, B.G.; Khammatova, Z.K.; Sokolov, M.P.; Zykova, T.V.; Alparova, M.V. Zh. Obshch. Khim. 1977, 47, 567; C.A.; 1977, 87, 6103.

123. (a) Sokolov, M.P.; Liorber, B.G.; Razumov, A.I.; Moskva, V.V.; Bulatova, Z.Ya.; Zykova, T.V. Zh. Obshch. Khim. 1978, 48, 1032; C.A.; 1978, 89, 109754; (b) Sokolov, M.P.; Liorber, B.G.; Razumov, A.I.; Moskva, V.V.; Bulatova, Z.Ya.; Zykova, T.V.; Salakhutdinov, R.A. Zh. Obshch. Khim. 1978, 48, 1036; C.A.; 1979, 90, 5385.

124. Haupt, E.T.K.; Dieck, H.T.; Petrova, J.; Momchilova, S. Phosphorus, Sulfur, Silicon 1991, 55, 27.

125. Boeckman Jr., R.K.; Walters, M.A.; Koyano, H. Tetrahedron Lett. 1989, 30, 4787.

126. (a) Öhler, E.; Kang, H.-S.; Zbiral, E. Chem. Ber. 1988, 121, 299; (b) Öhler, E.; Kang, H.-S.; Zbiral, E. Synthesis 1988, 623.

127. (a) Ismailov, V.M.; Moskva, V.V.; Dadasheva, L.A.; Zykova, T.V.; Guseinov, F.I. Zh. Obshch. Khim. 1982, 52, 2140; J. Gen. Chem. USSR (Engl. Transl.) 1982, 52, 1906; (b) Ismailov, V.M.; Moskva, V.V.; Zykova, T.V. Zh. Obshch. Khim. 1983, 53, 2793; J. Gen. Chem. USSR (Engl.Transl.) 1983, 53, 2518; (c) Moskva, V.V.; Guseinov, F.I.; Ismailov, V.M. Zh.Obshch. Khim. 1987, 57, 1668; J. Gen.Chem. USSR (Engl.Transl.) 1987, 57, 1487; (d) Ismailov, V.M.; Moskva, V.V.; Guseinov, F.I.; Zykova, T.V.; Sadykov, I.S. Zh. Obshch. Khim. 1986, 56, 2005; J. Gen.Chem. USSR (Engl. Transl.) 1986, 56, 1768; (e) Shagidullin, R.R.; Pavlov, V.A.; Buzykin, B.I.; Aristova, N.V.; Chertanova, L.F.; Vandyukova, I.I.; Plyamovatyi, A.Kh.; Enikeev, K.M.; Sokolov, M.P.; Moskva, V.V. Zh. Obshch. Khim. 1991, 61, 1590; J. Gen. Chem. USSR (Engl. Transl.) 1991, 61, 1459; (f) Guseinov, F.I.; Moskva, V.V.; Ismailov, V.M.Zh. Obshch. Khim. 1993, 63, 93; Russ. J. Gen. Chem. 1993, 63, 66.

128. (a) Sokolov, M.P.; Buzykin, B.I.; Pavlov, V.A. Zh. Obshch. Khim. 1990, 60, 223; J. Gen. Chem. USSR (Engl. Transl.) 1990, 60, 195; (b) Pavlov, V.A.; Aristova, N.V.; Moskva, V.V. Dokl. Akad. Nauk SSSR, Ser. Khim. 1990, 315, 1137; Dokl. Chem. (Engl. Transl.) 1990, 315, 358; (c) Pavlov, V.A.; Aristova, N.V.; Moskva, V.V.; Makhaeva, G.F.; Yankovskaya, V.L.; Malygin, V.V. Khim. Farm. Zh. 1991, 25, 31; Pharm. J. Chem. (Engl. Transl.) 1991, 25, 255; (d) Pavlov, V.A.; Smith, J.A.S.; Zyablikova, T.A. Magn.Reson.Chem. 1992, 30, 716; (e) Zyablikova, T.A.; Pavlov, V.A.;

Smith, J.A.S.; Liorber, B.G. J. Gen. Chem. USSR (Engl. Transl.) 1992, 62, 1046.

129. (a) Sokolov, M.P.; Buzykin, B.I. Zh. Obshch. Khim. 1991, 61, 1267; J. Gen. Chem. USSR (Engl. Transl.) 1991, 61, 1151; (b) Pavlov, V.A.; Tkachenko, S.E.; Aristova, N.V.; Moskva, V.V.; Komalov, R.M.; Pushin, A.N. Zh. Obshch. Khim. 1992, 62, 1772; J. Gen. Chem. USSR (Engl. Transl.) 1992, 62, 1457.

130. Aristova, N.V.; Gorin, B.I.; Kovalenko, S.V.; Pavlov, V.A.; Moskva, V.V. Khim. Geterotsikl. Soedin. 1990, 26, 1287; Chem. Heterocycl. Compd. (Engl. Transl.) 1990, 26, 1076.

131. (a) Buzykin, B.I.; Sokolov, M.P.; Pavlov, V.A.; Ivanova, V.N.; Chertanova, L.F.; Zyablikova, T.A. Zh. Obshch. Khim. 1990, 60, 546; J. Gen. Chem. USSR (Engl. Transl.) 1990, 60, 475; (b) Buzykin, B.I.; Sokolov, M.P.; Ivanova, V.N. Zh. Obshch. Khim. 1989, 59, 714; J. Gen. Chem. USSR (Engl.Transl.) 1989, 59, 631.

132. (a) Sokolov, M.P.; Mavrin, G.V.; Gazizov, I.G.; Ivanova, V.N.; Zyablikova, T.A. Zh. Obshch. Khim., 1989, 59, 53; J. Gen. Chem. USSR (Engl. Transl.) 1989, 59, 45; (b) Sokolov, M.P.; Mavrin, G.V.; Gazizov, I.G.; Ivanova, V.N.; Pavlov,

V.A.; Liorber, B.G. Zh. Obshch. Khim., 1987, 57, 1249; J. Gen. Chem. USSR (Engl.Transl.) 1987, 57, 1118; (c) Sokolov, M.P.; Pavlov, V.A.; Liorber, B.G.; Ivanova, V.I.; Buyatova, L.G. Zh. Obshch. Khim. 1985, 55, 458; J. Gen. Chem. USSR (Engl. Transl.) 1985, 55, 406; (d) Buzykin, B.I.; Sokolov, M.P.; Ivanova, V.N.; Liorber, B.G.; Pavlov, V.A. Zh. Obshch. Khim. 1986, 56, 1427; J. Gen. Chem. USSR (Engl. Transl.) 1986, 56, 1265.

133. (a) Buzykin, B.I.; Sokolov, M.P. Zh. Obshch. Khim. 1990, 60, 1288; J. Gen. Chem. USSR (Engl. Transl.) 1990, 60, 1150; (b) Buzykin, B.I.; Sokolov, M.P. Zh. Obshch. Khim. 1990, 60, 1980; J. Gen. Chem. USSR (Engl. Transl.) 1990, 60, 1767; (c) Buzykin, B.I.; Sokolov, M.P.; Chertanova, L.F. Zh. Obshch. Khim. 1990, 60, 2703; J. Gen. Chem. USSR (Engl. Transl.) 1990, 60, 2422; (d) Buzykin, B.I.; Bredikhina, Z.A.; Sokolov, M.P.; Gazetdinova, N.G. Zh. Obshch. Khim. 1992, 62, 551; J. Gen. Chem. USSR (Engl. Transl.) 1992, 62, 452; (e) Sokolov, M.P.; Buzykin, B.I.; Molodykh, Zh.V.Zh. Obshch. Khim., 1990, 60, 221; J. Gen. Chem. USSR (Engl. Transl.) 1990, 60, 194. 
134. Ismailov, V.M.; Moskva, V.V.; Guseinov, F.I.; Zykova, T.V. Zh. Obshch. Khim. 1986, 56, 227; J. Gen. Chem. USSR (Engl. Transl.) 1986, 56, 203.

135. Tarasova, R.I.; Dvoinishnikova, T.A.; Sinitsina, N.I.; Guseinov, F.I.; Ismailov, V.M.; Moskva, V.V. Zh. Obshch. Khim. 1989, 59, 1031; J. Gen. Chem. USSR (Engl. Transl.) 1989, 59, 910.

136. Guseinov, F.I.; Klimentova, G.Y.; Moskva, V.V. Zh. Obshch. Khim. 1993, 63, 710; Russ. J. Gen. Chem. $1993,63,501$.

137. Redmore, D. Chem. Rev. 1971, 71, 315.

138. Razumov, A.I.; Liorber, B.G.; Gurevich, P.A. Zh. Obshch. Khim. 1967, 37, 2782; J. Gen. Chem. USSR (Engl. Transl.) 1967, 37, 2648.

139. Razumov, A.I.; Gurevich, P.A.; Liorber, B.G.; Borisova, T.B. Zh. Obshch. Khim. 1969, 39, 392; C.A. 1969, 71, 115230.

140. Razumov, A.I.; Liorber, B.G.; Gurevich, P.A. Zh. Obshch. Khim. 1968, 38, 199; J. Gen. Chem. USSR (Engl. Transl.) 1968, 38, 203.

141. Razumov, A.I.; Gurevich, P.A. Zh. Obshch. Khim. 1967, 37, 1620; J. Gen. Chem. USSR (Engl. Transl.) 1967, $37,1537$.

142. Sokolov, M.P.; Buzykin, B.I.; Zyablikova, T.A. Zh. Obshch. Khim. 1990, 60, 1293; J. Gen. Chem. USSR (Engl. Transl.) 1990, 60, 1155.

143. Razumov, A.I.; Gurevich, P.A. Zh. Obshch. Khim. 1968, 38, 944; C.A. 1968, 69, 67467.

144. Razumov, A.I.; Gurevich, P.A.Tr. Kazan. Khim. Tekhnol. Inst. 1967, 480; C.A. 1969, 70, 20160.

145. Haelters, J.P.; Corbel, B.; Sturtz, G. Phosphorus Sulfur 1988, 37, 41.

146. (a) Regitz, M.; Anschütz, W.; Liedhegener, A. Chem. Ber. 1968, 101, 3734; (b) Regitz, M.; Anschütz, W. Liebigs Ann. Chem. 1969, 730, 194.

147. Petrov, K.A.; Raksha, M.A.; Korotkova, V.P.; Shmidt, E. Zh. Obshch. Khim. 1971, 41, 324; J. Gen. Chem. USSR (Engl.

Transl.) 1971, 41,319.

148. Moskva, V.V.; Nazvanova, G.F.; Zykova, T.V.; Razumov, A.I.; Chemodanova, L.A. Zh. Obshch. Khim. 1971, 41, 1680; J. Gen. Chem. USSR (Engl. Transl.) 1971, 41, 1687.

149. Bourne, S.; Modro, A.M.; Modro, T.A. Phosphorus, Sulfur, Silicon Relat. Elem. 1995, 102, 83.

150. (a) Johnson, A.W. Ylid Chemistry; Academic Press: New York, 1966. (b) Boutagy, J.; Thomas, R. Chem. Rev. 1974, 74, 87. (c) Wadsworth, W. Org. React.. 1977, 25, 73. (d) Walker, B.J. in Organophosphorus Reagents in Organic Synthesis; Cadogan, J.I.G., ed.; Academic Press: London, 1979; Chapter 3, p 155. (e) Battacharya, A.K.; Thyagarajan, G. Chem. Rev. 1981, 81, 415. (f) Burton, D.J.; Yang, Z-Y. Tetrahedron 1992, 48, 189. (g) Minami, T.;Motoyoshiya, J. Synthesis 1992, 333. (h) Johnson, A.W.; Kaska, W.C.; Ostoja Starzewski, K.A.; Dixon, D.A. Ylides and Imines of Phosphorus; John Wiley and sons: New York, 1993. (i) Burton, D.J.; Yang, Z-Y.; Qiu, W. Chem. Rev. 1996, 96, 1641.

151. Martin, S.F. Synthesis 1979, 633.

152. (a) Nagata, W.; Hayase, Y. Tetrahedron Lett. 1968, 4359; (b) Nagata, W.; Hayase, Y. J. Chem. Soc. C 1969, 460.

153. Hermann, K.; Areiding, A.S. Helv. Chim. Acta 1977, 60, 673.

154. Dolle, R.E.; Armstrong, W.P.; Shaw, A.N.; Novelli, R. Tetrahedron Lett. 1988, 29, 6349.

155. Meyers, A.I.; Tomioka, K.; Fleming, M.P. J. Org. Chem. 1978, 43, 3788.

156. Roberts, R.M.; Vogt, P.J. Org. Synth. Coll. Vol. IV, 1963, 464.

157. Tay, M.K.; Abajaoude, E.E.; Collignon, N.; Savignac, P. Tetrahedron Lett. 1987, $28,1263$.

158.

159.

160.

161 . Darling, S.D.; Muralidharan, F.N.; Muralidharan, V.B. Tetrahedron Lett. 1979, 2761.

Wenkert, E.; Guo, M.; Mancini, P. Bull. Soc. Chim. Fr. 1990, 127, 714.

McClure, C.K.; Jung, K.-Y.J. Org. Chem. 1991, 56, 2326.

162. Roberts, M.R.; Schlessinger, R.H. J. Am. Chem. Soc. 1979, 101, 7626.

163. Smith III, A.B.; Dorsey, B.D.; Visnick, M.; Maeda, T.; Malamas, M.S. J. Am. Chem. Soc. 1986, $108,3110$.

164. Büchi, G.; Wüest, H. Helv. Chim. Acta 1979, 62, 2661.

165. Nicolaou, K.C.; Daines, R.A.; Ogawa, Y.; Chakraborty, T.K. J . Am. Chem. Soc. 1988, 110, 4696.

166. Warren, W.A. Biochim. Biophys. Acta 1968, 156, 340.

167. (a) Horiguchi, M. Biochim. Biophys. Acta 1972, 102, 261; (b) Horiguchi, M.; Biochemistry of Natural C-P Compounds, Japanese Association for Research on the Biochemistry of C-P Compounds: Tokyo, 1984, pp. 88-103.

168. McQueney, M.S.; Lee, S.-L.; Bowman, E.; Mariano, P.S.; Dunaway-Mariano, D. J. Am. Chem.Soc. 1989, 111, 6885.

169. (a) Hammerschmidt, F. Liebigs Ann. Chem. 1988, 531; (b) Hammerschmidt, F. Liebigs Ann. Chem. $1988,537$.

170. Hidaka, T.; Seto, H. J. Am. Chem. Soc. 1989, 111, 8012.

171. Lee, S.-L.; Hepburn, T.W.; Swartz, W.H.; Ammon, H.L.; Mariano, P.S.; Dunaway-Mariano, D. J. Am. Chem. Soc. 1992,

114, 7346 .

172. Hammerschmidt, F. J. Chem. Soc., Perkin Trans. 1 1991, 1993.

173. Collignon, N.; Fabre, G.; Varlet, J.M., Savignac, P. Phosphorus Sulfur 1981, 10, 81.

174. Fabre, G.; Collignon, J.M.; Savignac, P. Can. J. Chem. 1981, 59, 2864.

175. Mayer, M.L.; Westbrook, G.L. Prog. Neurobiol. 1990, 28, 197.

176. Monaghan, D.T.; Bridges, R.J.; Cotman, C.W. Rev. Pharm. Tox. 1989, 29, 365.

177. Lehmann, J.; Schneider, J.; William, M. Annu. Rep. Med.Chem. 1987, 22, 31.

178. Perkins, M.N.; Stone, T.W.; Collins, J.F.; Curry, K. Neurosci. Lett. 1981, 23, 333.

179. Davies, J.; Fancis, A.A.; Jones, A.W.; Watkins, J.C. Neurosci. Lett. 1981, $21,77$.

180. Davies, J.; Evans, R.H.; Herrling, A.W.; Jones, A.W.; Olverman, H.J.; Pook, P.; Watkins, J.C. Brain Res. 1986, 382, 169.

181. Harris, E.W.; Ganong, A.H.; Monaghan, D.T.; Watkins, J.C.; Cotman, C.W. Brain Res. 1986, $382,174$.

182. (a) Lehmann, J.; Hutchinson, A.J.; McPherson, S.E.; Mondadori, C.; Schmutz, M.; Sinton, C.M.; Tsai, C.; Murphy, D.E.; Steel, D.J.; Williams, M.; Cheney, D.L.; Wood, P.L. J. Pharm. Exp. Ther. 1988, 246, 65. (b) Boast, C.A., Gerhardt, S.C.; Pastor, G.; Lehmann, J.; Etienne, P.E.; Liebman, J.M. Brain Res. 1988, 442, 345.

183.

184. Villanueva, J.M.; Collignon, N.; Guy, A.; Savignac, P. Tetrahedron 1983, 39, 1299. Gruszeka, E.; Mastalerz, P.; Soroka, M. Rocz. Chem. 1975, 49, 2127.

Garbay-Jaureguiberry, C.; McCort-Tranchepain, I.; Barbe, B.; Ficheux, D.; Roques, B.P. Tetrahedron: Asymmetry 1992, 3 , 637.

186. Takimiya, K.; Otsubo, T.; Ogura, F. J. Chem. Soc., Chem. Commun. 1994, 1859.

187. Möhrle, H.; Vetter, W. Z. Naturforsch. 1988, 43b, 1662.

188. Schrepfer, H.J.; Siegel, H.; Theobald, H. Patent 1978, BASF AG, DE 2715923; C.A. 1979, 90, 23253g 
189. Sentemov, V.V.; Krasil'nikova, E.A.; Berdnik, I.V.J. Gen. Chem. USSR (Engl. Transl.) 1989, 59, 2406.

190. Nifant'ev, E.E.; Patlina, S.I.; Matrosov, E.I. Khim. Geterotsikl. Soedin. 1977, 4, 513; Chem. Heterocycl. Compd. (Engl. Transl.) 1977, 13,414.

191. Lewis, R.T.; Motherwell, W.B. Tetrahedron Lett. 1988, 29, 5033.

192. Razumov, A.I.; Sokolov, M.P.; Liorber, B.G.; Zykova, T.V.; Zhikhareva, N.A. Zh. Obshch. Khim. 1977, 47, 563;J. Gen. Chem. USSR (Engl. Transl.) 1977, 47, 515.

193. Effenberger, F.; Straub, A. Tetrahedron Lett. 1987, 28, 1641

194. Petrov, K.A.; Chauzov, V.A.; Bogdanov, N.N.; Pastukhova, I.V. Zh. Obshch. Khim. 1976, 46, 1242; J. Gen. Chem. USSR (Engl. Transl.) 1976, 46, 1222.

195. Liorber, B.G.; Zverev, V.V.; Khamatova, Z.M.; Pavlov, V.A.; Alparova, M.V.; Vakar, V.M. J. Gen. Chem. USSR (Engl. Transl.) 1990, 60, 1572; Zh. Obshch. Khim. 1990, 60, 1761.

196. Crossley, R.; Curran, A. J. Chem. Soc., Perkin Trans. 1 1974, 2327.

197. Ito, Y.; Matsuura, T.; Saegusa, T. Tetrahedron Lett. 1985, 26, 5781.

198. Heckendorn, R.; Allgeiger, H.; Baud, J.; Gunzenhauser, W.; Angst, C. J. Med. Chem. 1993, $36,3721$.

199. Schmidt, U.; Lieberknecht, A.; Wild, J. Synthesis 1984, 53.

200. Meanwell, N.A.; Roth, H.R.; Smith, E.C.R.; Wedding, D.L.; Wright, J.J.K. J. Org. Chem. 1991, $56,6897$. 